\title{
Methodology for fabricating High Temperature Composite Panel and Evaluation
}

\author{
by \\ Gopinath Thamilselvan \\ Bachelor of Aeronautical Engineering \\ Hindustan College of Engineering, India, 2006 \\ A thesis \\ presented to Ryerson University \\ in partial fulfillment of the \\ requirements for the degree of \\ Master of Applied Science \\ in the program of \\ Aerospace Engineering
}

Toronto, Ontario, Canada, 2011

(C) (Gopinath Thamilselvan) 2011 
Author's Declaration

I hereby declare that I am sole author of this thesis.

I authorize Ryerson University to lend this thesis to other institutions or individual for the purpose of scholarly research.

Signature

I further authorize Ryerson University to reproduce this thesis by photocopying or by other means in total or in part, at the request of other institution or individuals for the purpose of scholarly research.

Signature 


\title{
Methodology for Fabricating High Temperature Composite Panel and Evaluation
}

\author{
Gopinath Thamilselvan - Ryerson University, Toronto \\ Master of Applied Science - Aerospace Engineering - 2011
}

\begin{abstract}
Ever increasing demand for composite materials in the aerospace industry has lead composite manufacturers to develop numerous innovations in the field of manufacturing. Composites play an important role in engine components and high-speed jet crafts where weight saving materials that can sustain high temperatures, with little reduction in performance are desired. A cost effective in-house novel manufacturing technique aimed at producing high glass transition temperature $\left(T_{\mathrm{g}}\right)$ composite panels on par with autoclave manufacturing technology has been designed and built. The designed compression molding system is integrated with an oven, to cater the need for high temperature and high pressure manufacturing system which can be a potential alternative for autoclaves in terms of fabricating panels for structural testing. Quality of the panel was demonstrated by conducting ultimate tensile test, fatigue test and microscopic examination results. High temperature mechanical testing was also carried out to study the behavior of high $\mathrm{T}_{\mathrm{g}} \mathrm{IM} 7 / \mathrm{RP} 46$ composites fabricated at the laboratory.
\end{abstract}




\section{Acknowledgements}

I am immensely thankful to my supervisors, Dr. Zouheir Fawaz and Dr. Hamid Ghaemi for their encouragement, guidance and support from the initial to final stages of my thesis.

I am grateful to Dr.S.Raja, at National Aerospace Laboratories, Bangalore for his guidance and advice that helped me to take up Master's program at Ryerson University.

I am thankful to Perlita Razon, (Unitech, LLC), whose support and assistance were helpful for successful completion of my thesis. I would also like to thank my colleagues John Montesano, Paul Yoon, Oclay Met and Kavya Roy, for their constant support and motivation towards completing my lab experiments and manufacturing setup.

Last but not least, I would like to express my wholehearted gratitude to my parents and friends who stood by me throughout all endeavors during my studies at Ryerson University. 


\section{Table of Contents}

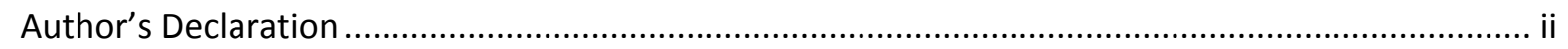

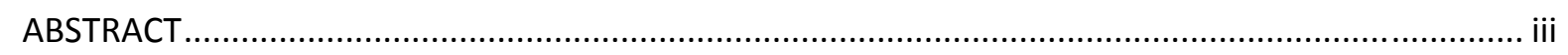

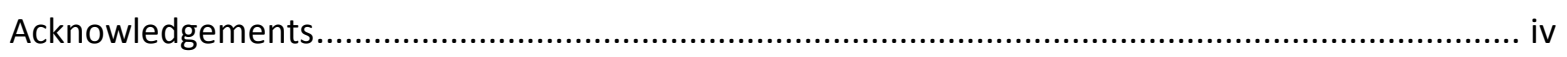

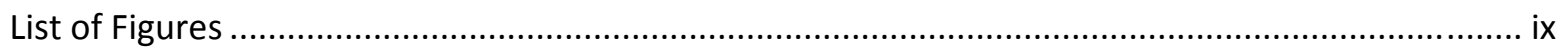

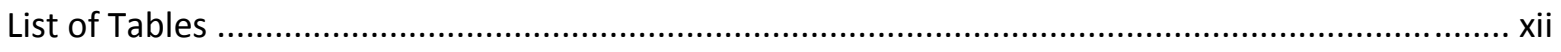

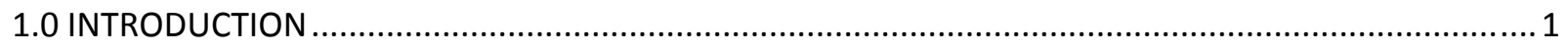

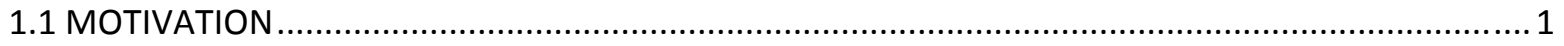

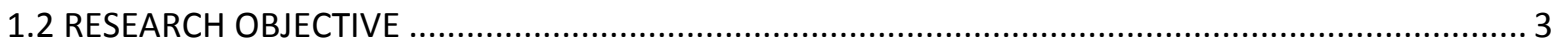

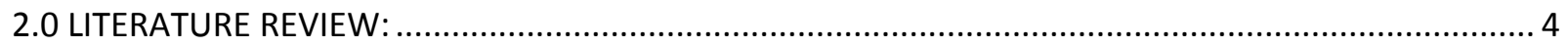

2.1 COST ANALYSIS OF HIGH TEMPERATURE COMPOSITES MANUFACTURING TECHNOLOGIES ........ 8

3.0 MATERIALS SELECTION FOR HIGH TEMPERATURE LAMINATES .............................................. 9

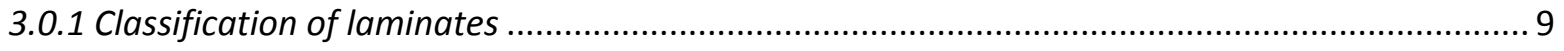

3.0.2 Fibre Terminologies ................................................................................................... 9

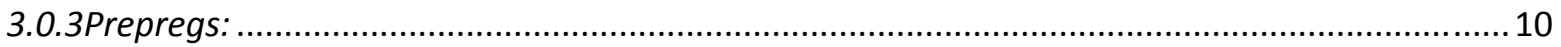

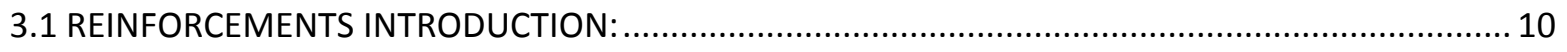

3.1.1 Types of Reinforcements and its Applications: ................................................................... 11

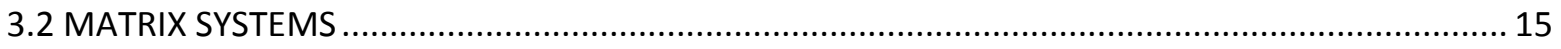

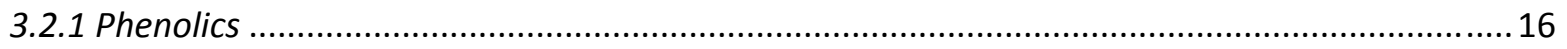

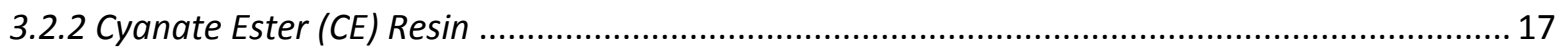

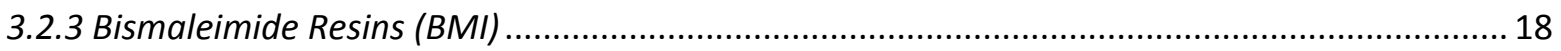

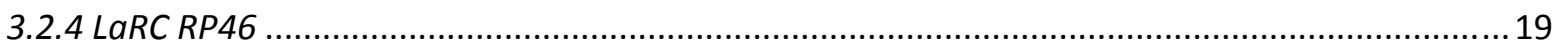

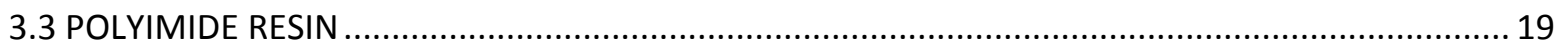

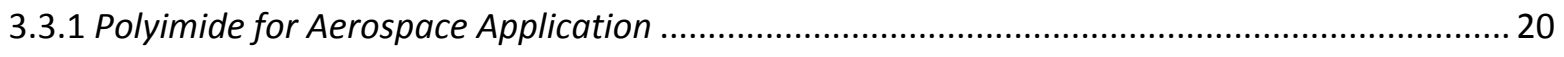

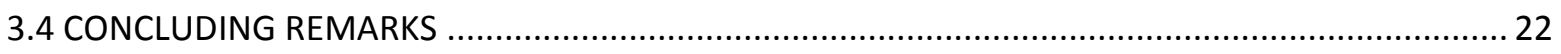

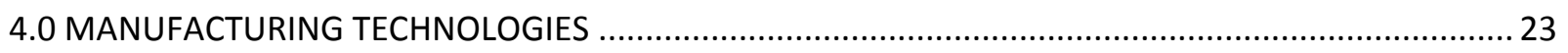




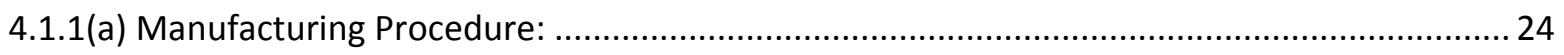

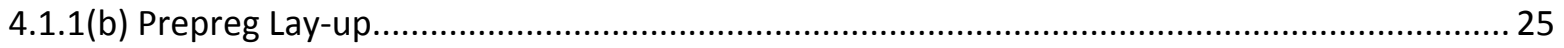

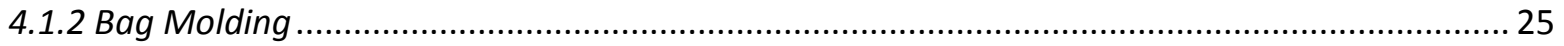

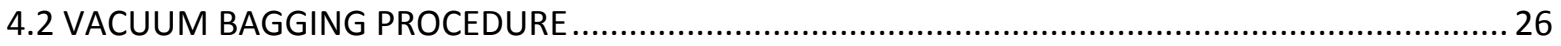

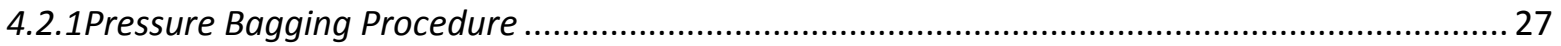

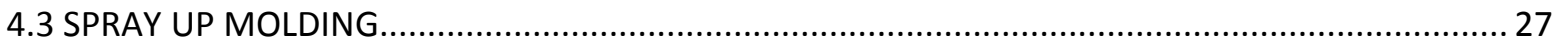

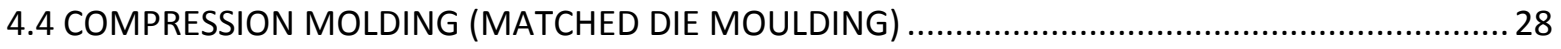

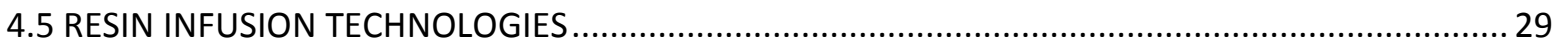

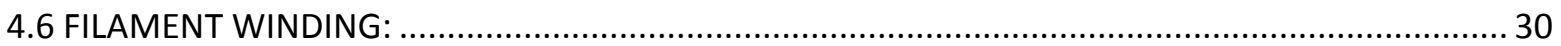

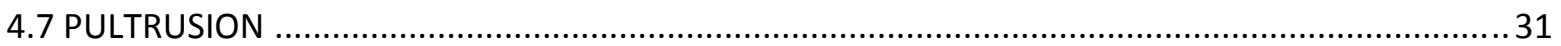

4.8 DRY MOLDING OF ADVANCED COMPOSITES (USING PREPREGS) ......................................... 32

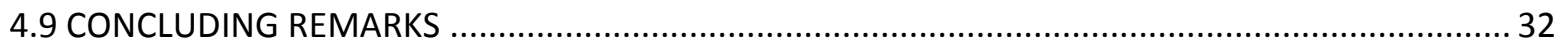

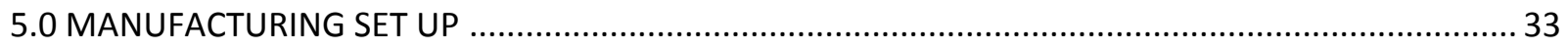

5.0.1 Scope of High Temperature Polymer Composite .................................................................. 33

5.1 MANUFACTURING OF HIGH TEMPERATURE MATERIALS ...................................................... 33

5.2 NOVEL MANUFACTURING METHODOLOGIES TO REDUCE PRODUCTION COST: Review .............34

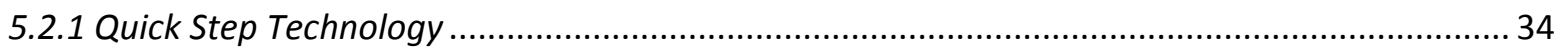

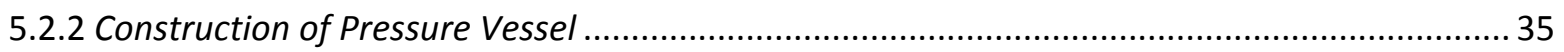

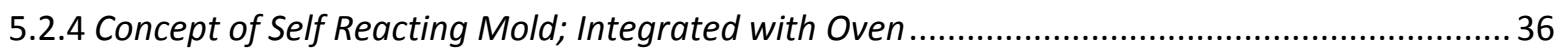

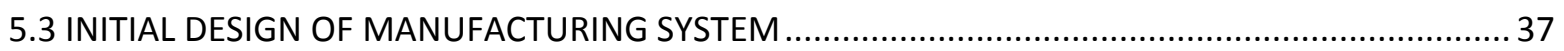

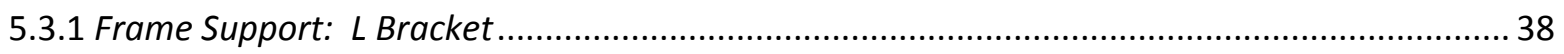

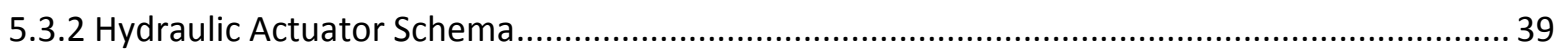

5.4 FINITE ELEMENT ANALYSIS OF THE SELF REACTING FRAME STRUCTURE................................. 40

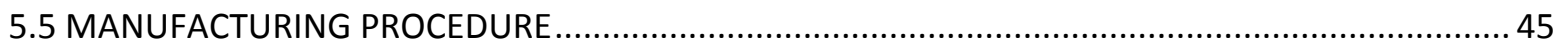

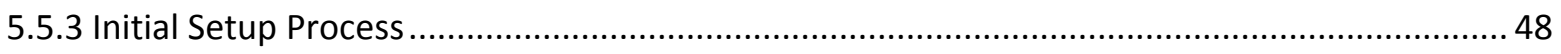


5.6 COMPRESSION MOLDING WITH SELF REACTING FRAME - WORKING PRINCIPLE .....................50

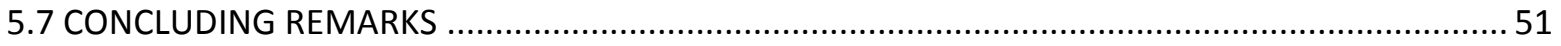

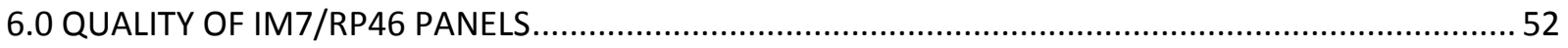

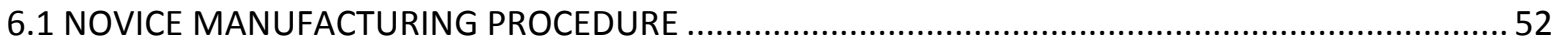

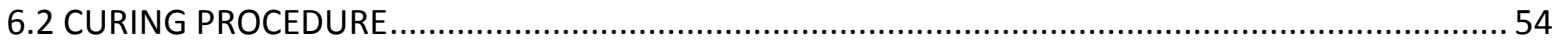

6.3 OBSERVATION OF THE INITIAL IM7/RP46 COMPOSITE PANEL .................................................. 56

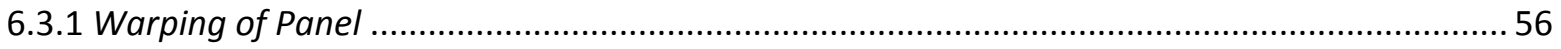

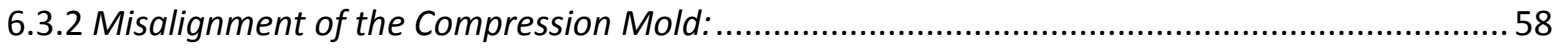

6.4 GOOD QUALITY SPECIMEN; ESTABLISHED PRODUCTION TECHNIQUE.................................... 60

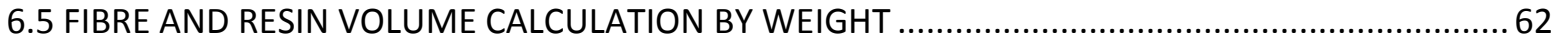

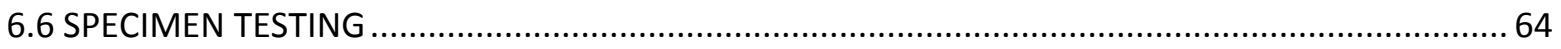

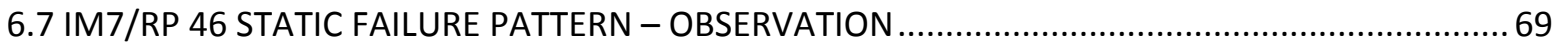

6.8 HIGH TEMPERATURE TESTING OF IM7/RP46 COUPONS ................................................... 72

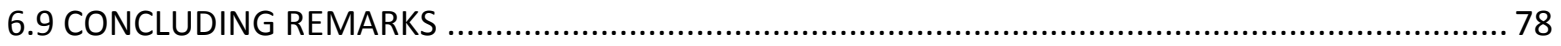

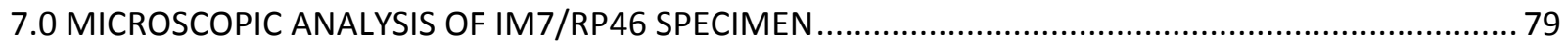

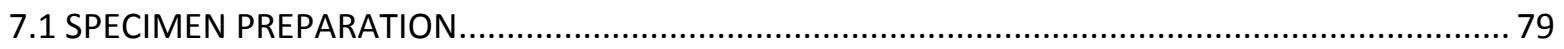

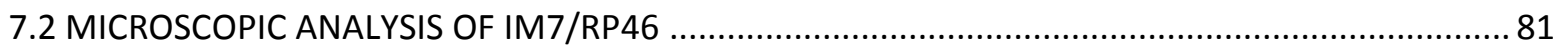

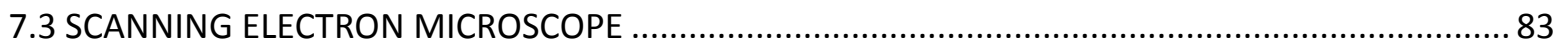

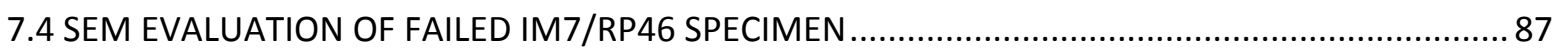

7.5 MICROSCOPIC EVALUATION OF FAILED IM7/RP46 SPECIMEN AT ELEVATED TEMPERATURE ..... 88

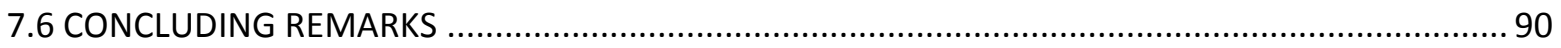

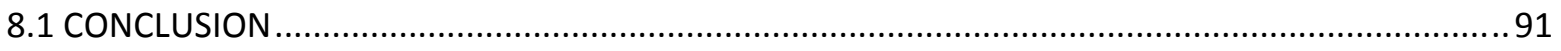

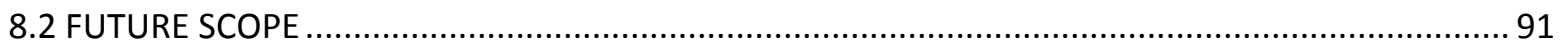

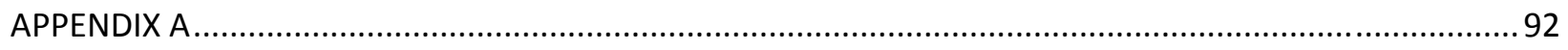

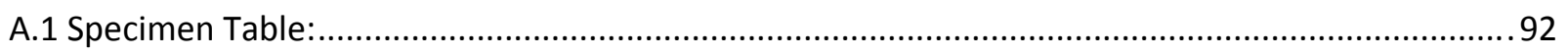




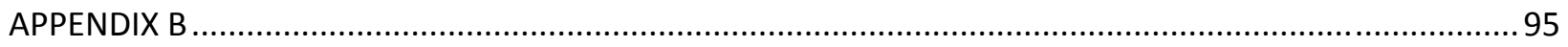

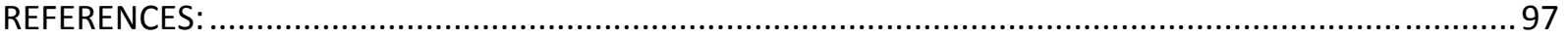




\section{List of Figures}

Figure 1: Density of conventional and composite structural material [Ref. 18] 13

Figure 2: Tensile strength of conventional and composite structural material [Ref. 18] 14

Figure 3: Comparison of Polymer matrix use temperature [Ref. 18] 21

Figure 4: Hand Lay-up/Wet Lay-up [Ref. 18] 24

Figure 5: Vacuum Bagging Method [Ref. 18] 27

Figure 6: Spray up molding [Ref. 18] 28

Figure 7: Filament winding [Ref. 18] 31

Figure 8: Pultrusion [Ref. 18]

Figure 9: Quick Step Curing Chamber [Ref. 19] 34

Figure 10: Heated Compression platen (wabashmpi) 35

Figure 11: Self-Reacting Frame Structure 36

Figure 12: Isometric view of reinforced L-Bracket $\quad 39$

Figure 13: Hydraulic Actuator Circuit $\quad 39$

Figure 14: Self-Reacting Frames Design 40

Figure 15: Critical Contact surface Condition 42

Figure 16: Equivalent Cauchy Stress plot 43

Figure 17: Frame Displacement Plot 44

Figure 18: Frame Equivalent Strain Plot 44

Figure 19: Autoclave curing cycle 46

Figure 20: Compression press curing cycle 47

Figure 21: NT-800 Standard Oven 49

Figure 22: Self-reacting Frame $\quad 49$

Figure 23: Integrated and Assembled Self-Reacting frame structure $\quad 50$

Figure 24: Working Principle $\quad 51$

Figure 25: Aluminum Caul Plate 53

Figure 26: RP46 Resin wetted IM7 53

Figure 28: Partially cured prepreg at $400^{\circ} \mathrm{F} \quad 54$

Figure 27: Staging Tray $\quad 54$

Figure 29: Prepregs on female compression mold

Figure 30: Suspended View of Warped Sample $\quad 56$

Figure 31: Flat view of the Warped Sample $\quad 57$ 
Figure 32: Observation of yellow appearance

Figure 33: Side view of the mold misaligned panel 58

Figure 34: Front view of the mold misaligned panel 58

Figure 35: Moisture entrapment in the panel 59

Figure 36; Resin Poor areas along the edges of the panel 60

Figure 37: Caul Plate enfolded with peel Ply $\quad 61$

Figure 38; End tabbed good quality sample $\quad 62$

Figure 39: Good Quality Specimen $\quad 62$

Figure 40: Specimen dimensions $\quad 65$

Figure 41: Stress-strain behavior $(E=84.5113 \mathrm{GPa}) \quad 66$

Figure 42: Stress-strain behavior (E=80.431 GPa) 66

Figure 45: Side view of matrix-failed specimen due to improper curing 70

Figure 46: Top view of matrix failure specimen $\quad 70$

Figure 47: Brittle natured failure of IM7/RP46 specimen $\quad 71$

Figure 48: Failure Pattern of IM7/RP46 71

Figure 49: Fabric pull out at the edge of the specimen 11

Figure 50: Edge pull out followed by delamination 12

Figure 51: High temperature experiment set-up [Ref. 12] 73

Figure 52: Static testing of IM7/RP46 using mechanical grips 74

Figure 53: Microscopic image of fatigue tested specimen $\quad 75$

Figure 54: Failure pattern of IM7/RP46 at high temperature 76

Figure 55: Enlarged view of failed specimen $\quad 77$

Figure 56: Stress-strain behavior (High temperature tested specimen) 77

Figure 57: Cross section of tested specimen 13

Figure 58: Cross section of tested specimen $10 \quad 81$

Figure 59: Cross section of tested specimen $10 \quad 82$

Figure 60: Cross section of Virgin specimen 15

Figure 61: Void content of Novice specimen 83

Figure 62: Isolated void observed at $100 \times$ magnifications $\quad 84$

Figure 63: highly magnified image of the void (1000x) 85

Figure 64: Image of the void free zone of fabricated specimen 85

Figure 65: Moisture entrapped zone combined with void content 86 
Figure 66: Matrix crack in between the fibre bundle

Figure 67: crack initiation and propagation on failed Im7/RP46 sample

Figure 68: Longitudinal crack along the fibre direction

Figure 69: Crack propagation from one fibre bundle to another through matrix

Figure 70: matrix crack in the IM7/RP46 specimen

Figure 72: Detailed Drawing of self reacting Frame 


\section{List of Tables}

Table 1: Physical and Chemical Properties of High Temperature Polymer Resin System [Ref. 3]

Table 2: Properties of some commonly used Thermoplastic and Thermosetting Polymers [Ref. 1]

Table 3: Comparison of Thermoset and Thermoplastic matrix [Ref. 1]

Table 4: Matrix materials and operating temperature [Ref. 8]

Table 5: Ultimate stress of initially manufactured specimen

Table 6: Ultimate stress of lately manufactured specimen

Table 7: Ultimate stress of elevated temperature tested specimen

Table 8: Specimen Lay-up- log

Table 9: Properties of IM7 (6K) Carbon Fabric [Hexcel corporation] 


\section{CHAPTER 1}

\subsection{INTRODUCTION}

\subsection{MOTIVATION}

Advancement in the field of structural technology has paved the way for intensive research on materials that is stable at extreme environmental conditions. The success of the material depends on the flexibility, durability, ease of manufacturing, damage tolerance, and low maintenance cost. One such innovation in structural application is advanced composite materials.

Advanced composite materials are solid materials composed of continuous fibre arrangements held together by a matrix that holds and surrounds the fibres in place. Matrix is the continuous phase, which protects the reinforcement, transfers the load to reinforcement, but often a limiting factor in terms of operating temperature. The highly favorable strength to weight ratio characteristics of advanced composites have not been taken advantage of in high temperature applications due to the aforementioned limitations. While numerous research programs have been carried out on low to moderate temperature composites limited studies have been published on the high temperature variety, once again due to limitations associated with the polymeric matrix material. Some of the High temperature matrix used in the industry includes bismaleimides, cynate esters, AMB-21, PMR-15, PMRII, Avimid N, AFR-700B, and RP-46. Researchers have found the applicability of those materials depends on the ease of manufacturing, processability, non-toxic nature, and economic production.

Thermoset polyimides have been proven to be a viable solution for high temperature application as they have exceptionally high thermo oxidative stability and superior mechanical performances at elevated temperatures. Some polyimides along with fibre reinforcements have used temperature ranging from $100^{\circ} \mathrm{C}-371^{\circ} \mathrm{C}$, with the advantage of weight saving compared to a regular epoxy material, and excellent resistance to moisture, chemical attacks and corrosion. Fabrication of polyimide composites has always 
been a feasible task but with heavy cost investment as it requires high processing temperature and high pressure.

There are numerous composites manufacturing processes like autoclave, pultrusion, compression molding, hand lay-up, filament winding, tow placement, and resin infusion technology that exist in the industry. The above-mentioned production techniques have been established and exploited in the past to fabricate composites that are used in the aerospace, automobile, and sports industry. The futuristic research relies on producing advanced composite materials, which could be used in aero engine application, building small satellites, and space exploration and give way to high speed civil transport. In order to study the suitability of the materials for specific application experimental studies are mandatory. Therefore, present research is targeted towards the futuristic research in terms of manufacturing advanced composite materials in a cost effective manner that could be used for experimental studies. Very few technologies are compatible for producing high $\mathrm{T}_{\mathrm{g}}$ composites which involves huge equipment cost. So, project studies were focused in analyzing and coining a novel technique to produce the samples for laboratory experiments with an economic budget instead of installing huge machineries whose expenses would increase the production cost tenfold and also invoke heavy maintenance cost in the long run. Hence, the need for cost effective production technique that could produce test coupons to study the materials behavior is addressed with the solution in the current research. 


\subsection{RESEARCH OBJECTIVE}

The main aim of this research is to fabricate advanced high $\mathrm{T}_{\mathrm{g}}\left(325^{\circ} \mathrm{C}\right)$ quality assured composite panels. In order to manufacture the advanced composites, resin rheology of RP46 polyimides and other high $\mathrm{T}_{\mathrm{g}}$ resin systems were studied. Compatibility of the fibre reinforcement and the cure cycle of the resin system were thoroughly understood before selecting the material for fabrication process. Cost analysis and feasibility studies were carried out in order to design a cost effective manufacturing set up for producing advanced composite panels.

To fulfill the objective, a self-reacting mechanical frame structure was designed in general purpose CAD software in consideration with the available space and economic budget. The finite element analysis was performed on the designed cold steel frame system to evaluate the structural strength, as the cure cycle required a high-pressure system for manufacturing the test coupons. Programmable High temperature industrial oven was used to control the cure cycle of the resin system. The provisions were made on the high temperature industrial oven to integrate the designed mechanical system without compromising the performance of the oven. The integration process necessitated a support structure to carry the mechanical system, which was catered by $L$ frame. Hand lay-up technique was studied and employed to wet out the reinforcement, which was later transferred to compression molding tool followed by curing procedure.

Final stage of the research was to qualify the fabricated composite panel by conducting microscopic analysis, scanning electron microscope imaging, uniaxial ultimate static testing, high temperature static testing, and fatigue test. 


\section{CHAPTER 2}

\subsection{LITERATURE REVIEW:}

Composites have been playing a major role in a variety of aerospace structural applications. Light weight, high strength, low production cost, and the ability to tailor the mechanical properties makes composites a fascinating material for use in various industries. Research is being carried out in the area of high temperature composites in order to coalesce the advantage of weight saving. Ceramic matrix composites with high temperature fibres and carbon-carbon composites are limited due to the high cost involved in their fabrication as a result of the high temperature curing as well as the cost of the fibre. The emergence of high speed civil aircraft and need for low weight engine components has led to processing of various high temperature polymer matrices that have both thermo oxidative stability and high glass transition temperature.

PMR 15 developed by NASA was the forerunner in the advent of high temperature resin for advanced composites in high temperature application. PMR 15 was easy to process and also had high thermal stability compared to the conventional epoxy systems. Restrictions in microcracking from thermal cycling, quality control, and health hazards, limited the applications. The pursuit for ideal high temperature resin systems still continues in the market of advanced composite materials, as a result a number of high temperature polymer systems have been developed and employed for high temperature applications.

Maverick Corporation has developed an ultra high-temperature polyimide [3], MVK-19 capable of withstanding jet engine environments up to $700^{\circ} \mathrm{F}$. The composite parts made up of MVK-19/Carbon fibre have been qualified to be used in the hottest compressor stages of military and commercial jet engines since 1994 . MVK-19 has a glass transition temperature range of $700-725^{\circ} \mathrm{F}$. In terms of thermal oxidative stability, it is observed to have $2-4 \%$ weight loss in a simulated jet engine environment at 
$700^{\circ} \mathrm{F}$, at $70 \mathrm{psi}$ for a period of 100 hours. Thermal gravimetric analysis shows $0.05 \%$ weight loss from $200-325^{\circ} \mathrm{C}$.

High temperature thermosetting polymers such as bismaleimides commonly incorporate a discrete toughening phase to improve impact resistance. Isothermal aging studies at temperatures above $150^{\circ} \mathrm{C}$ have shown a tendency for these systems to undergo phase separation. The phase separation can be observed with an optical microscope since it shows considerable darkening as exposure time increases.

Most critical damage mechanisms in high temperature polymer composites are due to the formation of transverse ply cracks and in-plane micro cracks in the matrix polymers of multiaxial composites. Matrix cracking can result from initial laminating processing, residual stress due to hygrothermal exposures, thermal cycling and combined effects of mechanical and environmental cycles [2]. Degradation of the polymer matrix is more likely due to thermal instability and the accelerating effects of oxidative attack. Matrix polymers are stable in the inert atmosphere due to their highly cross-linked and aromatic nature. Unfortunately, Most of the high temperature applications involve exposure in an oxidizing environment where both carbon fibre and polymer matrix are susceptible to oxidative degradation. However, oxidation of high temperature polymers must be considered in composite design and characterization. Oxidation is usually characterized in terms of weight loss. Various matrix systems have been considered for high temperature application such as bismaleimides, cyanate esters, benzocyclobutene, and polyimides. Studies [20] have been carried out and candidate polymers were ranked in terms of oxidative resistance from most stable to least stable: Polyimides, Polyarylenes Bismaleimides, Cynate esters, Epoxies. 
Table 1: Physical and Chemical Properties of High Temperature Polymer Resin System [Ref. 3]

\begin{tabular}{|c|c|c|c|c|c|c|}
\hline Resin & $\begin{array}{c}\text { Glass Transition } \\
\text { Temperature }\end{array}$ & Thermo oxidative stability & Density & Fabrication Method & & \\
\hline MVK-19 & $360-390^{\circ} \mathrm{C}$ & $\begin{array}{l}\text { 1-3\%weight loss@357º, } \\
100 \text { hrs }\end{array}$ & $1.1-1.3 \mathrm{gm} / \mathrm{cc}$ & Compression Molded & & \\
\hline AFR-PE-4 & $393-404^{\circ} \mathrm{C}$ & $\begin{array}{l}0.5-1.5 \% \text { weight loss@371º, } \\
100 \text { hrs }\end{array}$ & $1.1-1.3 \mathrm{gm} / \mathrm{cc}$ & $\begin{array}{l}\text { Autoclave Molded } \\
\text { Compression Molded }\end{array}$ & & \\
\hline PMR-II-50 & $357-371^{\circ} \mathrm{C}$ & $\begin{array}{l}1.0-2.0 \% \text { weigh loss@371ํ, } \\
100 \mathrm{hrs}\end{array}$ & $1.1-1.3 \mathrm{gm} / \mathrm{cc}$ & $\begin{array}{l}\text { Autoclave Molded } \\
\text { Compression Molded } \\
\text { Solvent Assisted } \\
\text { Molded (SARTM) }\end{array}$ & Resin & Transfer \\
\hline AFR-700B & $371-399^{\circ} \mathrm{C}$ & $\begin{array}{l}\text { 1.5-2.5\%weight loss@371º } \\
100 \mathrm{hrs}\end{array}$ & $1.1-1.3 \mathrm{gm} / \mathrm{cc}$ & $\begin{array}{l}\text { Autoclave Molded } \\
\text { Compression Molded } \\
\text { Solvent Assisted } \\
\text { Molded (SARTM) }\end{array}$ & Resin & Transfer \\
\hline AMB-21 & $260-274{ }^{\circ} \mathrm{C}$ & $\begin{array}{l}7-8 \% \text { weight loss @288 } \mathrm{C} \text {, } \\
5000 \text { hours }\end{array}$ & $1.0-1.1 \mathrm{gm} / \mathrm{cc}$ & $\begin{array}{l}\text { Autoclave Molded } \\
\text { Compression Molded } \\
\text { Solvent Assisted } \\
\text { Molded (SARTM) }\end{array}$ & Resin & Transfer \\
\hline MVK-14 & $325-335^{\circ} \mathrm{C}$ & $\begin{array}{l}1-3 \% \text { weight loss @316² } \\
125 \text { hours }\end{array}$ & $1.0-1.1 \mathrm{gm} / \mathrm{cc}$ & Compression Molded & & \\
\hline
\end{tabular}




\begin{tabular}{|c|c|c|c|c|}
\hline MVK-16 & $300-315^{\circ} \mathrm{C}$ & $\begin{array}{l}\text { 1-3\% weight loss@315ㄷ, } \\
125 \text { hours }\end{array}$ & $1.0-1.1 \mathrm{gm} / \mathrm{cc}$ & $\begin{array}{l}\text { Autoclave Molded } \\
\text { Resin Film Infusion (RFI)Solvent } \\
\text { Assisted Resin Transfer Molded } \\
\text { (SARTM) }\end{array}$ \\
\hline T115 & $360-390^{\circ} \mathrm{C}$ & $\begin{array}{l}1 \text { - } 3 \% \text { weight loss @ } 357^{\circ} \mathrm{C} \text {, } \\
100 \text { hours }\end{array}$ & - & Compression Molded \\
\hline RP 46 & $357^{\circ} \mathrm{C}$ & $\begin{array}{l}3.7 \% \text { weight loss @ } 371^{\circ} \mathrm{C} \text {, } \\
100 \mathrm{Hrs}\end{array}$ & $1.32 \mathrm{~g} / \mathrm{cc}$ & $\begin{array}{l}\text { Compression Molded } \\
\text { Autoclave Molded }\end{array}$ \\
\hline PMR 15 & $316^{\circ} \mathrm{C}$ & $\begin{array}{l}\text { 4\% weight loss@343, } \\
200 \text { hrs }\end{array}$ & $1.30-1.32 \mathrm{~g} / \mathrm{cc}$ & $\begin{array}{l}\text { Compression Molded } \\
\text { Autoclave Molded }\end{array}$ \\
\hline NR 150 & $350-370^{\circ} \mathrm{C}$ & $\begin{array}{l}9 \% \text { weight loss @ } 316^{\circ} \mathrm{C} \text {, } \\
24 \mathrm{hrs}\end{array}$ & $1.43-1.45 \mathrm{~g} / \mathrm{cc}$ & Autoclave Molded \\
\hline
\end{tabular}

The advent of numerous high temperature polymer systems demanded composite manufacturing technologies like autoclave and compression press system. One such attempt to manufacture HTPC, namely RP46/carbon composite, using an in house developed methodology will be explained in detail. Construction of IM7/RP 46 composite panels using dry molding cycle design and wet molding cycle design has already been proposed[5].Results show that both the cycle yielded well-consolidated, void free IM7/RP 46 composite parts. Unidirectional IM7/RP46 laminates with $62 \%$ fibre volume fraction were manufactured in a Wabash hot press by using the prepregs, which were used to study the interlaminar mode I fracture of composite at high temperature [21]. Feasibility studies related to cost effective manufacturing of composites with an RP46 system employing vacuum assisted resin transfer molding (VARTM) was found to have issues with void contents due to release of volatiles such as 
methanol and water during the infusion stage of the process [13]. Laminates made by VARTM process was tested for mechanical properties and thermal properties and compared with the RP46 samples produced using the autoclave procedure. Filament winding and tow placement were also attempted by industries to overcome the labour intensive prepreg lay-up methods [17]. Pultrusion techniques were investigated on PMR-15 composite by Alcoa [10]. Results concluded that fully imidized PMR-15 could be successfully pultruded, although the mechanical properties and void content indicated that further research has to be done to produce a quality assured panel.

\subsection{COST ANALYSIS OF HIGH TEMPERATURE COMPOSITES MANUFACTURING TECHNOLOGIES}

The following table shows the cost of manufacturing the high temperature composite panel using various fabrication techniques, which is prevalent in the aerospace industry. The cost involved in the manufacturing equipment is calculated for producing similar size panels. All the figures mentioned below are approximate values obtained from leading equipment manufacturing companies.

Table 1a: Cost Comparison of Manufacturing Technologies

\begin{tabular}{|c|c|c|c|}
\hline $\begin{array}{l}\text { Manufacturing } \\
\text { Technology }\end{array}$ & $\begin{array}{l}\text { Installation } \\
\text { Cost }\end{array}$ & $\begin{array}{l}\text { Utility and maintenance cost/ } \\
\text { year }\end{array}$ & \begin{tabular}{l} 
Other cost \\
\hline Autoclave
\end{tabular} \\
\hline$\$ 132,460$ & $\$ 5000$ & $\begin{array}{l}\$ 6000 \\
\text { (Vacuum bagging) }\end{array}$ \\
\hline Compression Press & $\$ 60,000$ & $\$ 3000$ & N.A \\
\hline Self-Reacting mold & $\$ 22,500$ & $\$ 500$ & N.A \\
\hline
\end{tabular}

An attempt is made in the current research to produce void free IM7/RP46 panels using compression molding production technology, which is elaborated in the following chapters of the report. 


\section{CHAPTER -3}

\subsection{MATERIALS SELECTION FOR HIGH TEMPERATURE LAMINATES}

Material selection is of prime importance for the best output and production efficiency. It's a part of process development to exploit the properties of the materials to favor the manufacturing project. Factors such as overall product design, processing methodology, and environmental conditions under which the final product could work efficiently are some important considerations. The material selection process involves studying the available resources in the composite industry and compatibility of the resin system with the reinforcement. The production of high temperature composites has two aspects: $\mathrm{n}$ labour intensive prepreg production and component fabrication. A short introduction about the reinforcements and prepregs will be presented in the upcoming sections. It is required to review the basic terminologies involved in the composites industry in order to understand the material selection process.

\subsubsection{Classification of laminates}

1. Unidirectional laminates - fibres are oriented in single direction

2. Bidirectional laminates - fibres run in 0 and 90 degrees.

3. Multidirectional Laminates - fibres oriented in various directions.

4. Woven Fabric Laminates - patterns of fibre weaved to form a sheet. (Currently used in the research)

5. Interplay Hybrid Laminates - different layers of fibres laminated together ( Ex: Carbon, Kevlar)

\subsubsection{Fibre Terminologies}

Fibres have high aspect ratio. Fibre lengths less than $0.5 \mathrm{~cm}$ are classified as whiskers. Chopped fibres of length $0.5-4.00 \mathrm{~cm}$ in are called staple fibres. Group of filaments are called tow or strand. The longitudinal direction of the fibres is called the warp or machine direction at usually $0^{\circ}$. The direction of 
interwoven crossing fibres is called the weft, woof, fill or transverse direction. The direction that cuts fibre at $45^{\circ}$ is called the bias. Edges of the rolls are called slevage edges.

\subsubsection{Prepregs:}

Optimum performance of laminate is obtained using unidirectional prepregs. Crimping diminishes the strength in the woven prepregs fabric. Unidirectional or interwoven fibres with partially cured resin matrix are called prepregs (Fabrics preimpregnated with matrix resin). The prepregs are then partially cured so that it does not run off the fibre. B-staged resin coating must include the entire hardening agent and required constituents for full curing. Typically prepregs are refrigerated for 6 months at $0^{\circ} \mathrm{C}$. A comb like structure is used to collimate the fibres so that they do not cross over each other resulting in uniform columns. This is later drawn in sheets of fibres that are directed onto a surface of thin papers which has a thin coating of resin. Prepreg sheets are placed on another sheet of resin with the coated paper on top. These sheets are then pressed into the rolls to achieve wet out. Prepregs have drape, the property that helps it to conform to the shape of the mold. It also has tack, as the resin is not fully cured.

\subsection{REINFORCEMENTS INTRODUCTION:}

Composites are made up of fibre and matrix. The fibre has the major influence on the mechanical properties of the composite part. Fibres have high aspect ratio hence load can be transferred onto the fibres along the long axis. It was believed that fibres with non-circular cross sections having larger perimeters than circular fibres might have improved adhesion to the matrix materials and therefore improved properties in the final composite part. Initially some favorable results were reported but they are not widely used in industry and are typically not commercially available. The rates of composite properties like tensile strength, modulus of elasticity, flexural strength and elongation are noticed to increase sharply until fibre are about 3 inches. 
An important consideration that has been proven significant in the selection of type of fibre is mechanical properties and density, which is a combination of the advantage of strength, stiffness and light weight.

\subsubsection{Types of Reinforcements and its Applications:}

In the present section different types of reinforcements are addressed with reference to their characteristics and properties. A thorough knowledge of reinforcements could assist in narrowing down the process of material selection. In the present research availability of material, material cost, processability, storage ability, and feasibility were considered in selecting the material for manufacturing with an in-house built fabrication technique.

Glass fibre is an amorphous material that consists of silica with various oxides to give specific compositions and properties. Glass fibres have high specific strength and used in high volume for manufacturing modern composite due to low cost. These fibres are almost always used in combination with polymeric resin as the matrix, hence the class of materials is known as Fibre reinforced Plastics (FRP). There are varieties of glass fibre used in the composite industry namely E-glass, S-glass, C-glass and quartz. E-glass fibres are used in electrical devices as it has high electrical resistivity, good strength and low cost. S-glass has higher strength and better retention of mechanical properties at elevated temperature in par with E-glass. Whereas quartz is used in applications where superior softening point temperature and superior electrical transparency are needed.

Continued demand for high strength and higher stiffness led to the development of carbon fibres. Presently, carbon fibre has the highest specific strength and highest specific modulus of any material. Carbon fibres are manufactured using polyacrylonitrile (PAN), Pitch, and rayon. PAN based fibres have good properties with low cost for standard modulus products. Pitch-based fibres have high modulus and good thermal conductivity. Rayon-based fibres were the first carbon fibres that were manufactured in 
the composite industry. PAN and pitch undergoes various steps like stabilization under tension followed by carbonization and graphitization in the nitrogen atmosphere, achieving high strength and stiffness properties. The PAN and pitch based carbon fibres are further categorized into standard modulus, intermediate modulus and ultra high modulus.

Carbon fibre has high tensile strength, high tensile modules, high stiffness, low weight, negative coefficient of thermal expansion, excellent thermal conductivity, creep resistant, not susceptible to fatigue, chemically inert and possesses an excellent damping characteristic which makes it a unique option for a number of applications.

The other classes of fibres are aramid and organic fibres, which include ultra high molecular weight polyethylene, nylon fibres, Kevlar etc. Aramid fibre often doesn't require sizing unlike glass and carbon fibres. Aramid fibre has more elongation than any other fibre, which results in high toughness an important property makes it compatible for the majority of applications involving composite materials. When fibres fail, they break into small fibrils this unique failure mechanism of aramids are responsible for their high strength and high toughness. Aramid is resistant to most of the solvents and has good resistance to heat. Light weight, strength, modulus, toughness, impact damage prevention and pressure strength retention has found a special niche in making bullet proof vests and high performance pressure vessel.

Powder of ultra-high-molecular-weight polythene has been molded into articles such as cutting boards, snowboards where high strength and scuff resistance are important. UHMWPE are also called extended chain polythene fibres (ECPE). Molecules of ECPE have a crease rod like structural shape similar to aramid fibres that have a high degree of molecular orientation and high crystallinity. UHMWPE fibres have same toughness as aramid fibres have the advantage over weight.

Boron and silicon carbide are high modulus reinforcements made from chemical vapor deposition process. Boron fibres have the unique feature that combines good tensile properties with good 
compressive properties. Boron fibres have been used in construction of stabilizers for F-14 and F-1 aircrafts as well as many sports products. Boron fibres combined with metals like aluminum are used as tubular struts in frame, rib truss members in space shuttles. Silicon carbide has the ability to retain bonding strength to the matrix even at high temperature processing. SiC fibres with aluminum have been used in aircraft wing structural elements as well as missile body casting. Applications also include SiC fibres in a titanium matrix for drive shafts and fan blade construction.

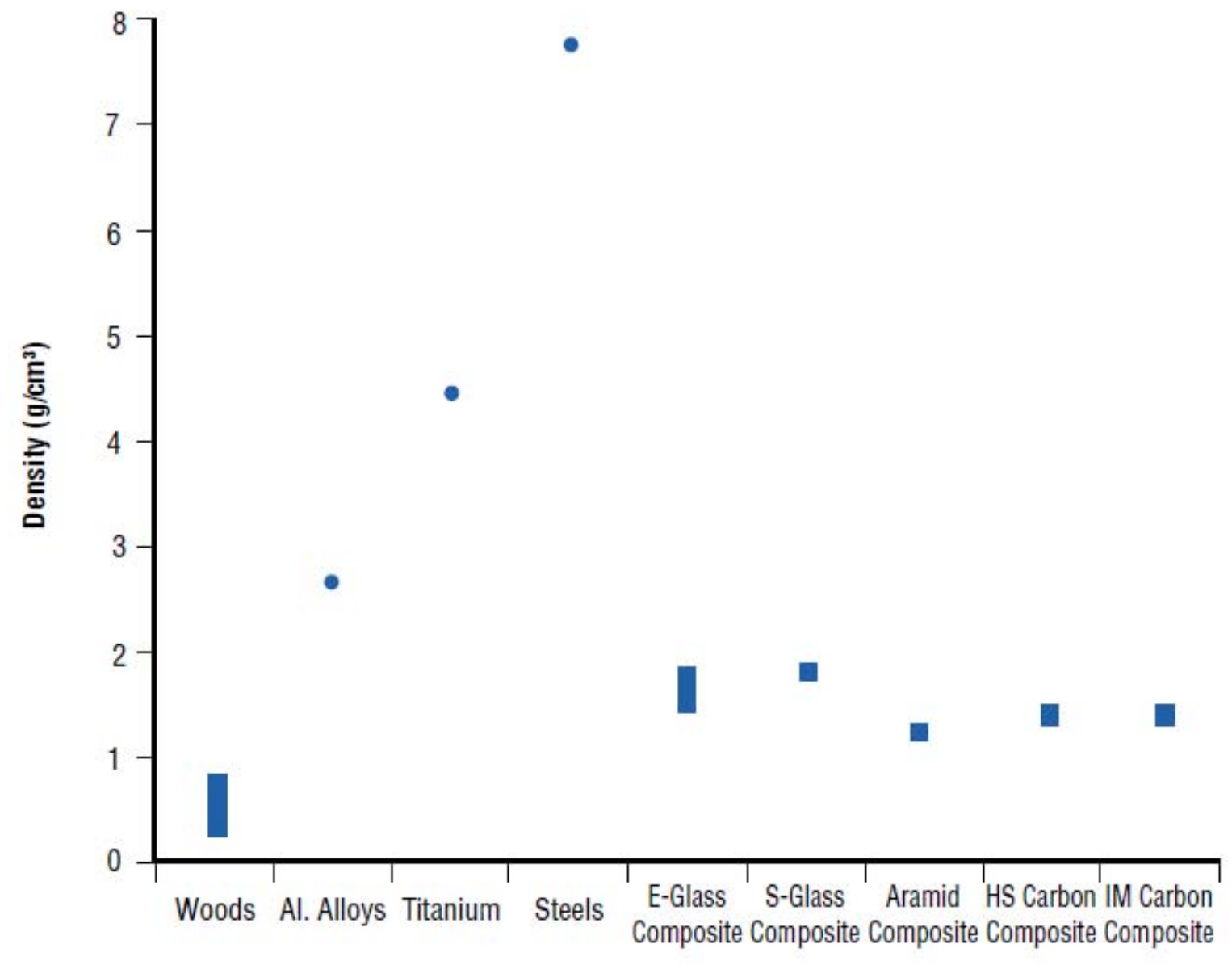

Figure 1: Density of conventional and composite structural material [Ref. 18] 


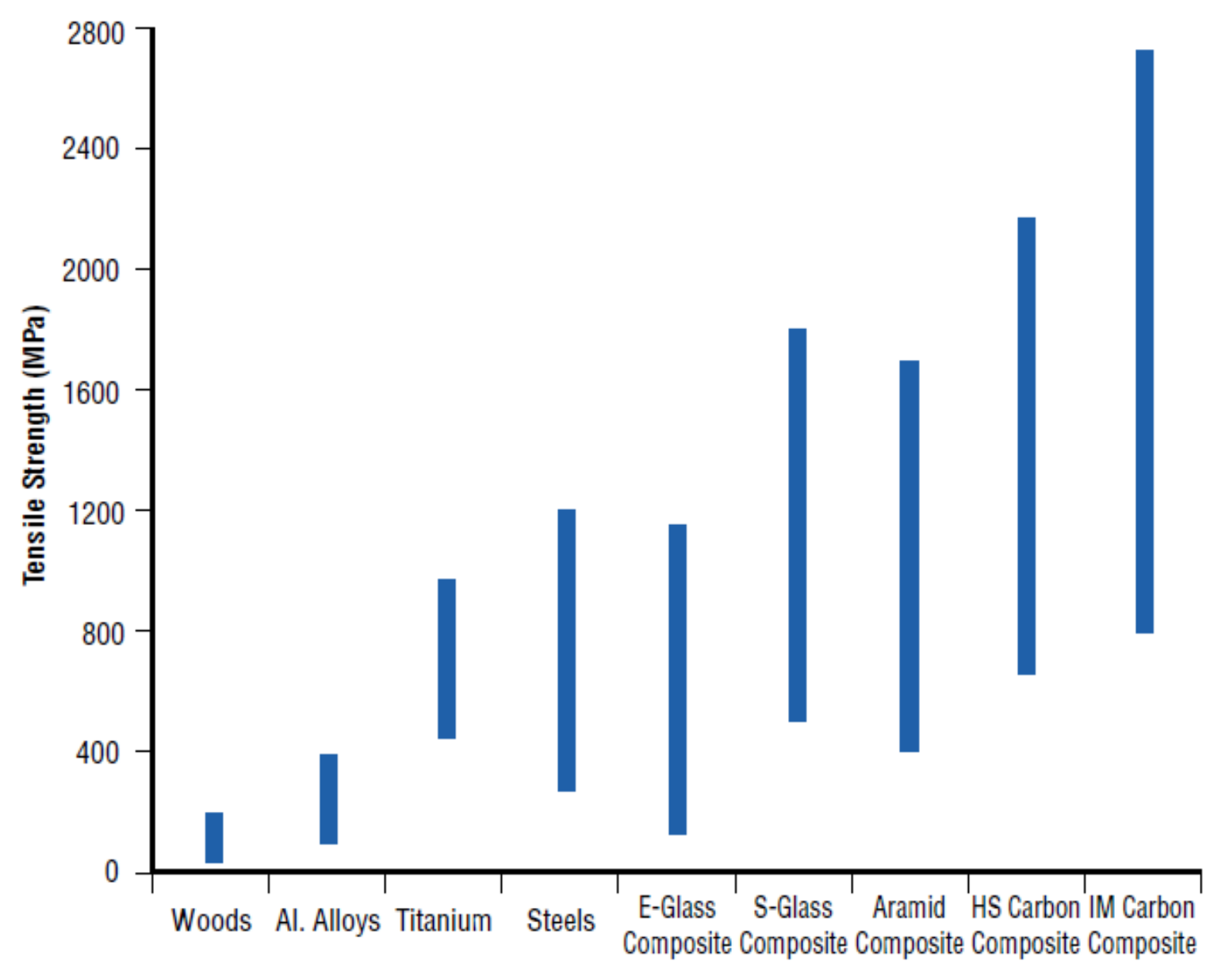

Figure 2: Tensile strength of conventional and composite structural material [Ref. 18]

The number of parameters considered in selecting the reinforcement is dependent upon the application being considered. Some of these important parameters are yarn weight, thread count, weave pattern, and fabric finish. The fabric thickness, weight, and strength are determined by the yarn weight.

The basic weave patterns that are normally used in the industry are plain, twill, basket, four harness, eight harness, and leno. However, woven fabrics are not limited to these styles as they can be tailored to any desired pattern and style depending on the application.

The plain weave consists of yarns interlaced in an alternating fashion, one over and one under every other yarn, which provides good fabric stability but is not considered beneficial in terms of pliability. The 
plain weave intermediate modulus carbon fabric is currently used in the high temperature panel fabrication. Basket weave is more pliable, flatter and stronger but is not as stable as plain weave. The four harness and eight harness fabric are similar in weave pattern and both have the advantage of pliability which makes them a better choice for forming over curved surface. Twill weave is pliable and has better drapability than plain weave while has more fabric stability than four or eight harness satin weave.

In the present study we are focusing on producing thin flat advanced composite panels by implementing a novel manufacturing apparatus. More stable, stiff plain weave carbon fabric is easily available in the industry, which is commonly used for manufacturing composite components. Plain weave helps the manufacturing technique by producing an ideally void free flat panel.

\subsection{MATRIX SYSTEMS}

Matrix is the dispersed phase in the composite structure, which provides bulk form to the materials by holding the fibres in a certain orientation. They protect the reinforcement from abrasion; helps transfer the loads uniformly between the fibres and provide interlaminar shear strength. The matrix has influences the mechanical properties of composites such as transverse modulus, shear properties and properties in compression. Normally, matrix materials limit a composite's service temperature in high temperature application.

Polymers are the most commonly used matrix materials for the fibre composite. Depending on their structure, temperature increases the effect on their properties and classification of thermoplastics or thermosets. Thermoplastics consist of linear or branched chain molecules having strong intermolecular bonds, which can be melted or solidified reversibly and reshaped with the application of heat and pressure. The thermosets have cross-linked covalent bond between molecules. Once solidified by curing, 
it cannot be reshaped or melted. It can only decompose to an amorphous polymer structure above a certain temperature called the glass transition temperature.

Table 2: Properties of some commonly used Thermoplastic and Thermosetting Polymers [Ref. 1]

\begin{tabular}{|c|c|c|c|c|c|c|c|}
\hline Property & Epoxy & $\begin{array}{c}\text { Thermosetting } \\
\text { polyimides }\end{array}$ & PEEK & $\begin{array}{l}\text { Polyamide- } \\
\text { imide }\end{array}$ & $\begin{array}{l}\text { Polyether } \\
\text { imide }\end{array}$ & $\begin{array}{c}\text { Poly- } \\
\text { sulphone }\end{array}$ & PPS \\
\hline Density $\left(\mathrm{g} \mathrm{cm}^{-3}\right)$ & $1.15-1.4$ & $1.43-1.46$ & 1.30 & 1.38 & & 1.25 & 1.32 \\
\hline Elastic Modulus (GPa) & $2.8-4.2$ & 3.2 & & & & & \\
\hline Flexural Modulus (MPa) & $15-35$ & 35 & 40 & 50 & 35 & 28 & 40 \\
\hline Tensile Strength $(\mathrm{MPa})$ & $35-130$ & $55-120$ & 92 & 95 & 105 & 75 & 70 \\
\hline Compressive Strength (MPa) & 140 & 187 & & & & & \\
\hline $\mathrm{CTE}\left(10^{-5}{ }^{\circ} \mathrm{C}\right)$ & $4.5-11$ & $5-9$ & & 6.3 & 5.6 & $9.4-10$ & 9.9 \\
\hline 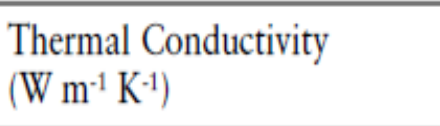 & $0.17-0.2$ & 0.36 & & & & & \\
\hline Water Absorption (24 h, \%) & 0.1 & 0.3 & 0.1 & 0.3 & 0.25 & 0.2 & 0.2 \\
\hline $\mathrm{T}_{\mathrm{g}}\left({ }^{\circ} \mathrm{C}\right)$ & $130-250$ & 370 & & & & & \\
\hline $\begin{array}{l}\text { Continuous Service } \\
\text { Temperature }\left({ }^{\circ} \mathrm{C}\right)\end{array}$ & $25-85$ & $260-300$ & 310 & & 170 & $175-190$ & 260 \\
\hline
\end{tabular}

\subsubsection{Phenolics}

Phenolics are formed from the condensation polymerization reaction between phenol (an aromatic molecule) and formaldehyde. They have high shrinkage and are quite brittle because of high cross link densities. Phenolics have excellent flammability performance, low smoke generation, low smoke toxicity, low heat transfer, high thermal stability, high electrical resistance, excellent resistance to chlorinated solvents, chemical resistance and good adhesion. Despite above mentioned properties and attractive price. Phenolics are less commonly used than epoxies and polyesters due to the difficulty in processing phenolics. When compression molding the phenolics in a hot press, the mold is slightly 
opened during the cure cycle permitting the vapors to escape, this process is called bumping or breathing the mould.

To minimize the condensated bubbles, phenolics are often initially cured at temperatures below the boiling point of water and then post cured at higher temperatures to advance the amount of cross linking. Phenolics have less flame spread index and specific optical index when compared to epoxies, vinyl esters and flame-resistant polyester.

The phenolic matrix system can be molded to composites using pultrusion, filament winding, sheet molding compound and hand lay-up technique. Filament wound pipes made of latent acid cured phenolic matrix attains a $\mathrm{T}_{\mathrm{g}}$ of $230^{\circ} \mathrm{C}$ after post curing process.

\subsubsection{Cyanate Ester (CE) Resin}

Cyanate ester (CE) resins belong to a family of high temperature thermosetting resins that bridges the gap in the thermal performance between the epoxy and polyimide. CE is high cost resin with a good combination of desirable characteristics like low dielectric loss, low moisture absorption, low shrinkage and low out gassing. The CE systems produce fewer micro cracks overall after 2000 cycles, with micro crack density increasing rapidly from zero to 500 cycles and then stabilizing (Ref. ASTM chap CE, Pg: 128) Some of the cyanate ester resins are: Bisphenol A dicyanate, ortho Methyl dicyanate, Arocy L10, Phenol triazine, and $\mathrm{XU71787} 0.2 \mathrm{~L}$ whose $\mathrm{T}_{\mathrm{g}}$ varies between a range of $252^{\circ} \mathrm{C}$ to $320^{\circ} \mathrm{C}$. CE is available as hot melt prepregs, tow prepreg, Resin Transfer Molding (RTM) resin, adhesive system, and syntactic core material which can be produced into composites using auto clave, press, Pultrusion, RTM, Seaman's composite resin injection molding or Vacuum assisted resin transfer molding methods. CE resins are normally post cured to $235^{\circ} \mathrm{C}$ to $315^{\circ} \mathrm{C}$ for structural service temperatures at or above $180^{\circ} \mathrm{C}$. 


\subsubsection{Bismaleimide Resins (BMI)}

BMIs are also most commonly used thermoset polyimides in the advance composite industry. BMI monomers are prepared by the reaction of maleic anhydride with a diamine. BMI's have excellent process ability, balance of thermal and mechanical properties, and almost constant electrical properties over a wide range of temperature. It can be operated up to temperature of $232^{\circ} \mathrm{C}\left(450^{\circ} \mathrm{F}\right)$ and processed using Resin Transfer Molding. BMI's have high compression after impact strength which certifies itself for aerospace applications namely F-22 fighter jet wings, C-17 aft flap hinge, thrust reverser structures, and helicopter tail boom.

Table 3: Comparison of Thermoset and Thermoplastic matrix [Ref. 1]

\begin{tabular}{|c|c|c|c|}
\hline Application & Property & Thermoset Matrix & Thermoplastic Matrix \\
\hline \multirow[t]{4}{*}{ Matrix } & Formulation & Complex & More Simple \\
\hline & Melt Viscosity & $\begin{array}{l}\text { Low } \\
\text { (at the Beginning) }\end{array}$ & Rather High \\
\hline & Fibre Impregnation & Comparably Easy & Very Difficult \\
\hline & Cost & Low to Medium & Low to High \\
\hline \multirow[t]{2}{*}{ Prepreg } & Tack/Drape & Good & Comparably Low \\
\hline & Shelf Life & Very Poor & Good \\
\hline \multirow[t]{9}{*}{ Composite } & Processing Cycle & Very Long & Short to Long \\
\hline & $\begin{array}{l}\text { Processing Temperature } \\
\text { and Pressure }\end{array}$ & Moderate & High \\
\hline & Size of Products & Can be Very Large & Small to Medium \\
\hline & Resistance to Solvents & Good & Poor to Good \\
\hline & Damage Tolerance & Poor to Excellent & Fair to Good \\
\hline & Resistance to Creep & Good & Not Known \\
\hline & Interlaminar Fracture & & \\
\hline & Toughness & Low & High \\
\hline & Ease of Fabrication & Labour Intensive & Less Labour Intensive \\
\hline
\end{tabular}




\subsubsection{LaRC RP46}

LaRC RP46 is an ultra high temperature thermosetting polyimide resin. RP 46 has exceptionally high thermo-oxidative stability and higher mechanical property even at elevated temperatures. Composites made of RP 46 have a service temperature ranging between $-100^{\circ}$ to $370^{\circ} \mathrm{C}$ and withstands up to $816^{\circ} \mathrm{C}$ for a few seconds. RP 46 has excellent resistance to corrosion, moisture, chemical, low dielectric constant and low coefficient of thermal expansion. RP46 provides considerable weight savings over any epoxies, which offer advantages for use in aircraft engine components, small satellites, missiles and electronic circuit boards [10].

RP46 was used in the current research. It was found to be economic and easily process-able when compared to other high Tg resin system. The curing cycle of RP46 is designed to remove the air pockets or voids caused due to moisture entrapment. The reason for selecting the RP46 resin system was favourable cure cycle. Staging at the initial curing phase helps removal of methanol or any moisture entrapped between the fibre and matrix inter-phases.

\subsection{POLYIMIDE RESIN}

Experience from the past about chemical structure reveals that aromatic polyimides with stiff molecular backbone from internal bonding, cross-linking or high crystalline were found to have outstanding thermal and thermo-oxidative stability. One such polymer is polyimide, which can be classified as either thermoplastic or thermoset. There are two types of polyimide, condensation type and additional type. End capped polyimides are synthesized by combining three monomers: two react to form polyimide and one attaches to the ends of the chains to form the end caps. Polyimides tend to be hard to process due to their condensation reaction emitting water during cure and are relatively brittle when cured. 


\subsubsection{Polyimide for Aerospace Application}

In order to overcome the deficiency of the conventional materials namely density, strength, temperature resistance, thermal cycling, water absorption and retention, radiation shielding capability, acid and base resistance, transmissivity, thermal resistance, and bonding capabilities, novel multifunctional polyimides have been produced by NASA's Langley Research Center. We know aluminum structure for the satellite weighs in the scale of tons, which could be replaced with LaRC RP46, a novel material embodied with new states of matter. Spray-On Polyimide (SOP) foam could be used on the inside of the fuel tank instead of the elastomeric foam with limited temperature range on the exterior of the external tank. This application will save weights by four fold in addition to providing dual thermal protection to the structures. The advantage of using SOP is low density, higher temperature resistance, and better light and chemical resistance. In compensation for the high cost it has ten times better shelf life and reproducibility, reliability, and dependability than conventional materials.

High temperature polyimide foams, known as TEEK developed using salt-like process are not flammable when tested at $1090^{\circ} \mathrm{C}$ for $25 \mathrm{sec}$. They have excellent hydrolytic stability, limited oxygen index, compression strength, thermal insulation and cryogenic capability.

Flexible TEEK foams are well suited for acoustic and thermal insulation in variety of applications including aircraft, spacecraft, ship hulls, automobiles, electronics and building construction. Structural components such as panels, struts, ball bearings, races, tubing, connectors, pressure vessels, housing, casings and stringers can be made with RP 46 polyimide. The Polyimide/graphite composites have a density of $1.50 \mathrm{~g} / \mathrm{cc}$ compared to lightest lithium-aluminum metal alloy with $2.53 \mathrm{~g} / \mathrm{cc}$ and also has high specific strength in temperature range of $320^{\circ} \mathrm{C}$. Experiments show that exposure of T650/RP 46 has less weight loss and thermo-oxidation induced damage than T650/PMR-15 at $343^{\circ} \mathrm{C}$ for $500 \mathrm{hrs}$. 
PMR-15 is one of the leading high temperature matrix resin developed by NASA in 1970s. However, PMR-15 had serious limitations such as non-reproducible processing and severe micro cracking, which is aggravated by thermal cycling. PMR-15 is an end-capped polyimide. It is synthesized by an imidization reaction and then the chain-lengthening step follows an end cap step. PMR-15 can be typically used in the temperature range of $550-600^{\circ} \mathrm{F}$ for continuous service and at $900^{\circ} \mathrm{F}$ for short durations.

Polyamides carry a high surface charge potential, which could be exploited to be used as an outer surface coating for lunar space suits to adjust the surface potential voltages to repel lunar dust, which was earlier reported as a severe problem in Apollo 16 mission. Some of the commercially available polyimides are Avimid-N, Avimid-K3A, AFR 700B, PMR-15, PMR-II-50, LARC-SI, PETI-5 and superimide 800. Here is a graph depicting the service temperature of the polymer matrix materials.

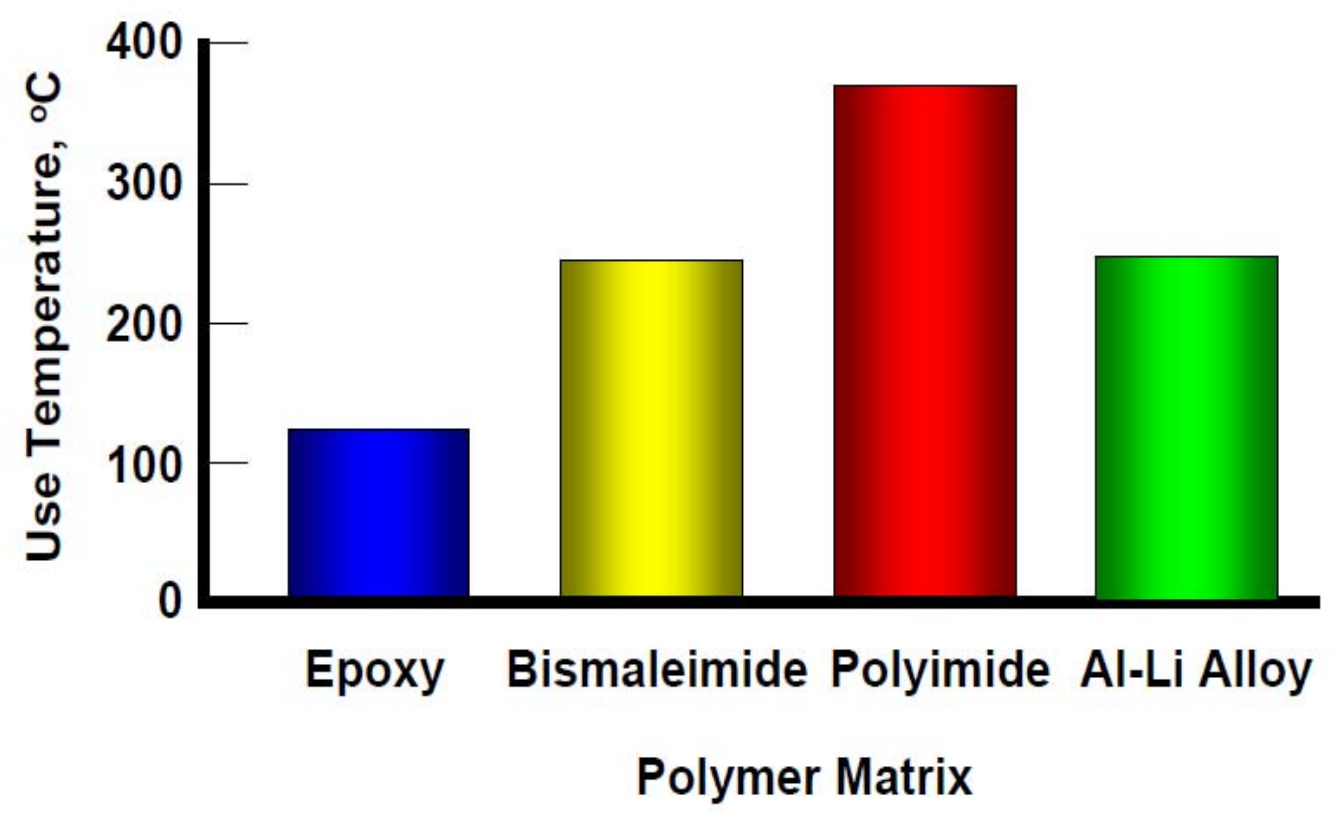

Figure 3: Comparison of Polymer matrix use temperature [Ref. 18] 
Polymer

Thermoset matrix

DGEBA epoxy

TGDDM epoxy

Bismaleimides (BMI)

Acetylene-terminated polyimide (ACTP)

PMR-15

Thermoplastic matrix

Polyether ether ketone (PEEK)

Polyphenylene sulfide (PPS)

Polysulfone

Polyetherimide (PEI)

Polyamide-imide (PAI)

K-III polyimide

LARC-TPI polyimide

\section{$T_{\mathrm{g}}{ }^{\circ} \mathrm{C} \quad$ Maximum Service Temperature, ${ }^{\circ} \mathrm{C}\left({ }^{\circ} \mathrm{F}\right)$}

180

$240-260$

230-290

320

340

143

85

185

217

280

250
$125(257)$

$190(374)$

$232(450)$

$280(536)$

$316(600)$

$250(482)$

$240(464)$

$160(320)$

$267(512)$

$230(446)$

$225(437)$

$300(572)$

\subsection{CONCLUDING REMARKS}

In this chapter we had a detailed discussion about the various options available for the selection of fibre reinforcements and matrix systems for fabricating high temperature flat composite panels. The reason for selecting RP 46 resin system and carbon fibre reinforcement was discussed briefly. In the following section a review of manufacturing technologies that is already used in the industry is discussed in detail, which serves as the base for designing a new manufacturing system to produce consistent quality panels. 


\section{CHAPTER 4}

\subsection{MANUFACTURING TECHNOLOGIES}

Advancement in the field of aerospace industry has led development of various design and manufacturing process to meet the ever increasing demand for advanced materials. Therefore manufacturing processes, aerospace materials, and associated designs must be optimized in an integrated manner to deliver product competitiveness. With the advent of new materials, product development and manufacturing, processes have to be given more importance to produce defect free final products with minimal wastages in raw materials.

Materials selection and contour of the final product also plays an important role in selection of manufacturing process. In producing composites there is a wide option in selection of fibre reinforcement and resin material to attain unique set of properties such as strength, stiffness, heat resistance, etc. Some of the common manufacturing processes in producing composites are discussed in the following section to compare the feasibility and cost effectiveness in producing the component.

\subsection{OPEN MOLDING OF ADVANCED COMPOSITES}

Manufacturing methods for advanced composites are established taking into account the difficulties faced in the standard manufacturing process.

1. Fairness in controlling the fibre/resin ration

2. Wetting out the entire fibre volume

3. Minimizing the void content

4. Controllability in aligning the fibre direction

5. Optimizing the amount of fibre to get the maximum benefit 


\subsubsection{Lay-Up Molding}

Almost any size and shape parts can be manufactured by lay-up processes at low production rates. Various forms of reinforcements include chopped strand mats, woven roving, woven yarns, or cloths, usually available in the form of a roll. Unrolled fibres are cut to desired shapes using templates or patterns at desired orientations. The simplicity of the lay-up process and general manual nature of resin application allows a wide variety of resin selection such as polyester, vinyl ester, phenolic and epoxy. The hand lay-up process involves low investment cost and little prior working knowledge, but it is highly sensitive to the skill level of the operator. This is considered as one of the potential methodology for producing flat panels of uniform thickness in the low production facility, which better suits our current requirement.

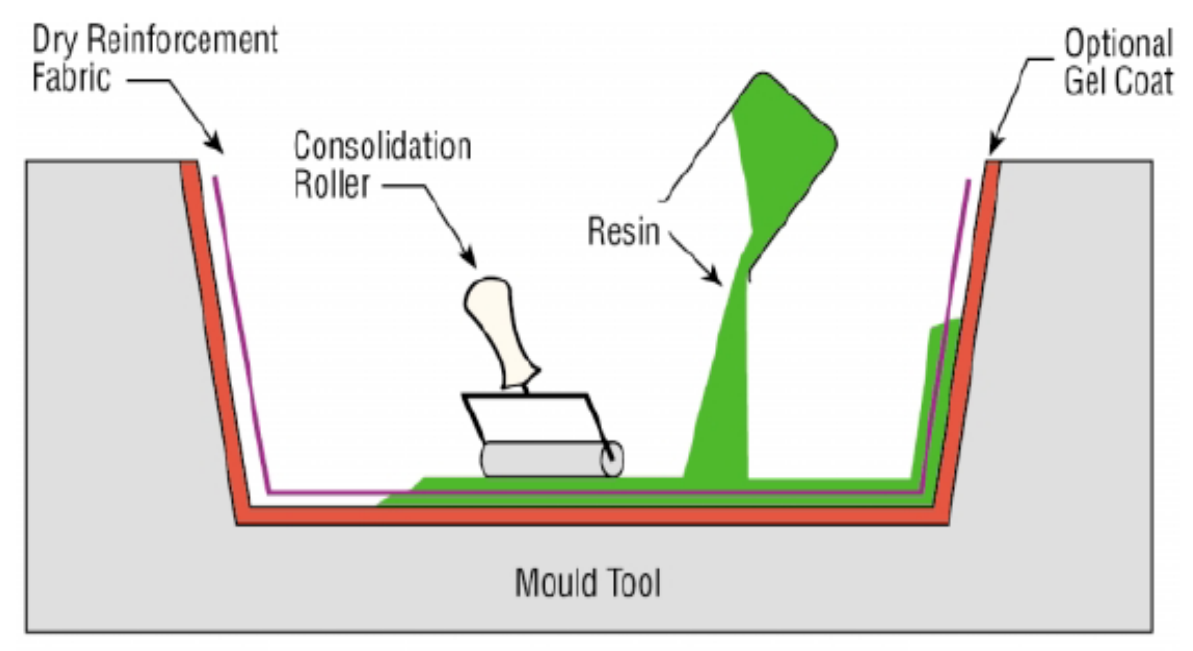

Figure 4: Hand Lay-up/Wet Lay-up [Ref. 18]

\subsection{1(a) Manufacturing Procedure:}

The first step in the hand lay-up is cleaning the surface of the mould, followed by the application of release agent for easy part removal. Thin layer of gel coat is normally applied for better surface finish of the final product. After the gel coat is set, alternating layers of fibre and resin is placed on top of the gel coat. Resins are generally catalyzed with hardeners and accelerators. Fibre impregnation, removal of air 
bubbles, and coverage of all reinforcement is accomplished with rollers, squeegees, or stipple brushes. Generally the brush method is used for the application of resin in the case of low production rates, while spray guns or pumping systems are preferred by manufacturers to achieve consistent resin mix for better fabric wet out. The wetted fibre is then cured in standard atmosphere or in oven at elevated temperatures. The completely cured part is finally removed from the mould and unwanted edges are trimmed to produce the final product.

Despite being a simple technique, hand lay-up/wet lay-up has limitations in terms of production rate. Laminate quality depends on the skill level of the personnel like mixing resin without bubble formation, controlling laminate resin content.

\subsection{1(b) Prepreg Lay-up}

The prepregs layup room should be environmentally controlled by maintaining constant temperature and filtering the air to eliminate dust. Contamination with silicone impurities on the layer is an important consideration as it affects the ability of bonding prepregs layer to another layer. Hence silicone based mold releases are not used, if unavoidable, then type that is less volatile and non-aerosol is employed. Automated machine layup suits well with flat panels and parts with moderate curvature.

When using thermoplastic prepregs for manufacturing they are softened by heating with a hot air gun or on a heating table as these materials do not have tack and drape under normal conditions.

\subsubsection{Bag Molding}

Though prime care is taken during the hand lay-up, air is inevitably trapped between the layers of prepregs or fabric. The process of removing the air after the lay-up and before the curing is called debulking. Debulking is usually done after the lay-up of every four to six layers. This technique compacts the laminate on the open mould surface. Applying the vacuum helps remove the volatiles in the resin and helps in the movement of resin during the curing stage. This helps is lower void content of the final 
part and eliminates any boundary between the layers thereby reducing the chance of delamination. High temperature composites can be manufactured by dry molding process or wet molding process. The wet molding process involves the usage of vacuum bagging procedure at certain time intervals in the curing cycle.

\subsection{VACUUM BAGGING PROCEDURE}

Mold is prepared by coating it with the appropriate mold release. The part is built with the desired orientation up to the required thickness and number of layers. Release film (commonly used perforated Teflon sheet or Teflon-coated glass fabric) or peel ply is placed over the part to facilitate pulling all the bagging materials after the part is cured. Generally release films are porous to allow excess resin to flow through them. Bleeder is applied on top of release films, which serves as absorbent for excess resin in the system. Resin content of the final part depends on the ability of the bleeder material to absorb the required amount of resin, thereby necessitating thickness calculation. Breather materials are applied on top of the bleeder that acts as a distributor for air and helps escape volatiles and gasses. A sealant material usually a sticky polymeric tape is placed around the entire setup. Finally a vacuum bag made of flexible polymeric film is pressed onto the sealant to create an airtight seal. Vacuum valve connections are made and connected to the vacuum pump to suck the air from the assembly eventually evacuating the volatiles and gasses released during the curing process. 


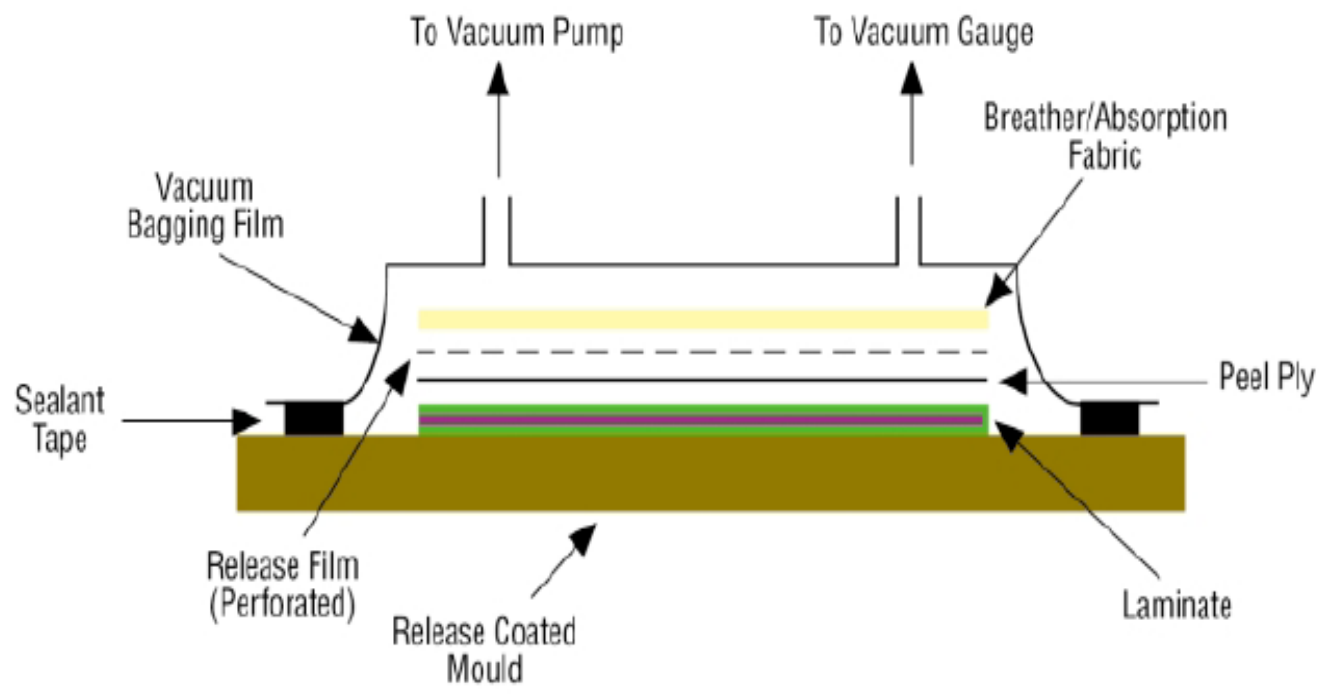

Figure 5: Vacuum Bagging Method [Ref. 18]

\subsubsection{Pressure Bagging Procedure}

In pressure bag molding positive pressure is applied to inflate an elastomeric bag covering the laminate on the open mold surface. Magnitude of the pressure applied can be approximately $300 \mathrm{kpa}$ compared to $98 \mathrm{kpa}$ in the vacuum bag method.

\subsection{SPRAY UP MOLDING}

Spray Up process is faster when compared to Hand Lay Up in terms of production rate. Parts with considerable size and simplicity in design can be manufactured with ease. Spray Up process requires spraying equipment, more limited resin choice in terms of viscosity, and high air pollution because of spraying the resin. The major drawback is its inability to control the orientation of the fibre and it also requires highly skilled labour to manufacture with uniformly distributed and controlled thickness for better curing. Spray up molding is preferred to make boat hulls and decks for luxury cruisers, however it is not considered ideal for producing flat panels. 
The spraying equipment has a chopping mechanism attached to the gun. The fibres are fed into the chopper as roving and then chopped so that they fall into the stream of resin at the tip of the nozzle. Chopped fibres have to be short (1-3 in) for ease of spraying and to fill the tight areas of the mold. After the fibre and resin are sprayed onto the mold, a roller is used to wet out the fibre bundles. Normally spray molding is used with polyester and glass roving.

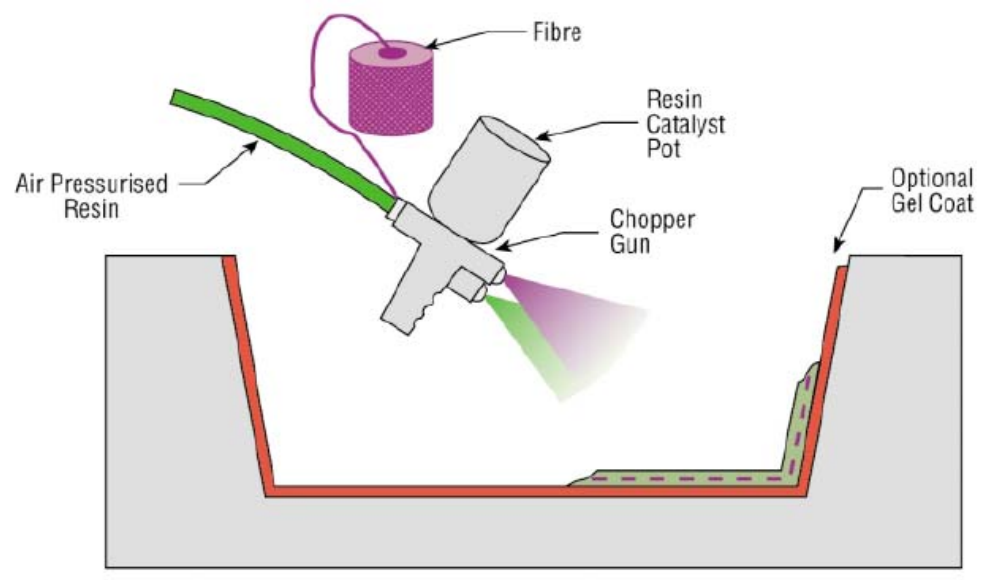

Figure 6: Spray up molding [Ref. 18]

\subsubsection{Drawbacks}

Laminates tends to be uneven in resin-rich areas. The use of short fibres severely limits the mechanical properties of the laminate. Resin has to be low in viscosity to be spray able. High styrene content of the spray lay-up resins has the potential to be harmful.

\subsection{COMPRESSION MOLDING (MATCHED DIE MOULDING)}

Compression molding is used in industries were high volume production and part repeatability is required. In this method charge of uncured resin and fibre is placed in a cavity of the matched mold. The male mold is then pressed against the female halves thereby exerting the pressure and squeezing the excess material, leaving uniformly filled material in the cavity. The application of pressure and elevated temperature causes the compound to flow into the mould. Heat is applied through the heated press 
which cures the material. There is low void content as the excess materials are squeezed out and amount of scrap is minimal. Fillers (calcium carbonate or kaolin clay) are used as inert addictives to reduce the CTE, modify the viscosity, and increase hardness, rigidity, and dimensional stability.

In bulk molding compounds (BMC), chopped fibre is mixed with initiated resin and filler to form a dough or paste like mass, whereas in sheet molding compounds (SMC) initiated resin and filler paste is spread onto a wide carrier film and then fibreglass is chopped and sprinkled across the coated film. Another layer of coated film is placed on top of the chopped fibreglass and the sandwich of material is kneaded between rollers to wet out the fibres. The initiator is normally heat active peroxide that helps maintaining minimal curing during the manufacturing process. Compression molding technique is currently applied in the novel in-house manufacturing set up.

\subsection{RESIN INFUSION TECHNOLOGIES}

Resin Infusion Technology can be used to manufacture advanced composite parts where direction of the fibre is considered important in terms of part performance. Some of the advantages of using resin transfer molding are better quality, repeatability, lower emission, low labour requirements, and does not involve additional equipment like autoclave, freezers, and bagging materials.

Fabrics are laid up as dry stacks of materials, in many cases the fabric is pre-pressed to the mould shape and held together by a binder known as preforms. These performs are laid on the base mould and the second mould tool is clamped over the base mould. The resin is then pressure injected into the cavity wetting the fabric completely with resin. The resin is allowed to cure and mold is opened to extract the final part. There are number of variations applied to infusion system to manufacture composite products, some of them are briefly discussed in this section. 
Vacuum is applied to the mould cavity to assist resin being drawn into fabrics. Usually, one end of the tool is fitted with the resin inlet and the other end is connected to the vacuum outlet. The vacuum suction pulls the liquid into the preform, enabling complete wet out, this process is known as vacuum assisted resin injection (VARI) or vacuum assisted resin transfer molding (VARTM). It requires resin of lower viscosity and unimpregnated areas can occur resulting in scrap parts. Generally epoxy resin, vinyl ester, phenolic, and high temperature reins like bismaleimides can also be used in the RTM process.

Resins with high viscosity, typically resin films, are used in the manufacturing process called resin film infusion. Dry fabrics are laid on the mould with layers of thin resin film in between the layers. The layup is then vacuum bagged to remove any trapped air in the dry preform followed by application of heat and pressure which allows resin's viscosity to decrease, permitting it to infuse into the preform.

\subsection{FILAMENT WINDING:}

This process is normally used for manufacturing cylindrical, hollow circular or oval section components like pipes and cylindrical tanks. The fibre spools are mounted on a rack called creek, which are gathered together and fed through the comb to make a band of fibres. The band enters the resin bath where fibres are soaked with resin. The fibres are then passed through the roller or wiper system to remove excess resin and directed onto a mandrel through the payoff. The payoff is placed on a carriage that moves along the long axis of the mandrel, so as the mandrel rotates synchronized payoff motion produces various fibre patterns on the mandrel. Filament winding is suitable for making composite pipe structure, pressure vessel, fuselage, rocket motors, power transmission shafts and sporting goods. Most common winding patterns are hoop or circumferential, helical, longitudinal or axial windings. This method is very fast and economic which can yield very good structural laminate properties. Recently, highly automated fibre placement techniques are used in the composite manufacturing. Fibre placement machines have an advanced controller, a high precision head that lays the fibres and a 
carriage. It can lay up fibres up to nine axis of rotation essentially required to manufacture any shape part.

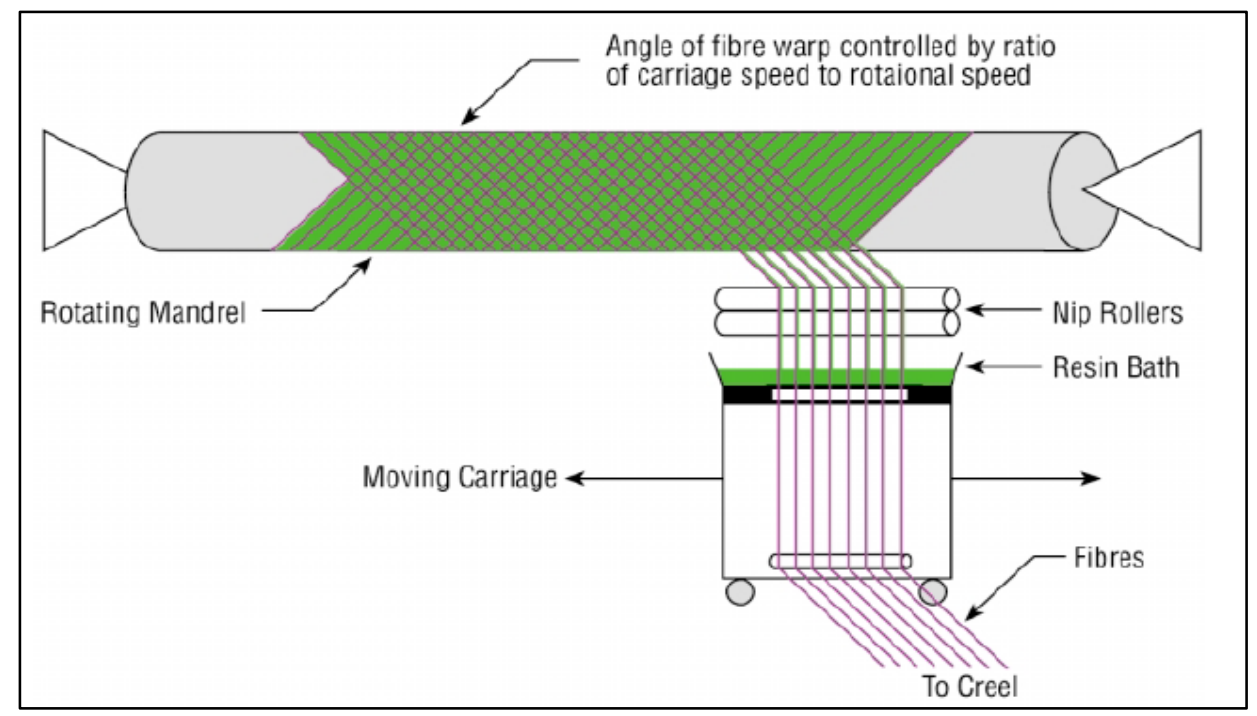

Figure 7: Filament winding [Ref. 18]

\subsection{PULTRUSION}

Pultrusion is a continuous process with high material utilization and can be used for high volume manufacturing of parts with constant cross section. The continuous fibres are drawn from reels through a resin bath. The fibres are wetted by resin, converged and passed through a heated die. Inside the die fibre gets impregnated and resin contents are controlled. The wetted reinforcement is cured in the die, which is then pulled, moved into the cutter and trimming station where the finishing process is performed.

Advantages of pultrusion are fast and economic, controlled resin content, minimized fibres cost, and very low scrap rates. Pultrusion method was used for manufacturing composites with PMR-15, the mechanical properties and void content indicated that further work has to be done to improve the production process. Pultrusion is a cost effective automated process, which is apt for manufacturing continuous and constant cross-section composite shapes. 


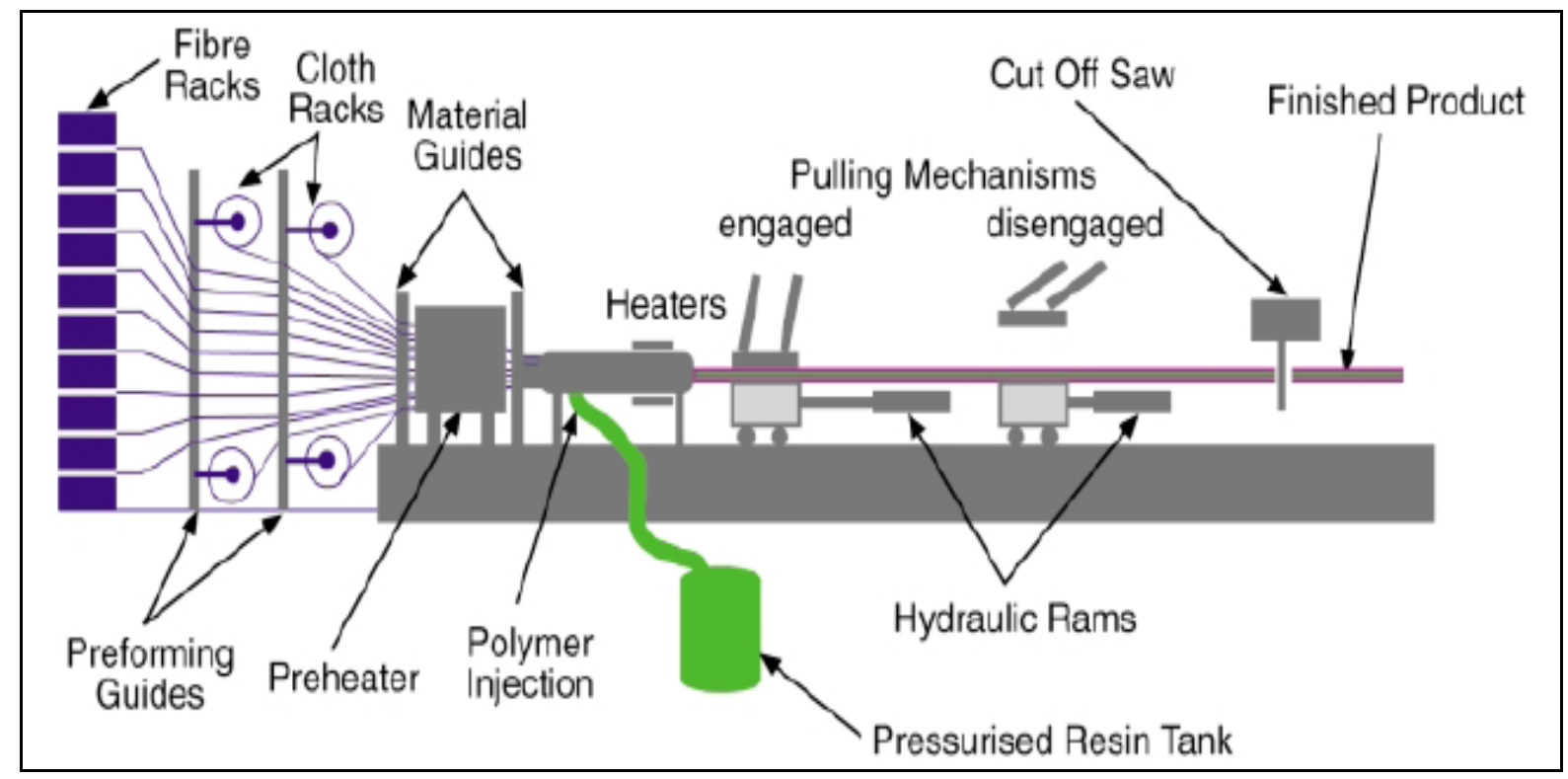

Figure 8: Pultrusion [Ref. 18]

\subsection{DRY MOLDING OF ADVANCED COMPOSITES (USING PREPREGS)}

Although wet lay-up is simple to process and needs minimum labour skill, there are a number of reasons for using a dry molding technique for manufacturing advanced composites. The difficulty in aligning the fibres exactly, controlling the fibre/resin ratio, achieving full wet out, reducing the void content, difficulty in mixing the resin and application of the resin adds up to the complexity in hand lay up using resin and fabric. On the other hand dry molding systems enable the control of ply thickness, fibre-resin ratio, and reduce internal stresses.

\subsection{CONCLUDING REMARKS}

A clear understanding of the manufacturing techniques was necessary to select the manufacturing process that could be applied for high temperature composites production process. The manufacturing techniques present in the industry were studied in detail in the current chapter followed by detailed description of the introduced novel manufacturing technology in the subsequent chapter. 


\section{CHAPTER 5}

\subsection{MANUFACTURING SET UP}

\subsubsection{Scope of High Temperature Polymer Composite}

Glass transition temperature of $\mathrm{BMIs}$ (bismaleimides) were limited to $230^{\circ} \mathrm{C}$ and $\mathrm{PMR}-15$ faced environmental restriction due to the 4-4"'-methylenedianiline (MDA) constituent which eventually lead to active research in the area of high-temperature polymeric materials to find more stable, low cost and easily processable materials. (Quickstep, 2010)

In the 1990s, NASA Langley research centre developed LARC - RP46 by replacing MDA with 3, 4oxydianiline. It retained the properties or PMR-15 combined with superior processability and excellent process reproducibility. The composites made with RP-46 significantly improved thermo-oxidative stability at $371^{\circ} \mathrm{C}$ when compared with existing PMR systems.

\subsection{MANUFACTURING OF HIGH TEMPERATURE MATERIALS}

Increasing demand for high temperature materials has resulted in the development of various advanced manufacturing technologies in the composites industry. However, costs involved in the production of high temperature composites remained high regardless of advancements in manufacturing methods. Due to the demanding temperature requirements and applications of pressure for manufacturing high temperature composites, autoclaves became necessity for a number of manufacturing processes. Cost factor, size limitations, and complexity involved in operating autoclaves led to the proposal of novel methodologies to produce defect free high temperature composites. One such attempt made in the present study to replace usage of an autoclave, with a novel in-house manufacturing technique that produces void free aerospace standard panels. 


\subsection{NOVEL MANUFACTURING METHODOLOGIES TO REDUCE PRODUCTION COST: Review}

The following section discusses the possibilities for manufacturing high temperature composites by not using an autoclave, which increases the manufacturing cost by manifold.

\subsubsection{Quick Step Technology}

In this process the laminate is placed in between the flexible bladder, which is encapsulated in the pressure chamber. The pressure chamber is filled with hot fluid, which supplies heat required for curing the laminate. The circulating fluid exerts pressure through the flexible membrane onto the laminate mould.

Features of Quick Step Curing:

- Rapidly applying heat to the laminate, placed between a rigid and semi rigid mould

- Mould and laminate are separated from the circulation HTF (heat transfer fluid) by a flexible membrane

- Use of balanced pressure and vacuum on the laminate to cure the part

- Economical construction due to low pressure in both chambers

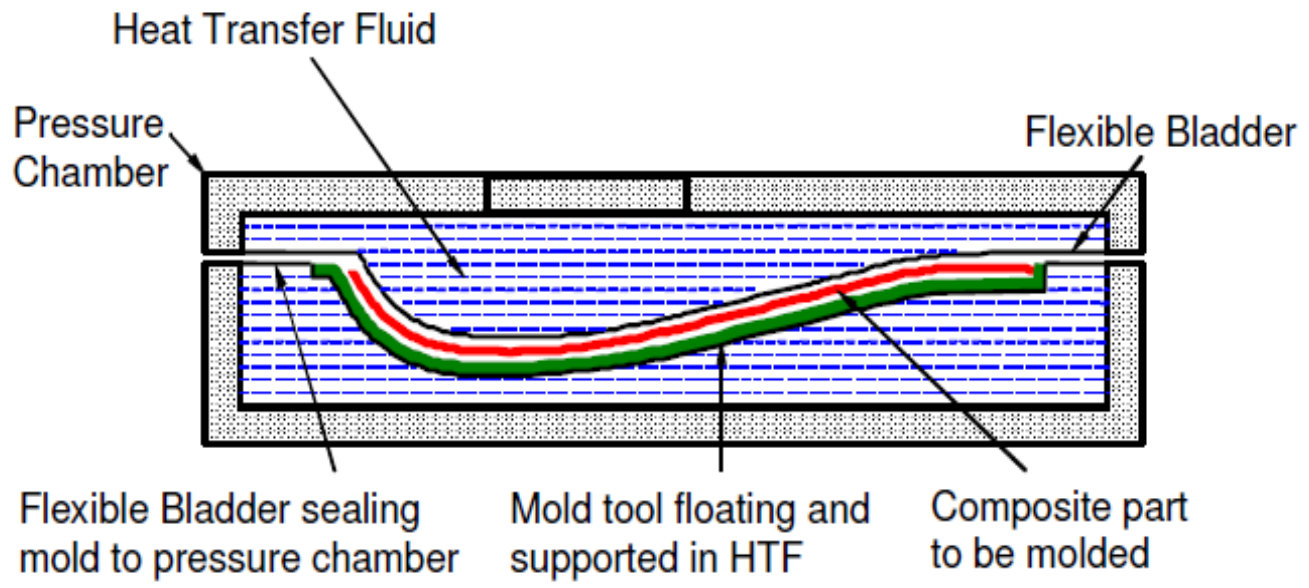

Figure 9: Quick Step Curing Chamber [Ref. 19] 


\subsubsection{Construction of Pressure Vessel}

An alternate production apparatus to an autoclave is a pressure vessel with a heating element and pressure control. The metallic cylinder with a hemispherical door was proposed with a heating element used to heat the chamber. A distributor fan circulates the heat produced by the heating coil thereby maintaining uniform heat throughout the chamber. Compressed air is supplied through the pressure port to pressurize the component. The features of the pressure vessel include the pressure relief valve, pressure sensor transducer, and sealed accessible door with locks. Although the pressure vessel surpassed the need for an autoclave, the cost associated with the design and production of the pressure vessel was still beyond the economic budget.

\subsubsection{Compression Press Molding}

Literature studies show that high temperature composites produced using hot compression press yielded laminates of void content less than $0.1 \%$ [2]. These laminates were fabricated with prepregs employing a dry molding cycle for which a vacuum was not required for part consolidation.

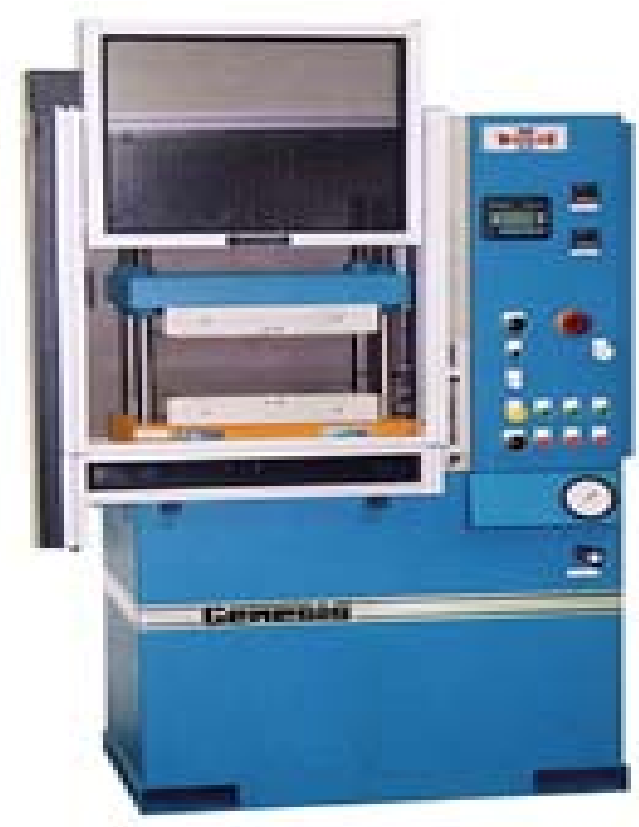

Figure 10: Heated Compression platen (wabashmpi) 
Wabash heated platen is used in industries for manufacturing flat advanced composite panel of uniform thickness. The compression press is hydraulically operated with adjustable platen closing and opening speed. The platens are heated with the electric cartridges and the PID digital controllers monitor the temperature. The available clamp pressure force varies from 15 tons to 150 tons. The heated platens have optional water-cooling system with platen size varying from 12 to 48 Sq.in.

The equipment costs were still high and beyond the economic budget with reference to production of test coupons. Hence, there was a need for the new in house technique that could produce cost effective test specimens.

\subsubsection{Concept of Self Reacting Mold; Integrated with Oven}

In present work, innovation is brought into reality through the novel idea of applying pressure and maintaining the cure cycle temperature by integrating two different systems. A frame structure with a self-reacting concept is designed and is made of high strength heat-treated steel. The high temperature laminate is laid-up on the molding tool with male and female molds that have fine surface finishes. The mold tool is pressurized by the hydraulic actuators to the required manufacturing pressure. The cure cycle temperature is programmed in the oven.

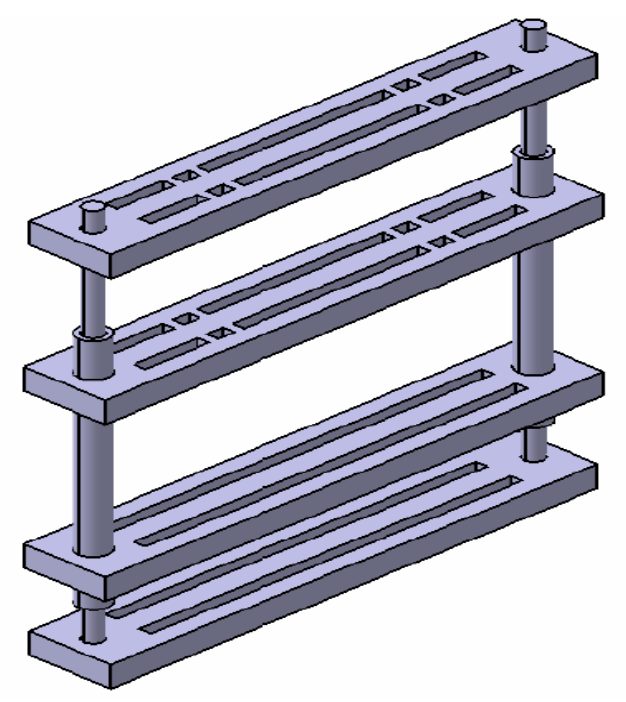

Figure 11: Self-Reacting Frame Structure 


\subsection{INITIAL DESIGN OF MANUFACTURING SYSTEM}

The manufacturing of high temperature composites involved compatibility assessment and preliminary design phases, which are discussed briefly in the following section. The critical element in the manufacturing set up is integration of the self-reacting frame (pressure controller) and compact industrial oven (temperature controller).

The high-pressure requirement to manufacture the IM7/RP46 composite panel was catered by implementing a mechanical system. The industrial oven space was wisely exploited to install the mechanical system. The equally spaced vent holes on the top of the oven body were taken as a reference point for building the oven, centre to centre distance between the ventilation holes were found to be $19 "$, the same was taken as the distance between the supporting rods in the mechanical system. The diameter of the hole was 0.65 ". The Inner supporting rods were designed to be $0.75^{\prime \prime}$ with reference to the results obtained from the FEM analysis. The outer rods had diameter of 1.25 " as they were required to have a bigger diameter to cater the design.

To accommodate the self reacting mold in the heating oven, precision holes had been drilled with the aid of a nibbler. Grinding tools with different grits were used over the holes to remove the burr, to present smooth and clean finish. Concentricity was kept in mind while drilling the oven holes whose wall thickness was 4.5 inches.

The oven top was constructed with two parallel steel sheets, which were filled with insulation in between. Concentric holes of 0.60 " were cut out on the top of the oven for the exhaust purpose and were enlarged to $1.25^{\prime \prime}$ to accommodate the outer rod of the frame. Allowance of $0.10^{\prime \prime}$ was set for the frames to move freely while applying the pressure. A concentric hole was marked on the surface with a scribing tool, using a rod element whose stem diameter is $0.65^{\prime \prime}$ fitted to a disc of diameter $1.25^{\prime \prime}$. The 
holes were carefully cut out using a hand held nibbler. Finally the sides were smoothed and grinded to exact dimension.

The designed self-reacting frame was made with high strength, heat treated steel. The total weight of the frame was 140 pounds including the compression mold. These frames were designed to be accommodated in the oven tray. As per the oven specification each oven tray was rated for a maximum load capacity of 20 pounds.

In order to support the structure an $L$ frame was designed. The self-reacting frame structures were expected to be suspended on the above-mentioned $L$ frame. Four $L$ frames were manufactured and fixed to the concrete wall surfaces to carry a load of 140 pounds.

\subsubsection{Frame Support: L Bracket}

The idea of external support was proposed as the cold treated steel frame was too heavy to be accommodated onto the oven self. In order to support the self-reacting frame a $L$ shaped bracket was designed in Catia V12 and static analysis was performed using a workbench in Ansys, to decide the thickness of the flat steel bar. The bracket was custom fabricated, as the length requirements did not match with the similar kind of brackets available on the market. A diagonal bar was welded between two ends to avoid excessive bending of the cantilever bar support. The holes were drilled onto the concrete wall using a hammer drill. Four L-brackets were fixed to the wall to provide firm support to the heavy frame. Precautions were taken in order to maintain the level of all four brackets. 


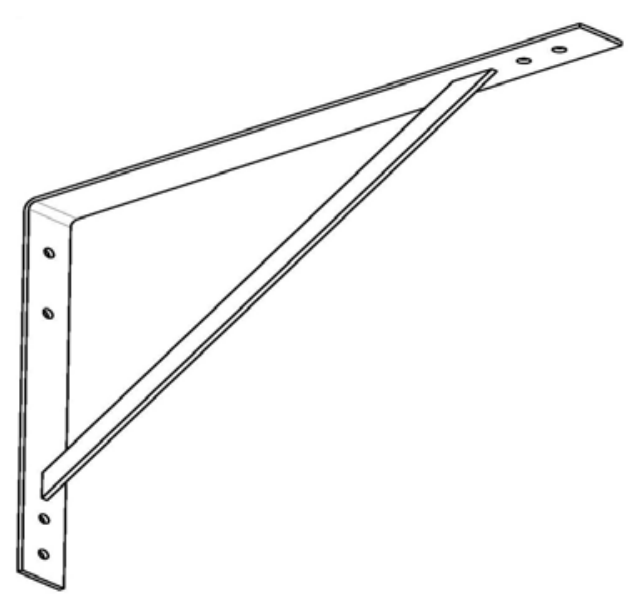

Figure 12: Isometric view of reinforced L-Bracket

\subsubsection{Hydraulic Actuator Schema}

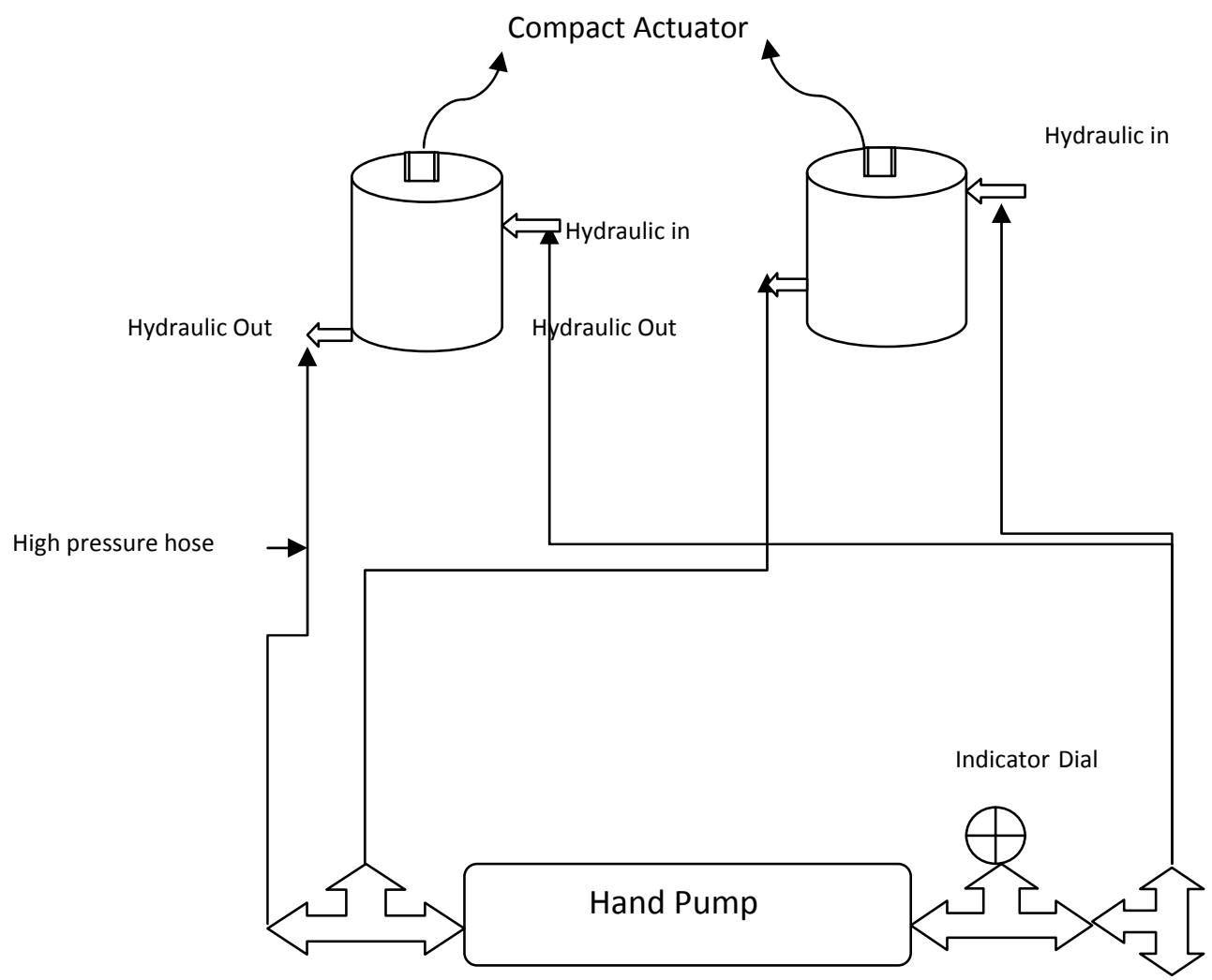

Figure 13: Hydraulic Actuator Circuit

The above diagram represents the hydraulic schema of the self-reacting molding system. The above detailed hydraulic actuator fits in between the top and mid plate of the molding frame. The hand pump with a T-joint at both ends was connected to the inlet and outlet of the cylinders. High-pressure polymer hoses with a rating of 2030 psi and high temperature insulation were used for all hydraulic connections. 
The hydraulic circuit had pressure gage, ball valve, and quick disconnect fittings. Hydraulic cylinders are the main source of the pressure applied on the compression mold to produce RP46 panels.

\subsection{FINITE ELEMENT ANALYSIS OF THE SELF REACTING FRAME STRUCTURE}

The main objective of this work was to use compression-molding technique to fabricate high temperature composite panel. It is apparent that the mould deformation under curing pressure would leave an imprint on the fabricated panels. The excessive deformation of the mould would translate to variation in thickness of the fabricated sample. The self-reacting frame for manufacturing the high temperature composite was designed to withstand the compression load during the fabrication of the IM7/RP46 specimen. The self-reacting frame was made from steel 4140 heat treated to $210 \mathrm{ksi}$ of yield strength. Steel was found to be economical and feasible to construct the frames system.

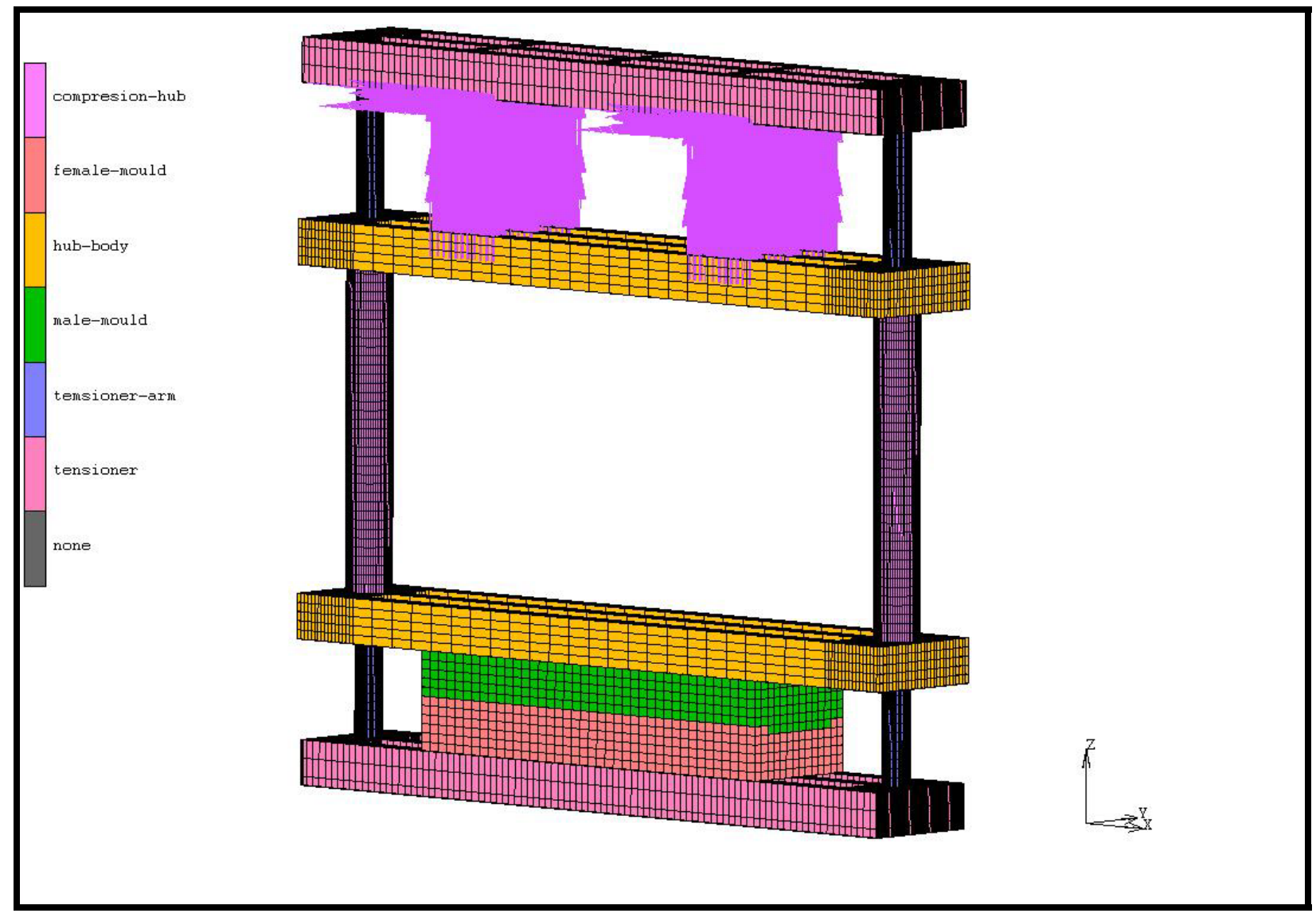

Figure 14: Self-Reacting Frames Design 
The design was proposed keeping in mind the ease of manufacturing by avoiding intricate dimensions, very small components, easy assembling features and robust construction. The initial design was made using CATIA (V5 R19 Dassualt System 2010) to visualize the three dimensional and the three dimensional model was converted to Initial Graphics Exchange Specification (IGES) format. The IGS then was transferred to MSC MARC Finite Element Analysis software (MSC family of Product, California, 2010) and the solid model then was discredited. Figure 14 depicts the three-dimensional model of the self reacting frame and molding. Tri linear hexagonal 8-noded elements were used in the analysis with fine meshes at contact surfaces and circular pockets. The solid model had 140888 elements. Thermal effects were negligible and were not included in the analysis.

As it was explain earlier, the self-reacting plate consists of four Plates of similar dimensions that house the two-part mold. There are two rods, one with 0.75 inches (main rod) that slides through the second rod of 1.25 inches diameter (Hollow hub). The main rods connect the two outer plates and the hubs connect the two inner plates, thereby giving sliding capability to the inner plates to move up and/or down depending on the load. This capability was simulated in finite element analysis to obtain realistic results. In order to perform FE simulation correctly, various contact schemes were used to simulate the fabrication process. For instance, a touching contact between male and female mold was defined using Frictional Coulomb contact definition, or the two main rods were connected to the two outer plates using contact glue scheme. On the other hand, the fabrication pressures exerted by the hydraulic actuators were simulated using distributed load as boundary conditions. Figure 15 depicts the various contacts used in this analysis. 


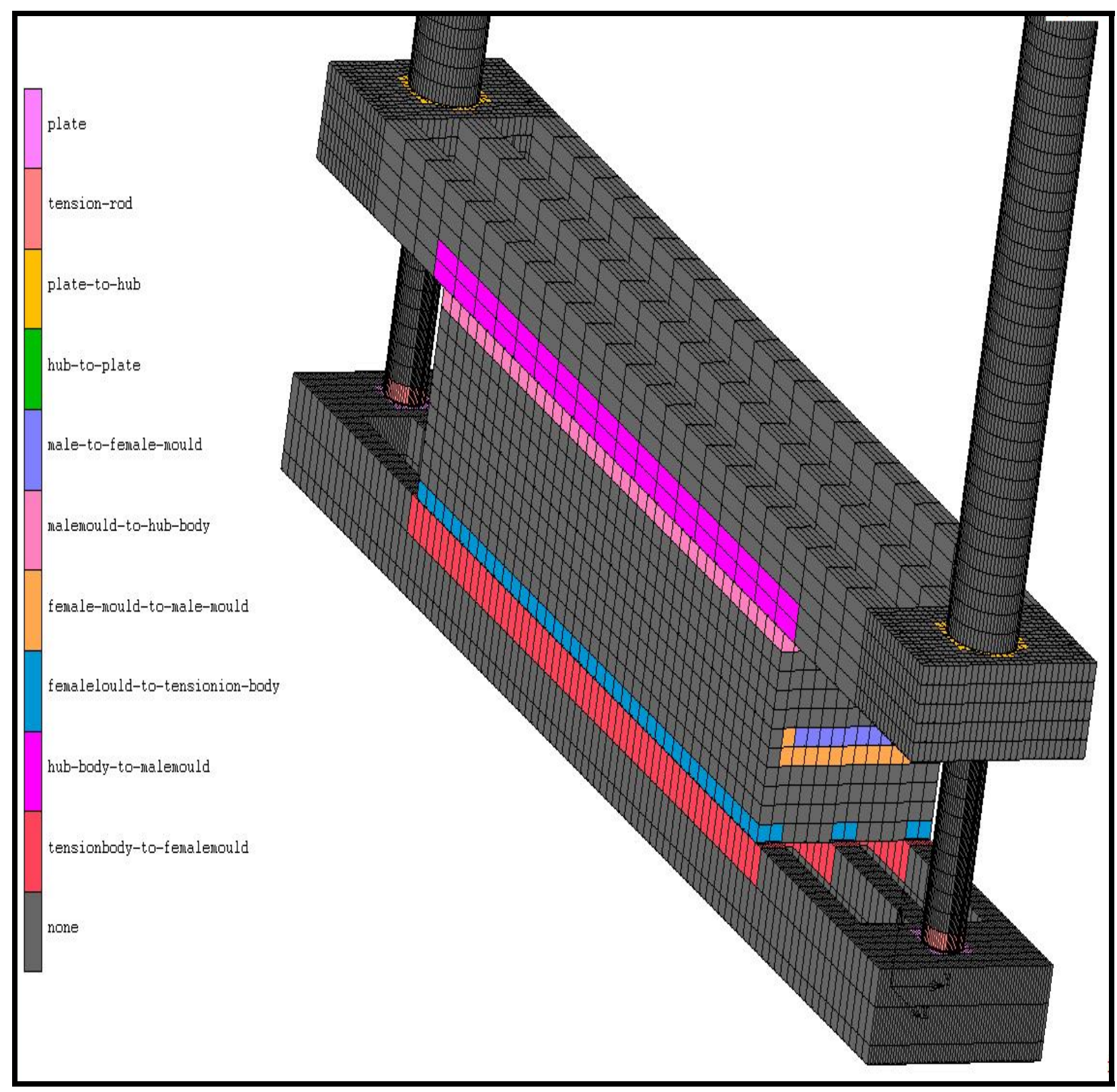

Figure 15: Critical Contact surface Condition

\section{4(a) Static Analysis of Frame Structure}

It was extremely important to perform the FE analysis of the self-reacting frame system to determine the geometry and select the material. The FE analyses of various self-reacting designs were performed on to determine the deflection of each frame. Ultimately, the frame with minimum deflection was chosen. This was due to the fact that composite panel with a uniform thickness could not have been fabricated in a frame that experiences high deformation during fabrication process. The FEM analysis 
was performed using MSC Marc $^{\circledast}$ by invoking a material nonlinear solution (elastic-plastic analysis utilizing Cowper-Simon strain hardening). The importance of the FEM was to study the deformation pattern of the self-reacting mold at high pressure and temperature. In order to obtain the high quality flat panel it is required to keep the deformation of the mold to very small level as to avoid interfering with the flatness of the composite panel. Figure 16 shows the Cauchy stress; clearly the stress level is below yield limit of the material.

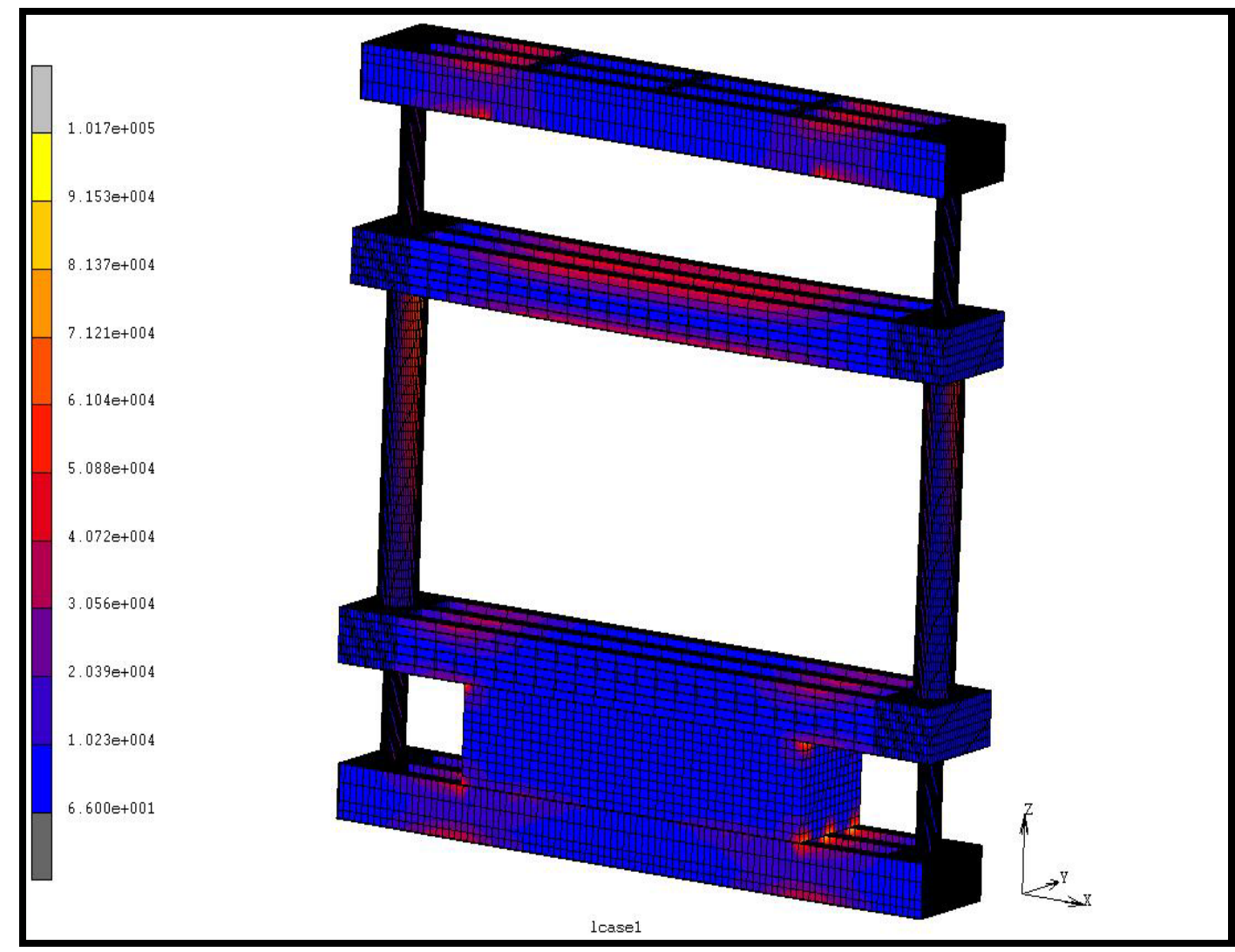

Figure 16: Equivalent Cauchy Stress plot

Figure 17 and Figure 18 depicts the displacement and strain respectively. As the contour plot show, the displacement between male and female mold is approximately 0.003 inches and strain is 297 micron. Clearly, the deformation and strain during fabrication is within an acceptable range and does not cause appreciable thickness variation. 


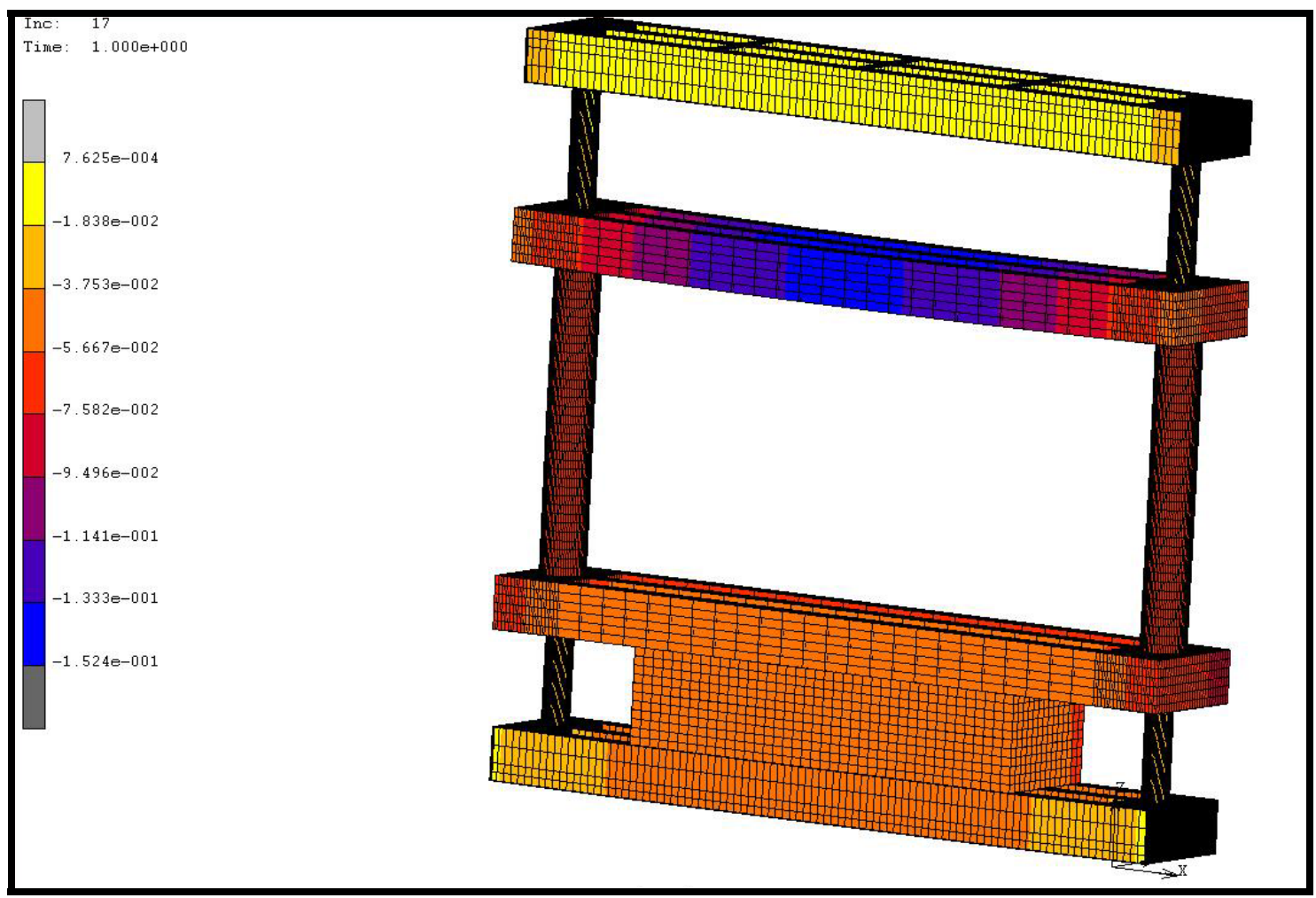

Figure 17: Frame Displacement Plot

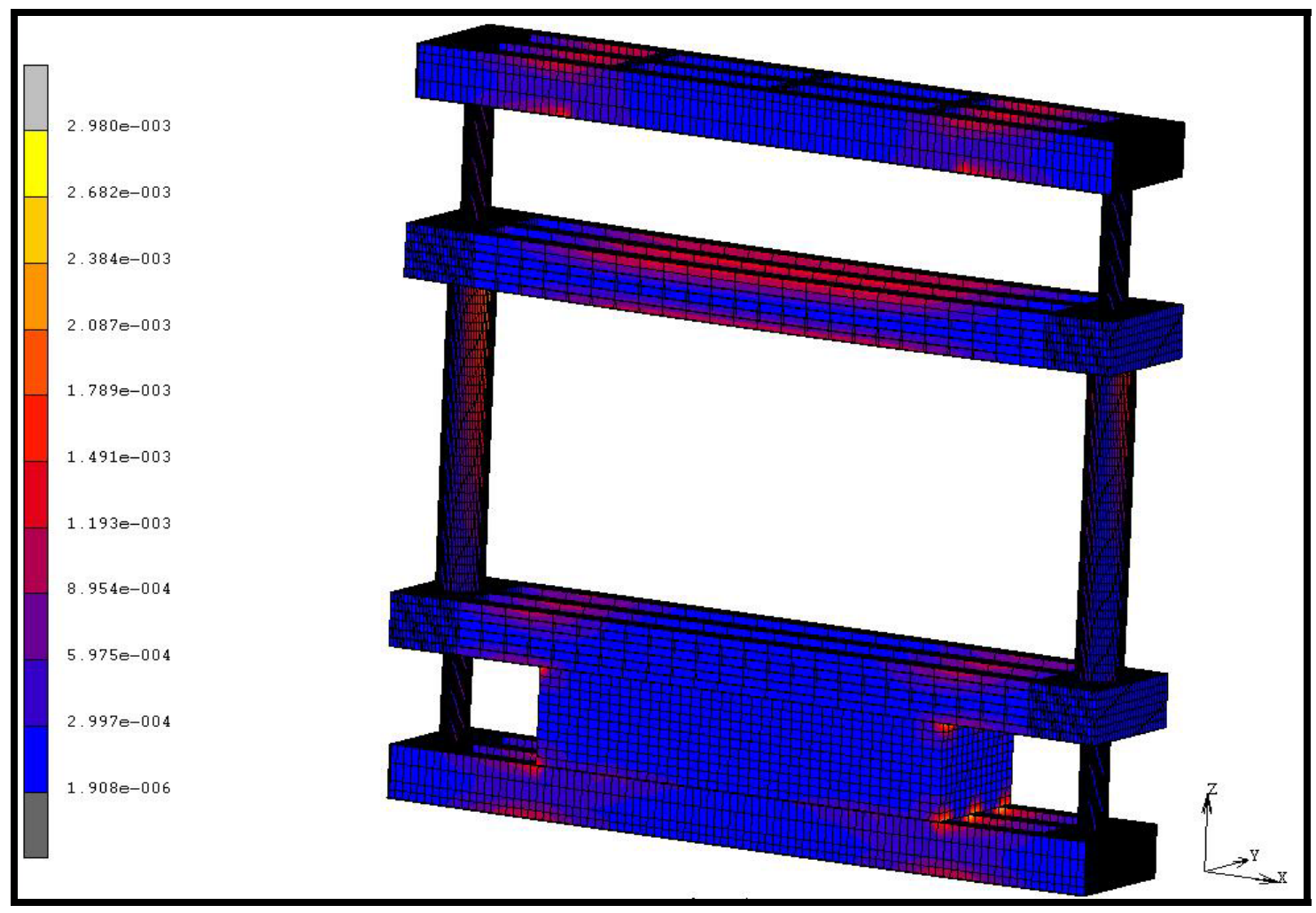

Figure 18: Frame Equivalent Strain Plot 


\subsection{MANUFACTURING PROCEDURE}

IM7/RP-46 composite can be manufactured using an autoclave curing or compression molding process. The production procedure and curing cycle varies for both autoclave curing and compression molding process each manufacturing procedure described in the following section.

\subsubsection{Autoclave Curing Process}

Autoclave curing is believed to be an ideal method for manufacturing composites as it can control pressure and temperature simultaneously. Processing of RP46 composites requires high pressure and temperature, which is applied in various steps. It is essentially similar to compression molding with trivial change in application of pressure and post cure condition. After lay-up, the mold tool is kept vacuum bagged till the end of the cycle, to avoid entrapment of air in between the laminate during the curing process. Initially 30 inch of vacuum are applied followed by a temperature raise to $430^{\circ} \mathrm{F}$ at the rate of $5^{\circ} \mathrm{F}$ per minute. Depending upon the number of plies in the laminate, it is staged for one to three hours at $430^{\circ} \mathrm{F}$. The temperature is then raised to $475^{\circ} \mathrm{F}$ and staged for one hour. A pressure of $200 \mathrm{psi}$ is then applied and it is held for one hour. The temperature is further raised to $617^{\circ} \mathrm{F}$ at the rate of $5^{\circ} \mathrm{F}$ per minute where it has to be staged for two hours. The composite part is now cooled slowly to $150^{\circ} \mathrm{F}$ when both pressure and vacuum is released. The Vacuumed part is then post cured by slowly raising the temperature from $74^{\circ} \mathrm{F}\left(23^{\circ} \mathrm{C}\right)$ to $663^{\circ} \mathrm{F}\left(350^{\circ} \mathrm{C}\right)$ at the rate of $2^{\circ} \mathrm{C}$ per minute. The part is staged for four hours at $663^{\circ} \mathrm{F}$ and cooled slowly $\left(2^{\circ} \mathrm{C}\right.$ per minute) to room temperature in an air circulating oven in a free state. Thus post cured RP46/Carbon composite is expected to have a $\mathrm{T}_{\mathrm{g}}$ range of $380^{\circ} \mathrm{C}-400^{\circ} \mathrm{C}$. 


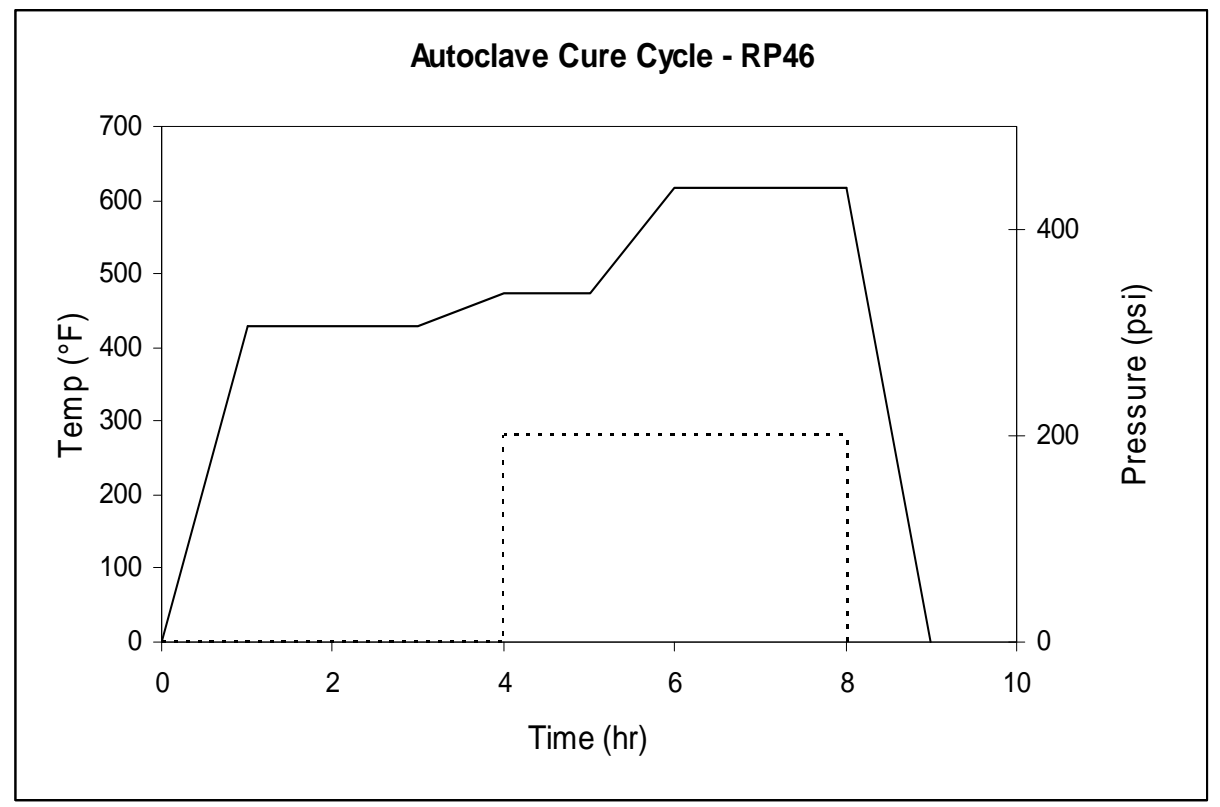

Figure 19: Autoclave curing cycle 


\subsubsection{Compression Molding}

In the compression molding process, the dry fabric is impregnated with RP46 resin solution to get desired fibre and resin volume fraction. The preimpregnated fabric is then staged at $160{ }^{\circ} \mathrm{F}$ for 10 to 15 minutes in the convection oven to remove the major portion of methanol as well as to imidize the RP46 resin solution before lay-up. Staging allows volatiles to escape partially, though volatiles are expected to evolve during the curing cycle. It is advantageous to remove possible maximum volatiles to alleviate excess voids in the cured composite structure, followed by second staging of impregnated cloth in the convection oven at $400^{\circ} \mathrm{F}$ for one hour. The staged Prepregs are then laid-up to desired fibre orientation in the compression molding tool. The molding tool is placed into the preheated press at $450^{\circ} \mathrm{F}$ and held for 15 minutes. Compression at of 250 psi is applied to the assembly, while holding the pressure the temperature is ramped up to $617^{\circ} \mathrm{F}$ at a rate of $5^{\circ} \mathrm{F}$ per minute. The assembly is put on hold for a minimum of one hour at 250 psi upon attaining $617^{\circ} \mathrm{F}$. Finally, the assembly is slowly cooled to $350^{\circ} \mathrm{F}$ a ranging between $8^{\circ} \mathrm{F}-10^{\circ} \mathrm{F}$ before releasing 250 psi pressure.

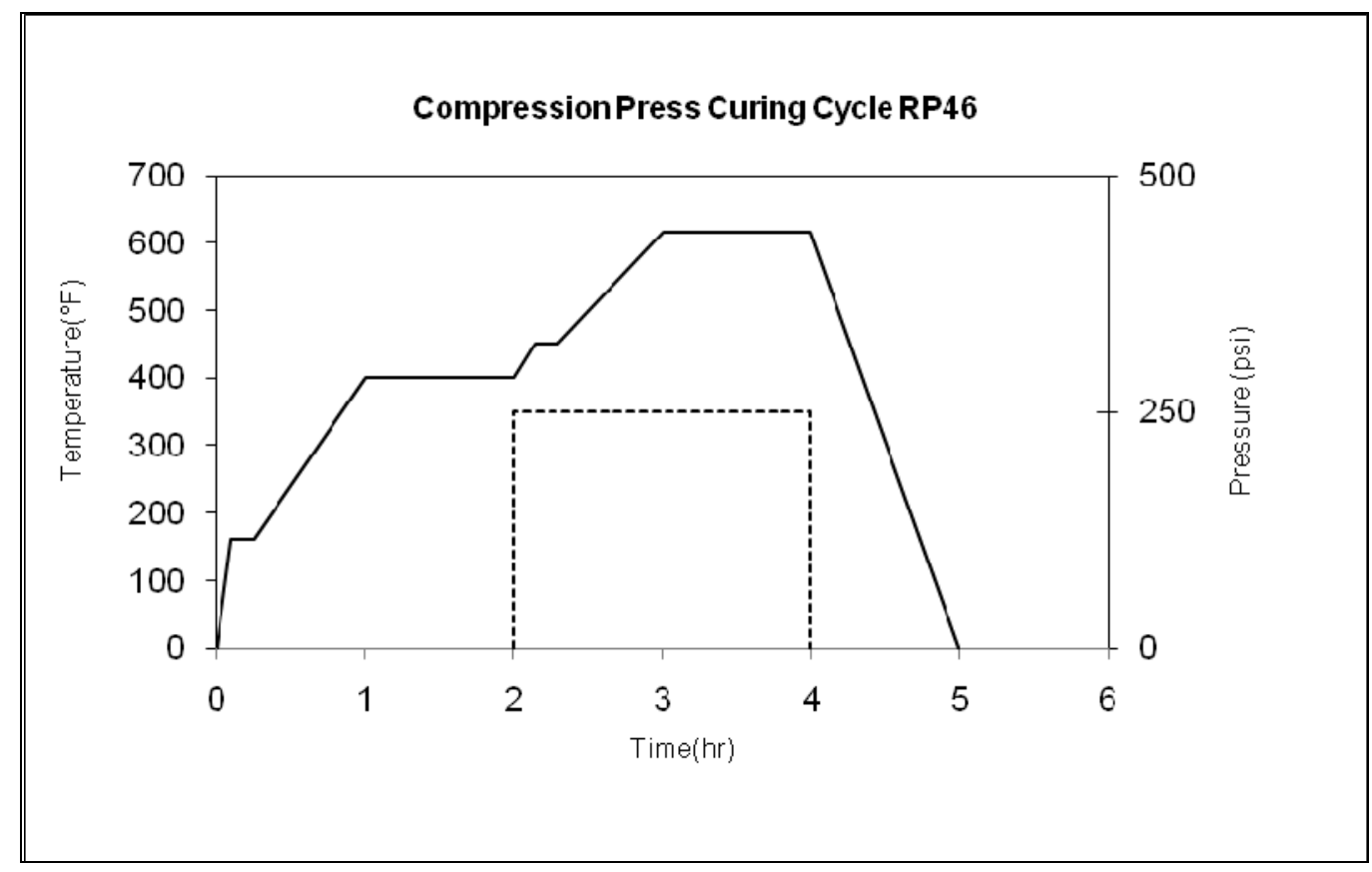

Figure 20: Compression press curing cycle 


\subsubsection{Initial Setup Process}

The preliminary step in the manufacturing set-up is the enlargement of vent holes to accommodate the $1.25^{\prime \prime} \mathrm{rod}$. As the oven had no critical component except the thermal insulation material on the top surface it was easy to cut out the holes. The ventilation hole centre to centre distance was measured to be $19^{\prime \prime}$, which was taken as the reference element for enlarging the holes to $1.25^{\prime \prime}$ diameter. The stainless steel sheet was cut with the metal nibbler and the edges were levelled with a hand-grinding tool.

The second stage in the manufacturing setup was to fix the supporting $L$ brackets. The purpose of the brackets was to carry the integrated mechanical system with the compression mold. The initial markings were made to position the brackets after which holes were drilled using an industrial drilling machine. Precautions were taken to fix the brackets at the uniform level to avoid the tilting of the mechanical system. After assembling the mechanical system, the top plate was secured to the bracket to arrest the movement of the frame.

Finally, the hydraulic circuit was assembled after securing the bracket fixtures and frames assembly firmly. The compact cylinders were placed in between the top plate and mid press with ports facing the front of the assembly to facilitate visual inspection in case of any problems such as an oil leak. The room at the rear of the brackets were used to place the hand pump that kept the system handy and feasible. After the setup was completed the final inspection was carried out including checking the movement of the frame rods, checking the operation of the cylinder, and verifying the level of the four plates of the frames. 


\subsubsection{Industrial Oven-Self Reacting Frames Integration Procedure}

The L-frames were first secured on the concrete wall and leveled.The frame was designed and fabricated with the threads along the entire length of the rod, which facilitated the assembly and the fine adjustment of the frames level. The rods were dropped from the top side of the oven through the machined hole. The bottom portion of the base frame and midpress were Then, assembled with the bolts on either side of the frame followed by the top portion of the assembly. The four plates of the frames were assembled parallel to one another and parallelisms were verified using a magnetic toolbox level. The frames were then suspended on the L- frame and connected with nuts and bolts to secure the position firmly.

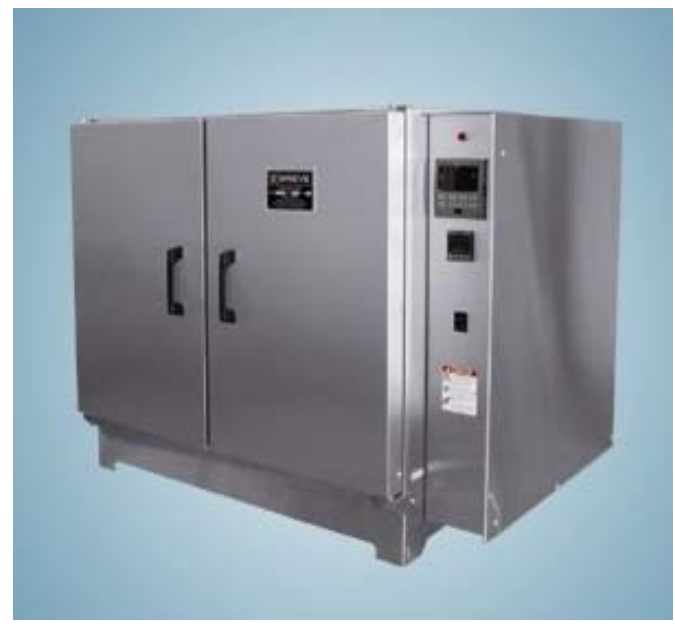

Figure 21: NT-800 Standard Oven

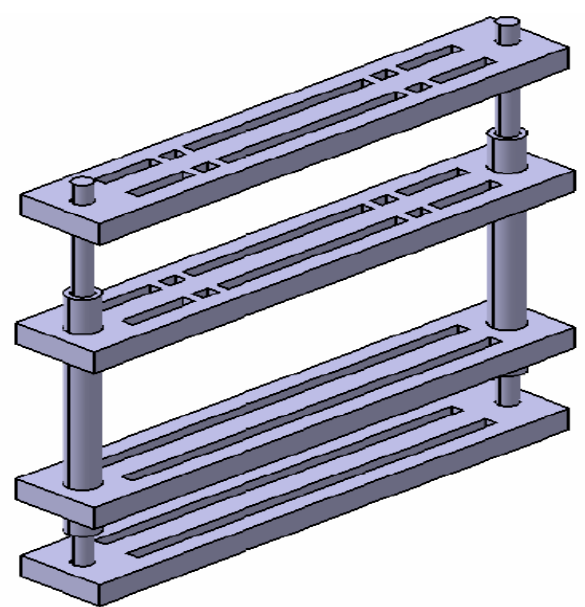

Figure 22: Self-reacting Frame

The hydraulic units were placed at equal distances from the centre line of the frame with the piston end facing up and the base supported on the mid press. The inlets and outlets of the cylinder were connected to the hand pump with the T-joint. The hydraulic unit was fitted with the pressure gage to read the pressure applied to the compression mold. The entire unit was seated on the rear side of the Lframe. 
A 19 " clamp was fixed at the middle of the assembly to facilitate placement of the male and female mold after the lay-up of the prepregs. Clamps assisted in the easy movement of the mid press and also helped in the alignment of the mold at the centre of the frame.
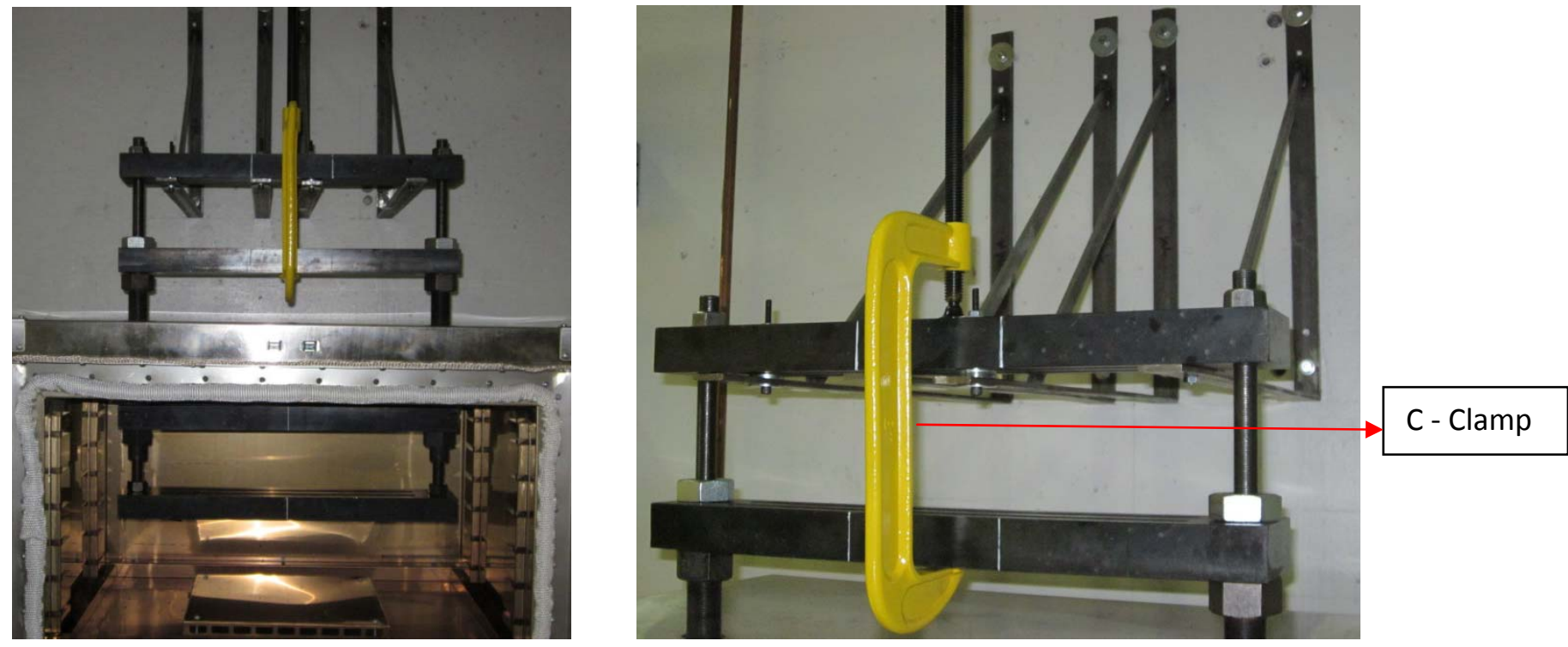

Figure 23: Integrated and Assembled Self-Reacting frame structure

\subsection{COMPRESSION MOLDING WITH SELF REACTING FRAME - WORKING PRINCIPLE}

The resin coated carbon fabric was placed in the oven tray and staged at $160^{\circ} \mathrm{F}$ and $400^{\circ} \mathrm{F}$, for 15 minutes and 60 minutes correspondingly. The staged prepreg was placed in the mould in the designed orientation and then placed in the oven with the aid of the C-clamps. The suspended self-reacting frame was assembled with the compact hydraulic cylinders located equidistant from the centre of the frame. The hydraulic fluid was pressurised by hand cranking the lever in the hand pump, which extends the piston of the cylinder. The extension of the piston pushes the top and mid-press apart on the topside, while compressing the mould between the mid press and bottom plate. The external frame experienced tension force while the inner mid press was in compression phase. Sufficient pressure was applied and monitored by the pressure gage. The temperature was measured by the $\mathrm{J}$ type thermocouple in the oven. 


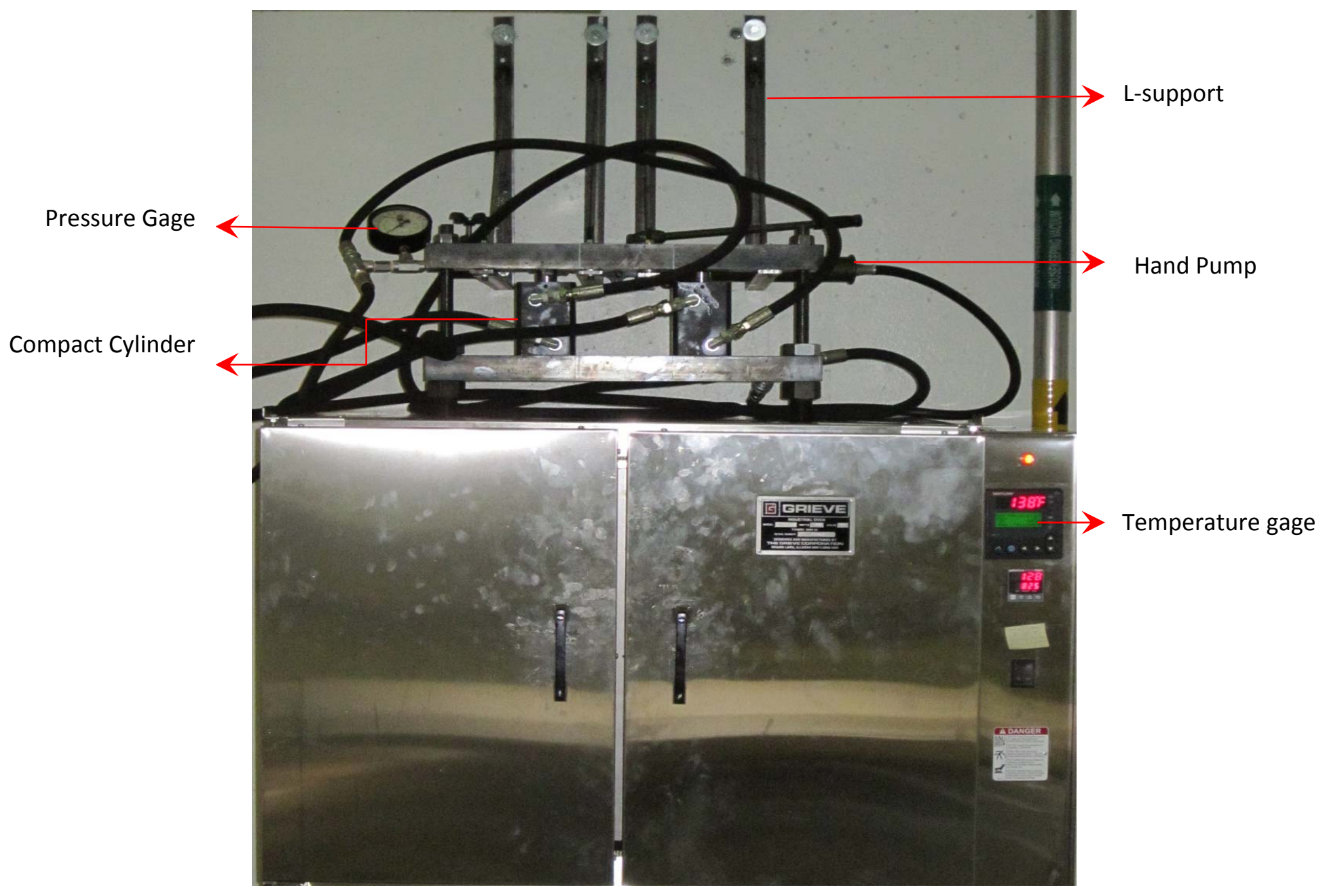

Figure 24: Working Principle

\subsection{CONCLUDING REMARKS}

Viable manufacturing equipments were compared in terms of production cost with the present novel technique. The working principles and experimental set of the manufacturing technique were explained in detail in the current chapter. The following chapter will discuss about the quality of the panels produced using the in-house manufacturing setup and test carried to verify the quality of the manufactured specimen. 


\section{CHAPTER 6}

\subsection{QUALITY OF IM7/RP46 PANELS}

Initial phase of manufacturing revealed various intricacies involved in the manufacturing procedure. The chemistry of the resin and workability of the fabric was understood in order to produce a fair quality composite panel. The resin was found to be easily workable at room temperature. It was evident from the static testing that hand lay-up involves various parameters that affect the quality of the panel. The proficiency of the manufacturer is of prime importance. The quality of the specimen was found to be sensitive depending on the skill level of the lay-up personnel.

In the current section, the initial manufacturing procedures and improvised manufacturing procedure that resulted in good quality panels will be discussed in detail.

\subsection{NOVICE MANUFACTURING PROCEDURE}

The Carbon fabric roll was cut into $3 \times 11$ Sq.in layers with the templates that were made out of hard cardboard. A Stanley knife was used to cut the fabric. A self-resilient cutting mat made of urethane was placed at the bottom of the fabric roll to make a clear cut of the layers. The cut fabric was drawn out from the fabric roll by finishing the template with the carbon shears.

The RP46 resin was taken out of the freezer at $-18^{\circ} \mathrm{C}\left(0.4^{\circ} \mathrm{F}\right)$ and allowed to reach room temperature. Practically, it was found that the RP46 resin reaches room temperature in approximately 30 minutes. Cooling the resin to room temperature is important because the viscosity at room temperature is perfectly apt for the layup, whereas below room temperature the RP46 resin remains highly viscous. The remaining resin was purged with the nitrogen gas to provide inert gas blanket in order to prevent entrapment of moisture into the resin container. 


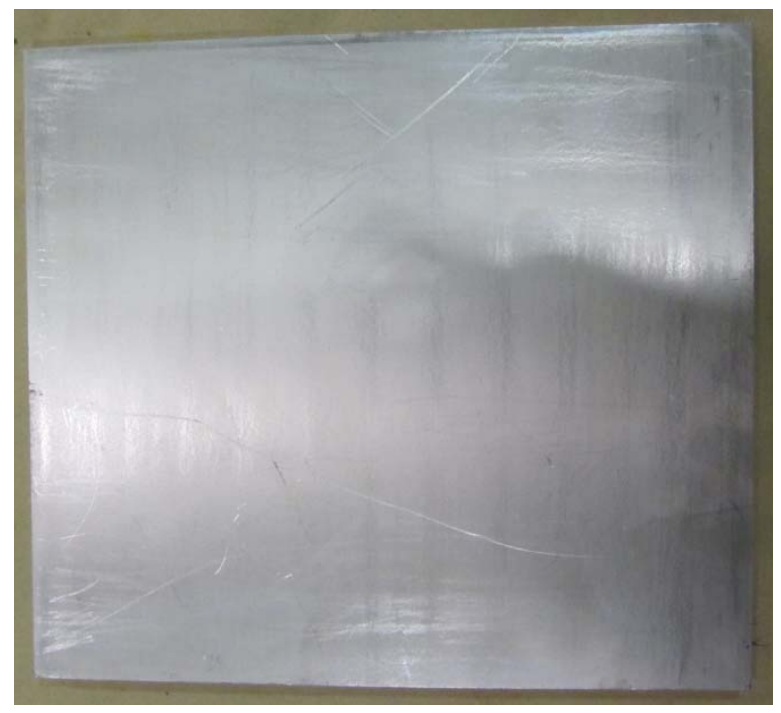

Figure 25: Aluminum Caul Plate

The flat aluminum caul plate ( $12 \times 12$ Sq.in) was coated with release agent before placing the fabric for wetting with RP 46 resin. After the coating was dried, a layer of carbon fabric was placed on the plate and RP46 was applied using the hard bristles hand brush. Precautions were taken to make sure a uniform coating of resin was applied to the fabric layer. It was noted that after 30 minutes the resin in the caul plate started sticking to the carbon fabric and removing the resin impregnated fabric was found to be difficult. The wetted fabric was then transformed onto the oven tray for staging.

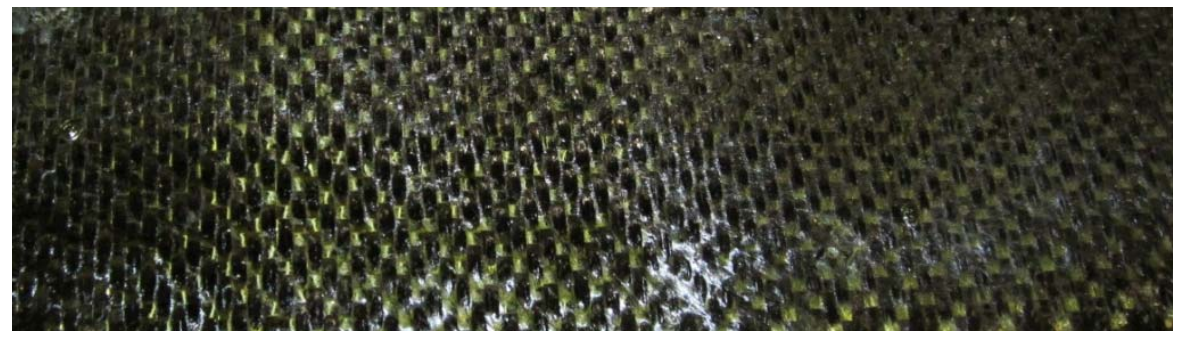

Figure 26: RP46 Resin wetted IM7 


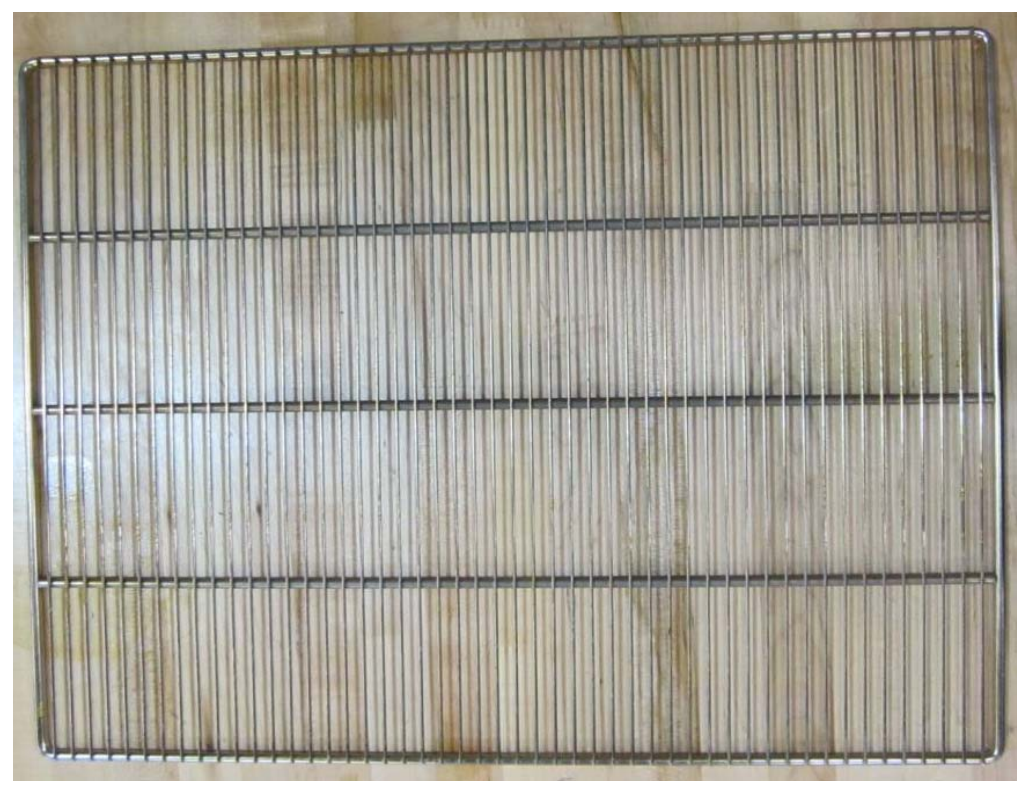

Figure 27: Staging Tray

\subsection{CURING PROCEDURE}

The resin impregnated carbon fibre was placed on the oven tray and staged inside the oven. The prepreg was staged at $160^{\circ} \mathrm{F}$ for 15 minutes to remove $10 \%$ of the volatile contents.

The prepreg was taken out of the oven and the oven was now set to ramp up to $400^{\circ} \mathrm{F}$ for the second staging. Once the required temperature of $400^{\circ} \mathrm{F}$ was reached the prepreg was tossed inside the oven and staged for 1 hour. At this stage the pliable prepreg partially cured and was observed to be a stiff ply.

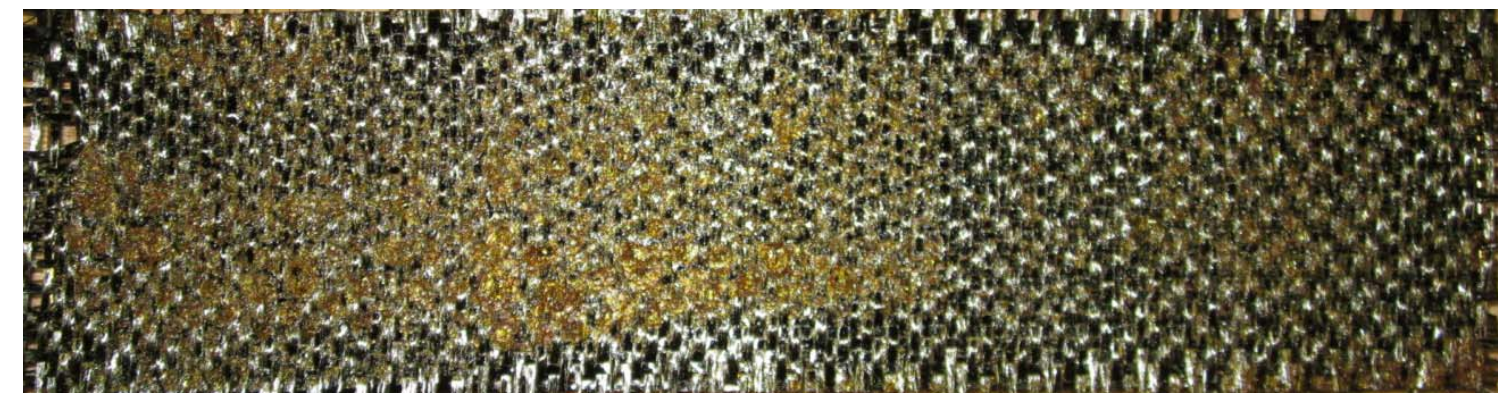

Figure 28: Partially cured prepreg at $400^{\circ} \mathrm{F}$ 
The partially cured prepreg was cut into $2.9 \times 11$ sq.in and stacked up on the female mold. The male mold was placed on top of the female mold aligning the edges. Simultaneously, the oven temperature was ramped up to $450^{\circ} \mathrm{F}$. The male and female molds were then placed between the bottom and lower mid press. The mid press was lifted up using the C-clamp set up, which created enough room to place the compression mold. The mold was placed at the centre of the frame to ensure the uniform distribution of pressure. During the initial stage of manufacturing considerable amount of time was spent for aligning the mold at the centre. Lately, lines were marked for ensuring the alignment of the mold with the frame, which reduced the setup time.

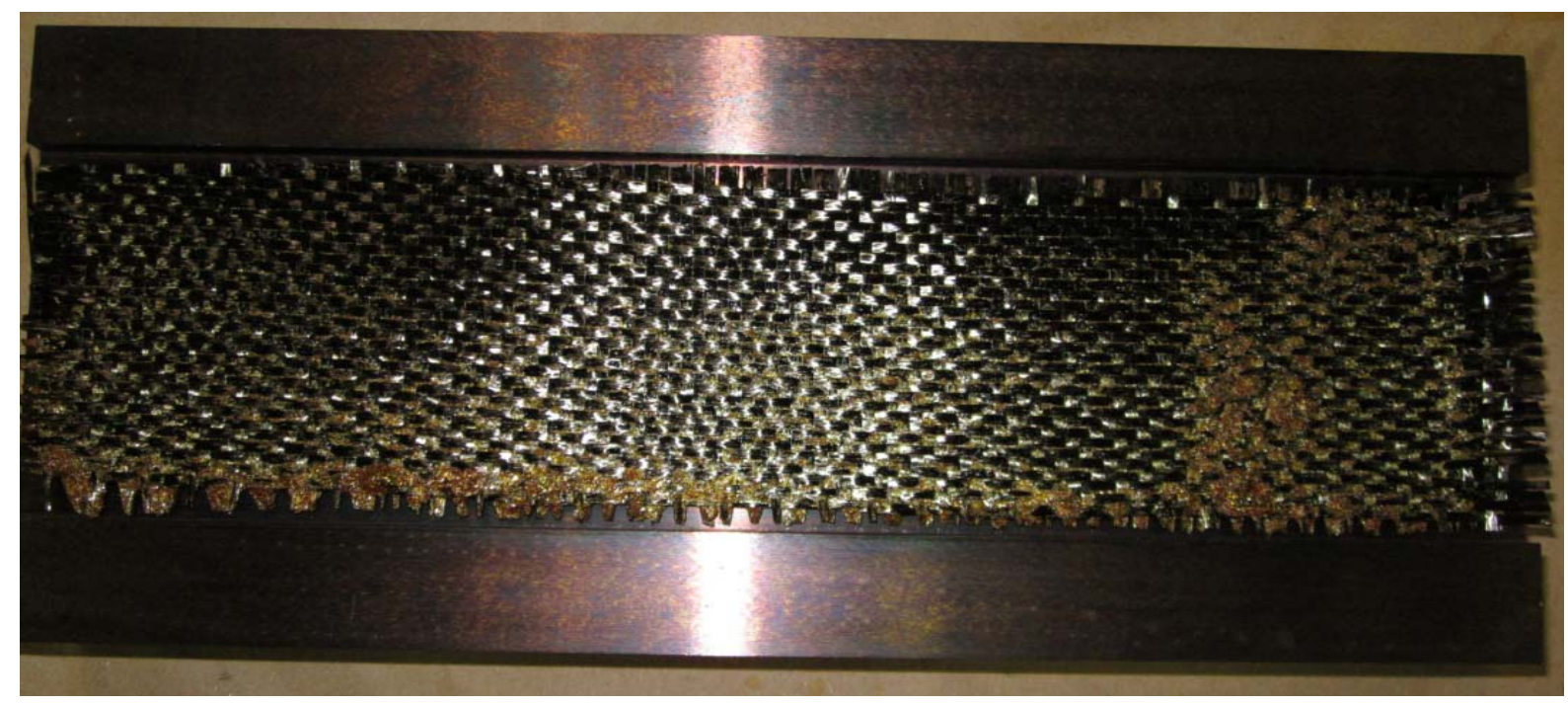

Figure 29: Prepregs on female compression mold

After placing the mold, the temperature was ramped up again, to $450^{\circ} \mathrm{F}$, leading to approximately 45 minutes of wait time. Once the target temperature was reached the third hold started at $450^{\circ} \mathrm{F}$ for 15 minutes. The oven had the feature of setting up the profile to ramp up at a particular rate, hold at a certain temperature, and ramp again continually, which facilitated partial automation of the curing process. 
The temperature started ramping up at the rate of $5^{\circ} \mathrm{F}$ per minute upon completing the hold at $450^{\circ} \mathrm{F}$. Simultaneously the pressure was applied to the compression mold by hand cranking the hydraulic system while monitoring the magnitude of pressure on the gage. When the pressure reached 1400psi, the supply valve was closed to hold the applied pressure. The ramp up rate and the pressure was monitored periodically. As the temperature profile was automated, the temperature ramped to $617^{\circ} \mathrm{F}$ at the rate of $5^{\circ} \mathrm{F}$ per minute and was held there for 1 hour. The oven power control goes off once the profile is completed. The temperature is allowed to cool down at a rate of between $8-10^{\circ} \mathrm{F}$ until it reached $350^{\circ} \mathrm{F}$. At $350^{\circ} \mathrm{F}$ the supply valve of the hydraulic system was opened and the pressure valve was released thus the applied pressure fell to zero. The mold was allowed to cool down slowly to the room temperature. The cured IM7/RP46 panel was removed from the mold and the edges were trimmed, to cut out the two specimens size $1 \times 10$ sq.in.

\subsection{OBSERVATION OF THE INITIAL IM7/RP46 COMPOSITE PANEL}

\subsubsection{Warping of Panel}

First panel was manufacture with odd number of layers, which resulted in pre strained panel. The panel appeared to be warped and twisted.

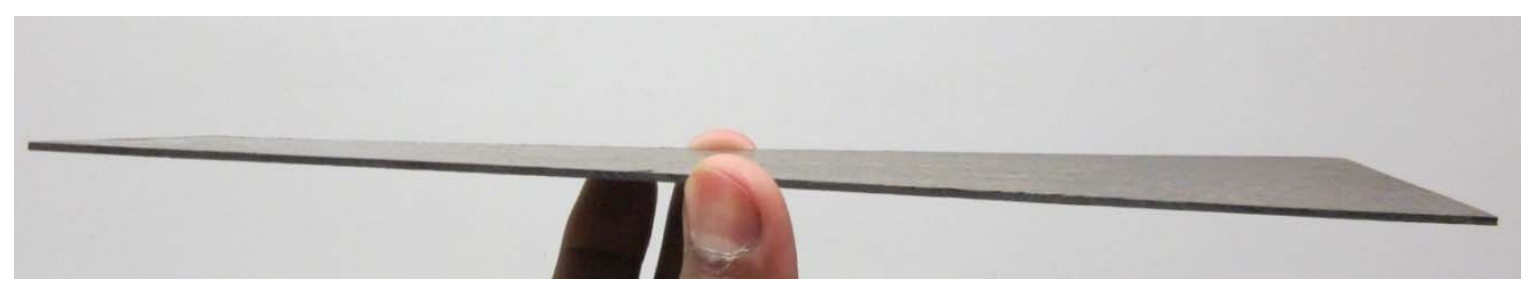

Figure 30: Suspended View of Warped Sample 
Figure 31: Flat view of the Warped Sample

Interesting observations were made with the partially cured prepreg that were staged at $400^{\circ} \mathrm{F}$ for one hour. These prepregs were stored at room temperature approximately for a day and stacked on the compression mold to continue the rest of the curing cycle. The cure cycle was completed and the cured panel appeared to be straight with noticeable observations.

The panel was unusually thicker than that of the regular panels. It had yellow powder dispersed to the surface intermittently and had dull appearance throughout the panel. It also had dark spots around the centre region of the panel, which revealed the moisture entrapment in the panel.

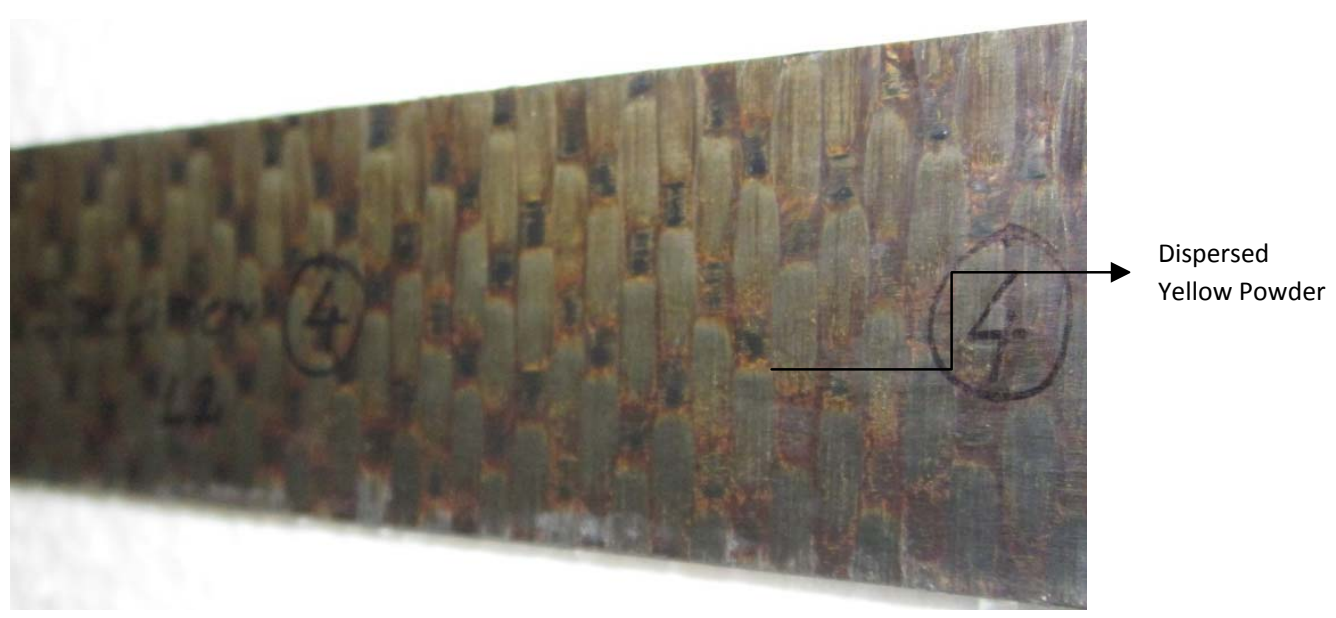

Figure 32: Observation of yellow appearance 


\subsubsection{Misalignment of the Compression Mold:}

The male and female molds were designed with allowable tolerance so as to match perfectly. When the mold is loaded with stiff prepregs the male mold sits on top of the female mold in a way that even a slight movement of the male mold could cause misalignment of the mold set up. One such case was observed during the initial phase of the production. After placing the mold inside the frame set up, failure to verify the alignment resulted in the unevenly pressed specimen. This case called for verifying the level and alignment of the male and female mold after placing it in frame set up.

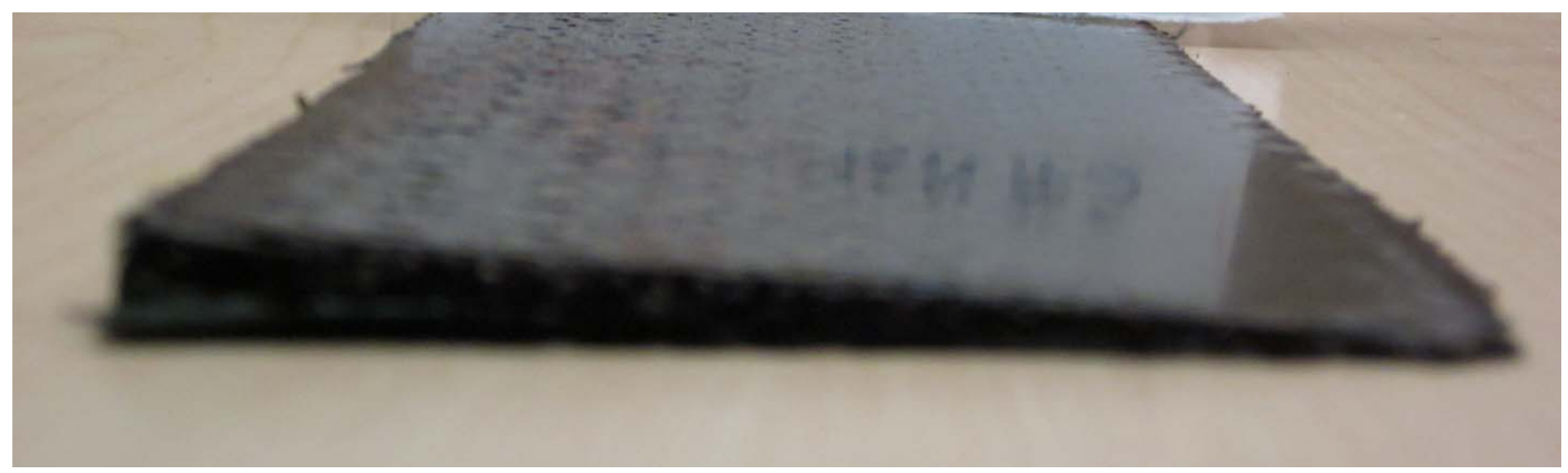

Figure 33: Side view of the mold misaligned panel

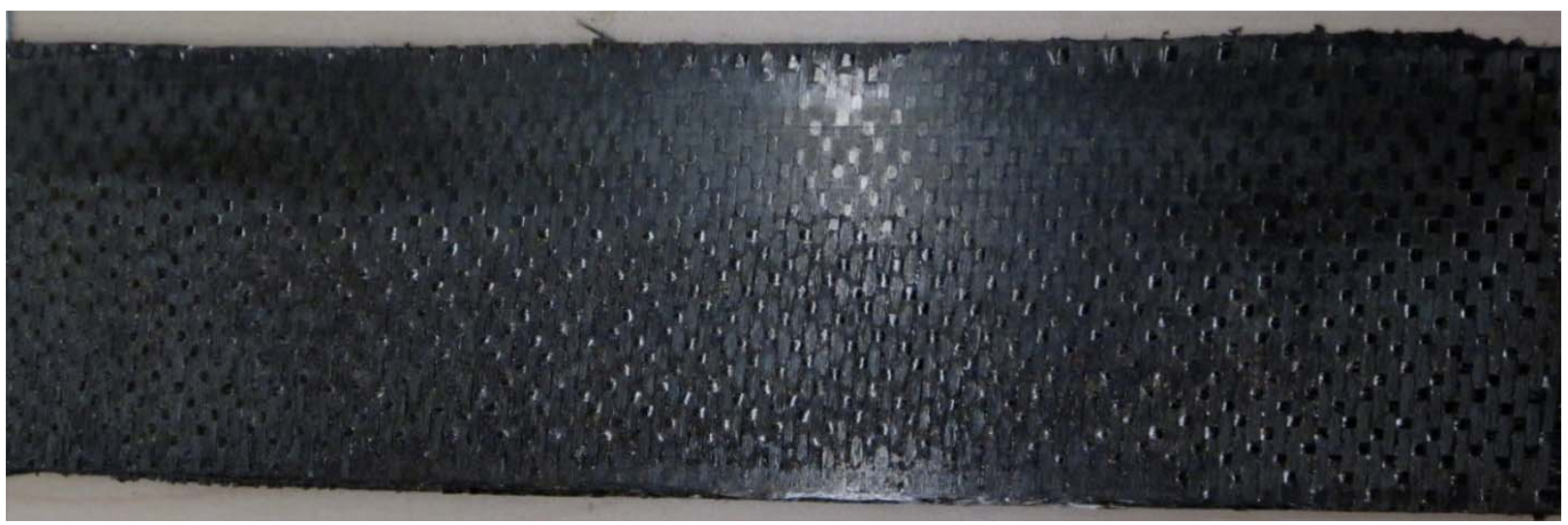

Figure 34: Front view of the mold misaligned panel

\subsubsection{Combined Staging and Curing Cycle}

It was noticed that the alignment of the mold was necessary after stacking up the prepregs. An alternate approach was adopted to manufacture the specimen without taking it out of the oven after the second 
staging at $400^{\circ} \mathrm{F}$. The prepregs were pliable and soft at the end of the first staging at $160^{\circ} \mathrm{F}$. These prepregs were stacked inside the female mold and male mold was placed on top without applying any pressure. It was observed that the weight of the male mold exerted some pressure on the prepregs while staging at $400^{\circ} \mathrm{F}$. This led to accumulation of moisture in the panel, as the male mold pressure was high enough to prevent the venting of volatile and moisture escape from the resin.

Finally, resulting in moisture trapped dark spots on the resin similar to the one observed in the second panel.

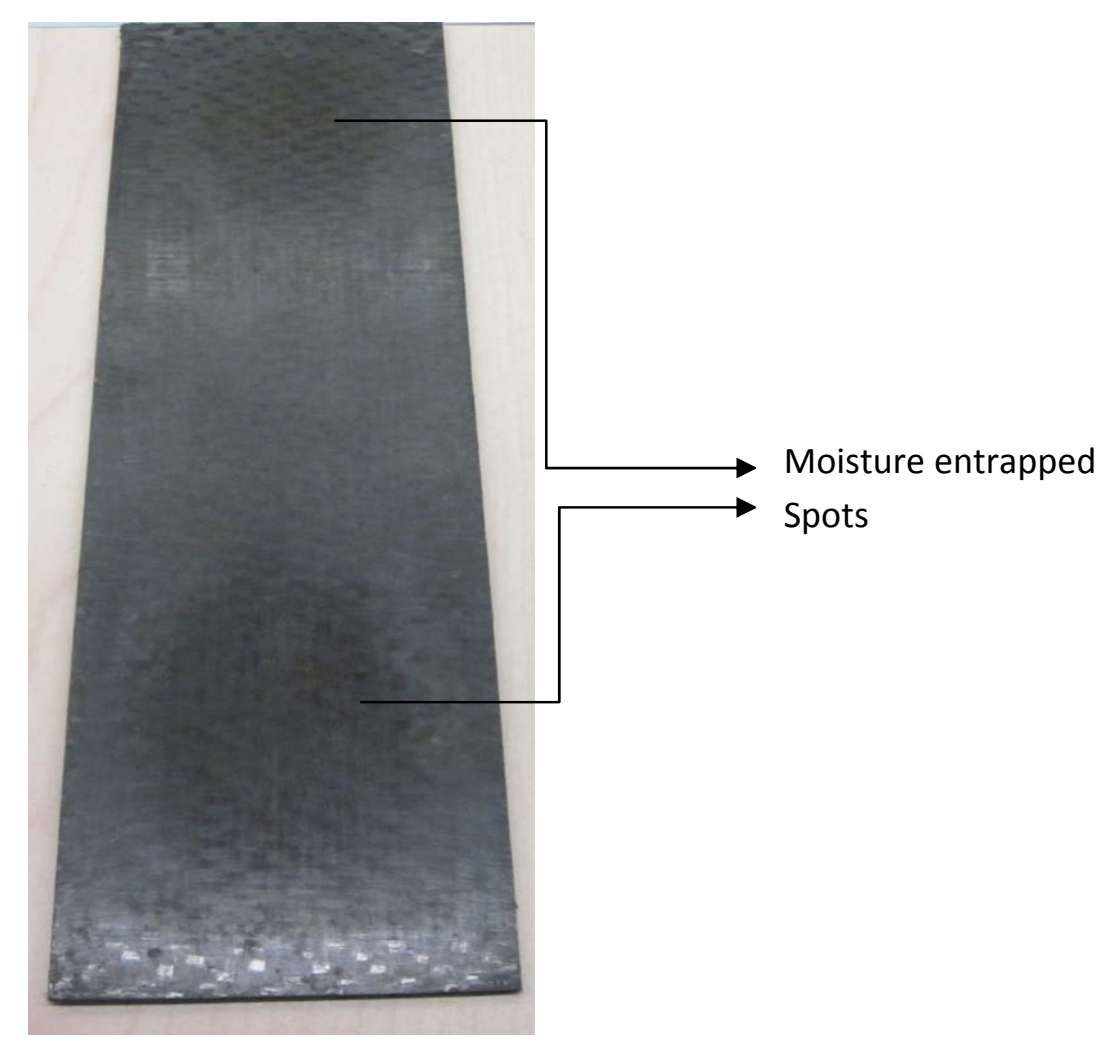

Figure 35: Moisture entrapment in the panel

\subsubsection{Resin Poor Areas in the IM7/RP46 Panel}

Flex sealer GP was initially applied on the surface of the compression mold. After sealer GP was dried, the coating of Flex mold release 6.0 was applied. Though release coat was applied to the mold, the excess resin that squeezed during the compression process, cured along the edges of the mold, which 
later created an issue while removing the panel. Thus, removal of panel was intricate at the end of the manufacturing cycle.

In order to avoid the problem of removing the panel, the edges of the fabric were not wetted with the resin. Assuming that on application of pressure, the excess resin at the centre of the panel would flow towards the edges and help in wetting the edge portion of the specimen. But, the flow of resin was not sufficient enough to wet the entire panel, leaving resin poor areas around the edges of the cured panel.
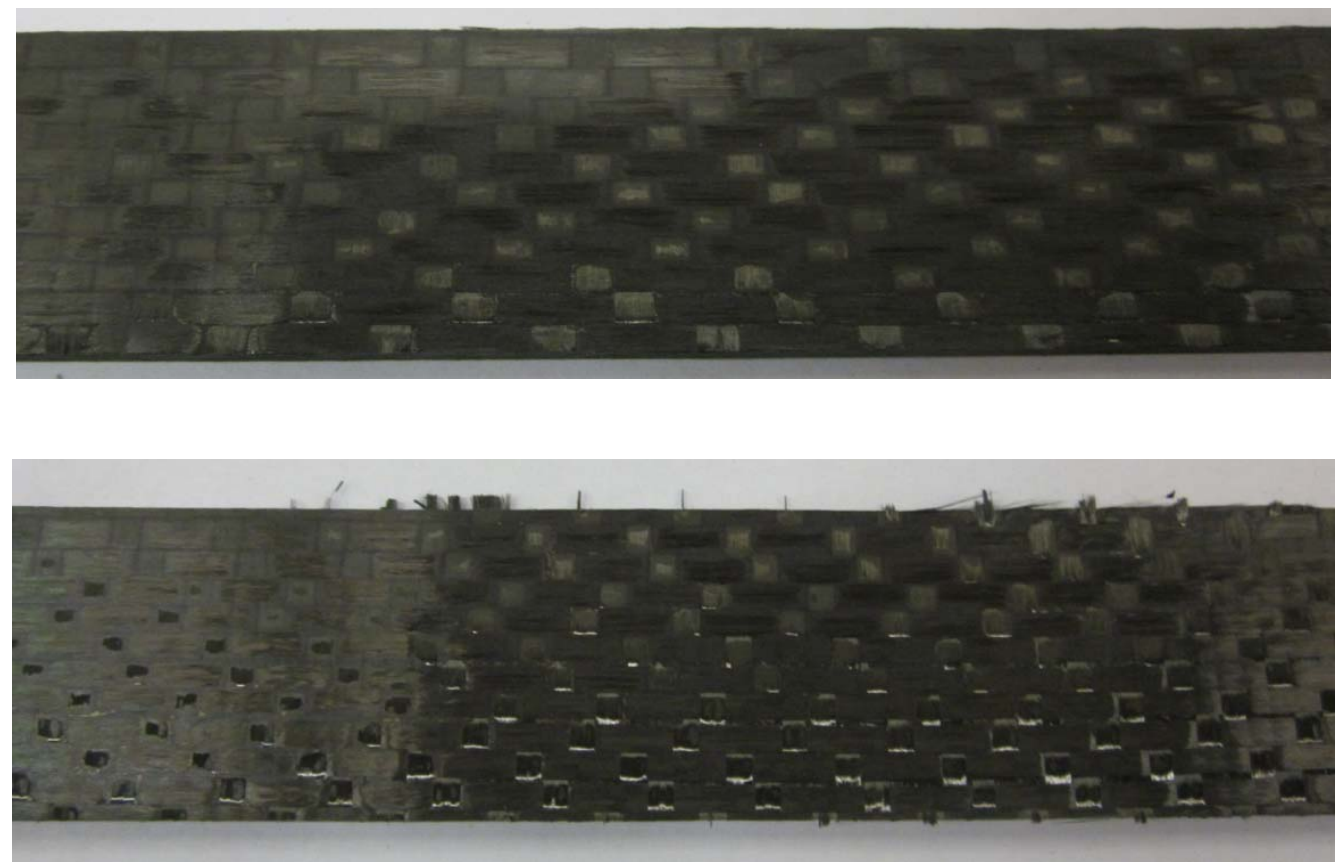

Figure 36; Resin Poor areas along the edges of the panel

\subsection{GOOD QUALITY SPECIMEN; ESTABLISHED PRODUCTION TECHNIQUE}

The manufacturing setup was completely understood after production of four panels. The production became familiarised after key observations from the earlier trails were understood to avoid repeating in upcoming samples. Few new handling techniques were adapted and cure cycles were completed without any interruption during the alignment of the mold. 


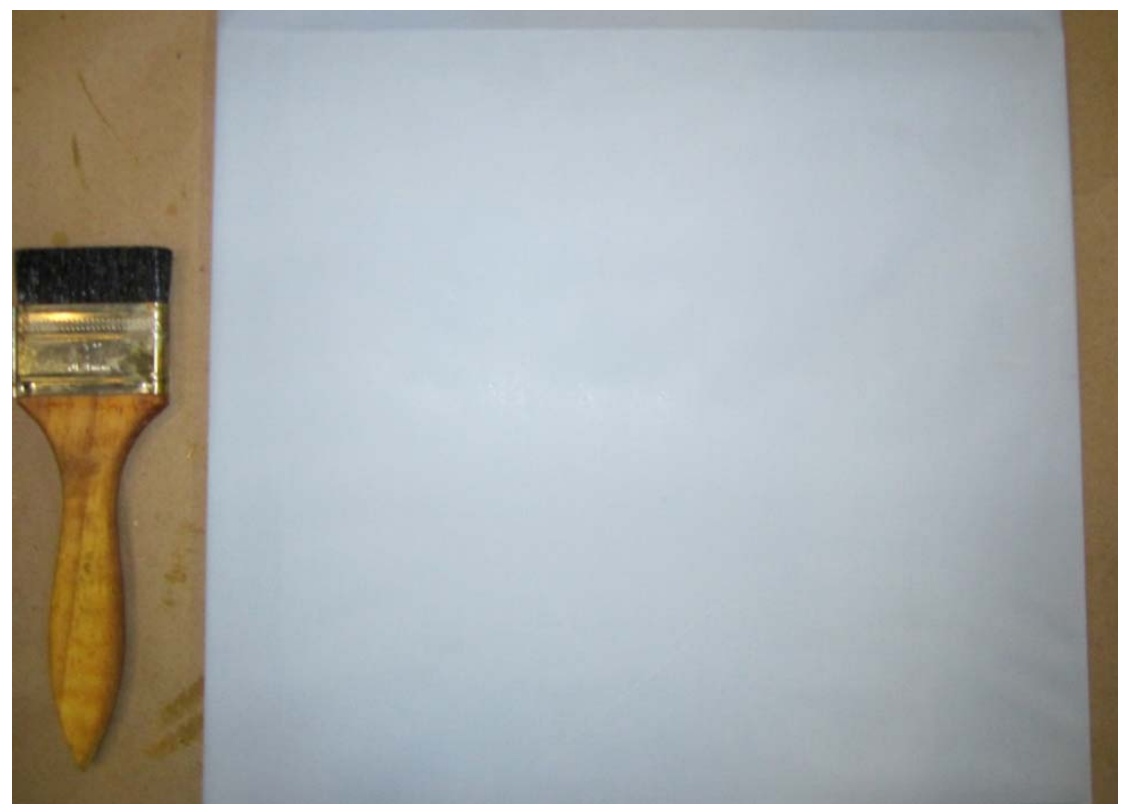

Figure 37: Caul Plate enfolded with peel Ply

The caul plate was insulated with the peel ply, which assisted in the easy removal of the fabric after wetting with resin solution. The staging tray was covered with the Vacuum bagging film, which prevented the sticking of the prepreg on the tray.

The mold and frame structure were marked with permanent white marker to make the alignment easy. The prepregs were sheared after the first staging at $160^{\circ} \mathrm{F}$ unlike after the second staging at $400^{\circ} \mathrm{F}$ in the earlier procedure which facilitated trimming operations.

The pressure was constantly monitored as a pressure drop was noticed around $550^{\circ} \mathrm{F}$.To compensate the pressure drop due to the polymerization of the resin additional pressure has to be supplied by hand cranking the pump.

In order to avoid the resin poor areas, carbon fabric was cut to $2.90 \times 11$ Sq.in leaving some room along the corner of the compression mould. This helped in easy removal of the panel and also avoided resin poor areas along the edges. Use of peel ply could also help in getting the $3 \times 11$ inch specimen with ease and not needing to use release coat in terms of removal of the panel. 
The IM7/RP46 specimen obtained lately was proved to have more strength than the initial panels. It is evident that the quality of the panel greatly varies depending on the skill level of the manufacturer. Cleanliness of the manufacturing atmosphere, following standard procedures, constant ramping rate of the oven and familiarization of resin cure cycle are the important parameters that help improve the quality of the panel consistently.

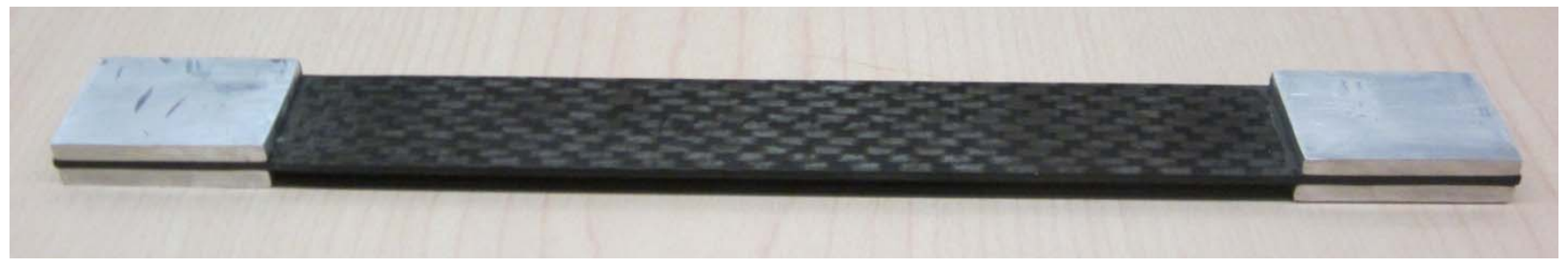

Figure 38; End tabbed good quality sample

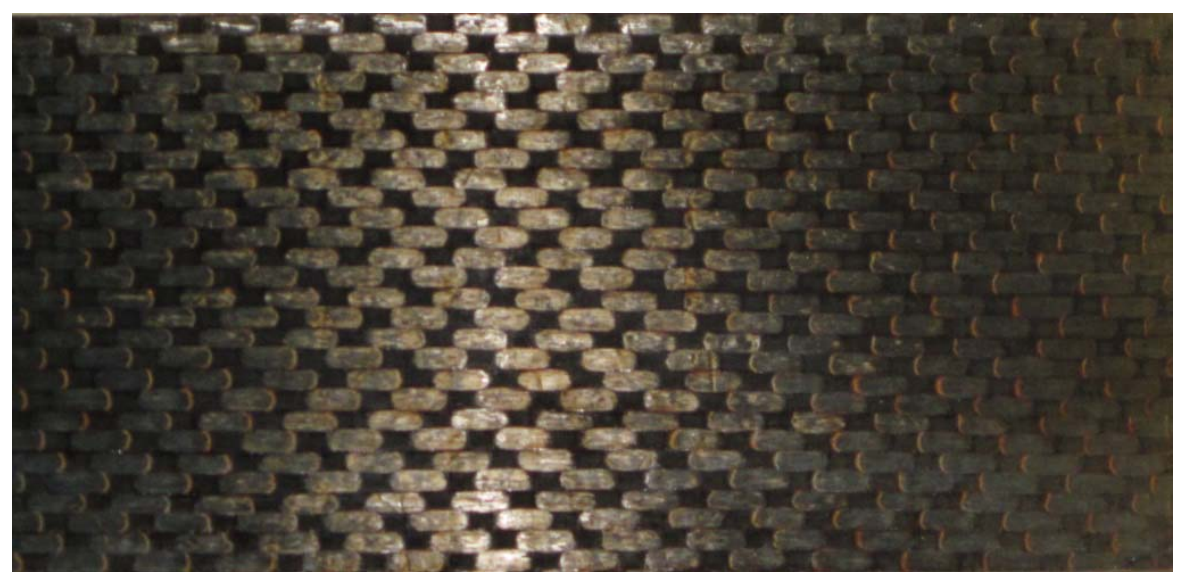

Figure 39: Good Quality Specimen

\subsection{FIBRE AND RESIN VOLUME CALCULATION BY WEIGHT}

The Volume fraction of the constituents in composite panel is calculated by measuring their individual weight. The weight of the dry carbon fabric of dimension $3 \times 11$ Sq.in was measured to be 4 grams. After the application of the resin the prepreg weighed 6 grams. The total weight of the panel was found to be 60 grams. The IM7/RP 46 panels have a total of ten layers carbon fabric. 
The mass fraction of fibre: $W_{f} / W_{p} \times 100$

The mass fraction of resin: $W_{r} / W_{p} \times 100$

Where,

$W_{f}$ - weight of fabric layer

$W_{r}$ - weight of resin

$W_{p}$-weight of panel

\subsubsection{Mass Fraction Calculation by Weight}

$40 / 60 \times 100=66.67 \%$ of fibre mass fraction

$20 / 60 \times 100=33.33 \%$ of resin mass fraction

Dry weight of the fabric, prepreg weight and weight of finally produced panel was measured with scale CS 2000. From the numerical calculations of weight measured, volume fraction of fibre and resin was found to be $67 \%$ and $33 \%$ respectively. 


\subsection{SPECIMEN TESTING}

In the case of orthotropic symmetric laminates, tensile test on the specimen of thickness " $t$ " under uniform axial force per unit length can give effective axial modulus and poisson ratio. Tensile testing also helps to determine the stress-strain behaviour of the material as either elastic or non-elastic. The ultimate stress of the material was calculated from the maximum force applied per unit length and thickness of the sample. The manufactured specimens were tested in accordance with ASTM D 3039/D $3039 \mathrm{M}$, which is described in the following sections.

\subsubsection{Ultimate Static Testing}

The manufactured IM7/RP46 panels were perfectly flat and had a thickness of 0.08 ". The edges of the panels were trimmed off to get two specimens of size $1 \times 10$ Sq.in. The MTS 322 test frame was used to carry out the tensile testing of the specimen. The main focus of the tensile testing was to find the maximum axial load and ultimate failure stress of the manufactured IM7/RP46 sample. It was assumed consistent manufacturing procedures would produce specimens that have close range of tensile strengths.

Extensometers were clamped at the mid section of the specimen for strain measurements. Two springs provided the clamping force on either edge of specimen of 1" width. They provide a measurement of the average strain over the finite length.

The MTS 322 test frame had wedge shaped hydraulic grips with a maximum pressure of $69 \mathrm{MPa}$. The emery cloth was initially used to grip the specimen. As the emery cloth caused slipping of the test specimen, aluminum tabs with $10^{\circ}$ taper were used for gripping the specimen. The bonding ends of composite specimens were sanded with a 320 grit sand paper and degreased before bonding. Similarly, aluminum tabs were also sanded with 320 grit sand paper and degreased to avoid entrapment of foreign particles for effective bonding. The ideal gripping pressure was found to be $2750 \mathrm{psi}$. 
The tension load was applied to the specimen at the rate of $2 \mathrm{~mm}$ per minute. The specimen was loaded until failure to determine the ultimate failure load in order to determine the ultimate stress of the fabricated specimen.
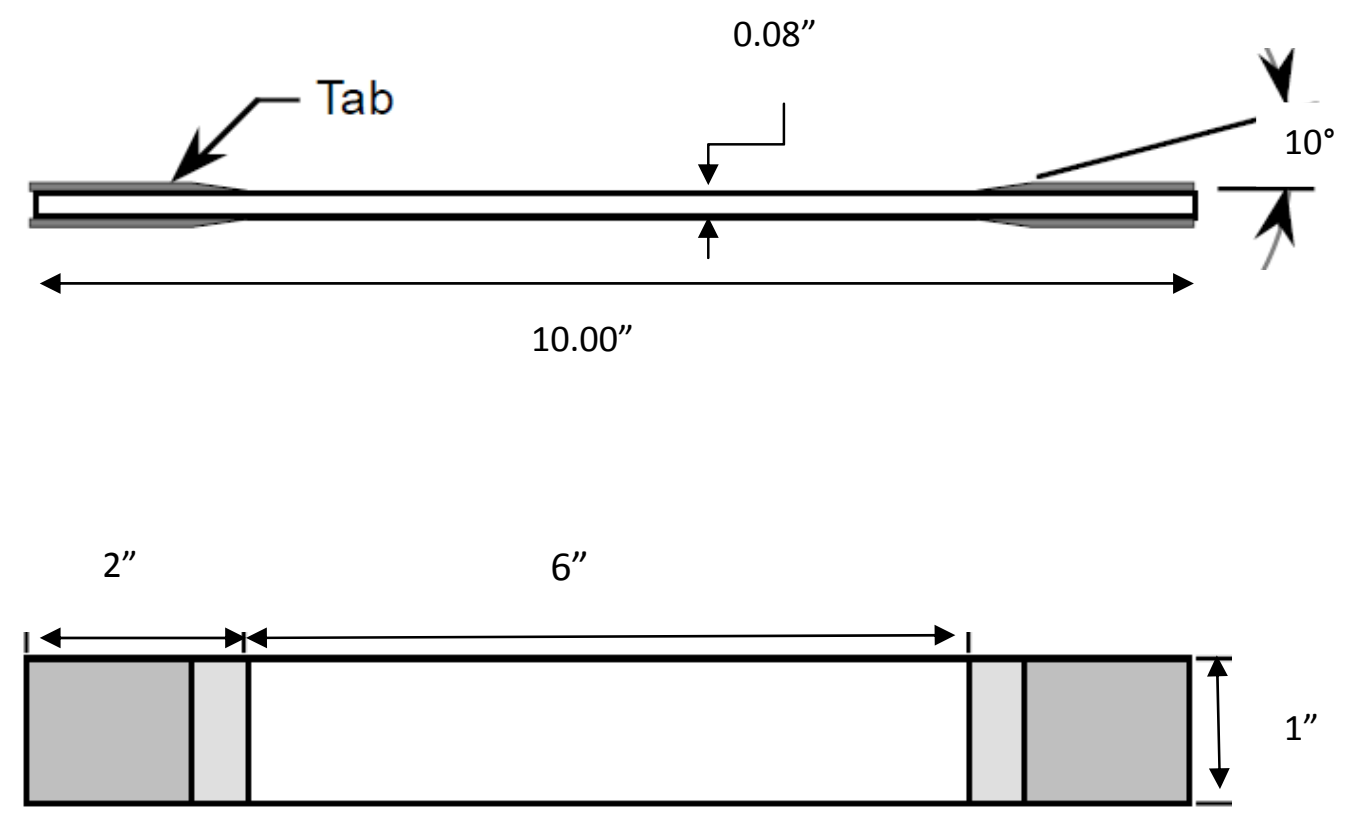

Figure 40: Specimen dimensions

\subsubsection{Stress - Strain Curve of the Specimen}

The IM7/RP46 produced by self-reacting compression molding procedure showed linear elastic behavior. Stress values were calculated with the maximum applied load by cross section area. Strain values were obtained with the extensometer clamped at the gauge length of the specimen. The slope of the curve was plotted to determine the Young's modulus of the specimen. The average slope of the tested specimen was found to be $81.4354 \mathrm{GPa}$. The stress values in pounds per square inch are plotted against the percentage strain values as shown below. 


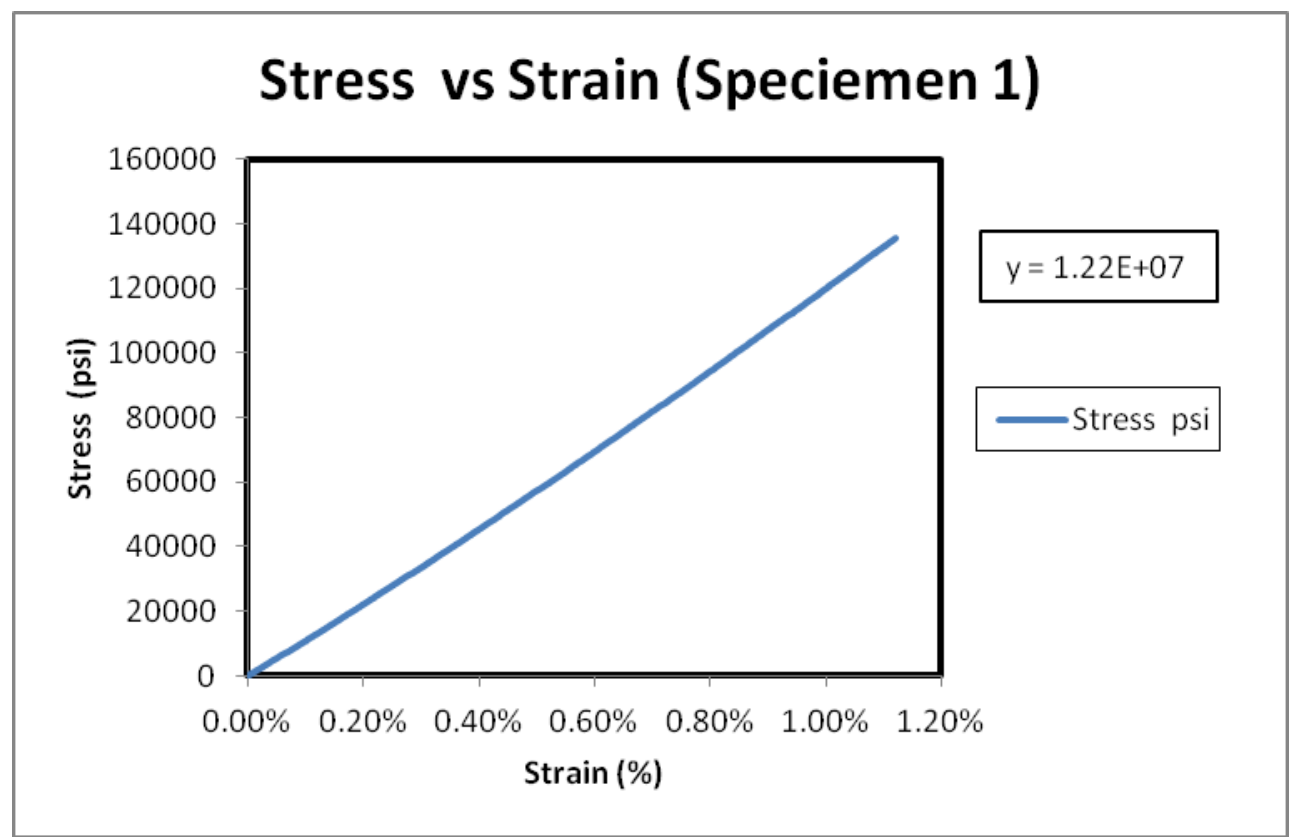

Figure 41: Stress-strain behavior ( $\mathrm{E}=84.5113 \mathrm{GPa}$ )

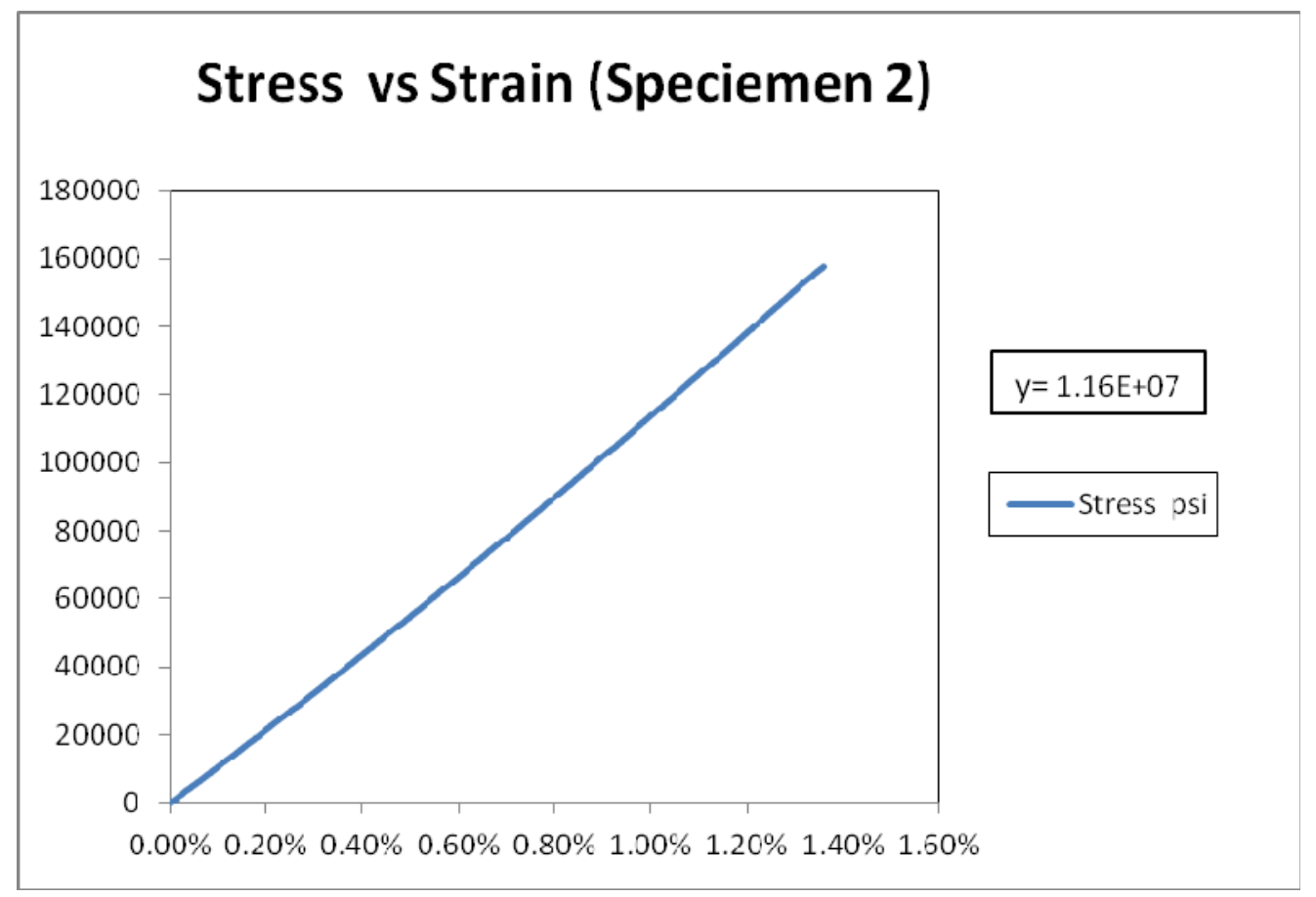

Figure 42: Stress-strain behavior ( $E=80.431 \mathrm{GPa})$ 


\subsubsection{Results and Discussion; Static Test}

The ultimate static testing results were tabulated to compare the maximum stress taken by similarly manufactured panels. The initially manufactured specimens were tabulated together, as the ultimate stress values were varying and inconsistent.

Table 5: Ultimate stress of initially manufactured specimen

\begin{tabular}{|c|c|c|c|c|c|c|}
\hline Specimen 5 & Location 1 & Location2 & Location 3 & Average & Area & Length \\
\hline Thickness & 0.081 & 0.082 & 0.081 & 0.081333 & \multirow{2}{*}{0.077511} & \multirow{2}{*}{10.06} \\
\hline Width & 0.961 & 0.948 & 0.95 & 0.953 & & \\
\hline $\begin{array}{l}\text { Ultimate } \\
\text { Load(Ibs) }\end{array}$ & 10421.4425 & & Stress & 134451.7 & & \\
\hline Specimen 6 & Location 1 & Location2 & Location 3 & Average & Area & Length \\
\hline Thickness & 0.083 & 0.083 & 0.082 & 0.082667 & \multirow{2}{*}{0.086084} & \multirow{2}{*}{10.04} \\
\hline Width & 1.041 & 1.041 & 1.042 & 1.041333 & & \\
\hline $\begin{array}{l}\text { Ultimate } \\
\text { Load(Ibs) }\end{array}$ & 13141.1266 & & Stress & 152655.5 & & \\
\hline Specimen 9 & Location 1 & Location2 & Location 3 & Average & Area & Length \\
\hline Thickness & 0.082 & 0.082 & 0.08 & 0.081333 & \multirow{2}{*}{0.082526} & \multirow{2}{*}{9.98} \\
\hline Width & 1.012 & 1.015 & 1.017 & 1.014667 & & \\
\hline $\begin{array}{l}\text { Ultimate } \\
\text { Load(Ibs) }\end{array}$ & 11379.4005 & & Stress & 137888.3 & & \\
\hline Specimen 10 & Location 1 & Location2 & Location 3 & Average & Area & Length \\
\hline Thickness & 0.08 & 0.082 & 0.082 & 0.081333 & \multirow{2}{*}{0.08071} & \multirow{2}{*}{10.00} \\
\hline Width & 0.995 & 0.995 & 0.987 & 0.992333 & & \\
\hline $\begin{array}{l}\text { Ultimate } \\
\text { Load(Ibs) }\end{array}$ & 12865.297 & & Stress & 159402 & & \\
\hline
\end{tabular}


Fabricated IM7/RP46 specimen were found to have more strength and proved to have consistent stress values when compared to the novice coupon test results.

Table 6: Ultimate stress of lately manufactured specimen

\begin{tabular}{|c|c|c|c|c|c|c|}
\hline Specimen 11 & Location 1 & Location2 & Location 3 & Average & Area & Length \\
\hline Thickness & 0.082 & 0.084 & 0.083 & 0.083 & \multirow{2}{*}{0.083885} & \multirow{2}{*}{10.00} \\
\hline Width & 1.018 & 1.008 & 1.006 & 1.010667 & & \\
\hline $\begin{array}{l}\text { Ultimate } \\
\text { Load(Ibs) }\end{array}$ & 13985.1144 & & Stress & 166717 & & \\
\hline Specimen 12 & Location 1 & Location2 & Location 3 & Average & Area & Length \\
\hline Thickness & 0.08 & 0.082 & 0.082 & 0.081333 & \multirow{2}{*}{0.080493} & \multirow{2}{*}{9.97} \\
\hline Width & 1 & 0.982 & 0.987 & 0.989667 & & \\
\hline $\begin{array}{l}\text { Ultimate } \\
\text { Load(Ibs) }\end{array}$ & 13228.3086 & & Stress & 164341.3 & & \\
\hline Specimen 13 & Location 1 & Location2 & Location 3 & Average & Area & Length \\
\hline Thickness & 0.083 & 0.084 & 0.083 & 0.083333 & \multirow{2}{*}{0.085222} & \multirow{2}{*}{9.96} \\
\hline Width & 1.02 & 1.017 & 1.031 & 1.022667 & & \\
\hline $\begin{array}{l}\text { Ultimate } \\
\text { Load(Ibs) }\end{array}$ & 14260.0747 & & Stress & 167328.1 & & \\
\hline Specimen 14 & Location 1 & Location2 & Location 3 & Average & Area & Length \\
\hline Thickness & 0.082 & 0.084 & 0.083 & 0.083 & \multirow{2}{*}{0.081672} & \multirow{2}{*}{10.10} \\
\hline Width & 0.982 & 0.985 & 0.985 & 0.984 & & \\
\hline $\begin{array}{l}\text { Ultimate } \\
\text { Load(Ibs) }\end{array}$ & 12852.6723 & & Stress & 157369.4 & & \\
\hline
\end{tabular}


Table 7: Ultimate stress of elevated temperature tested specimen

\begin{tabular}{|c|c|c|c|c|c|c|}
\hline Specimen 18 & Location 1 & Location2 & Location 3 & Average & Area & Length \\
\hline Thickness & 0.074 & 0.076 & 0.073 & 0.074 & 0.07252 & 10.02 \\
\hline Width & 0.987 & 0.975 & 0.977 & 0.980 & & \\
\hline $\begin{array}{l}\text { Ultimate } \\
\text { Load(Ibs) }\end{array}$ & 9701.55 & & Stress & 13377.75 & & \\
\hline Specimen 19 & Location 1 & Location2 & Location 3 & Average & Area & Length \\
\hline Thickness & 0.080 & 0.080 & 0.080 & 0.080 & 0.081672 & 10.00 \\
\hline Width & 0.978 & 0.975 & 0.975 & 0.0 .976 & & \\
\hline $\begin{array}{l}\text { Ultimate } \\
\text { Load(Ibs) }\end{array}$ & 11805.46 & & Stress & 151196.97 & & \\
\hline
\end{tabular}

\subsection{IM7/RP 46 STATIC FAILURE PATTERN - OBSERVATION}

As we know at micro-level fibrous composite exhibit various failure mechanism which include fibre fracture, fibre splitting, fibre pull out, matrix cracking and fibre/matrix debonding. Interesting failure patterns were observed among the IM7/RP46 composites manufactured in the laboratory. Among them was a failure pattern of the panel manufactured from the prepreg that was stored in the room temperature for a day, followed by compression molding the next day. The appearance of the panel was described before in the novice panel section. On loading the specimen beyond 8000 pounds force the matrix powder started falling off the sample, followed by rapid delamination. The fibre rupture was observed at the edges of the sample. 


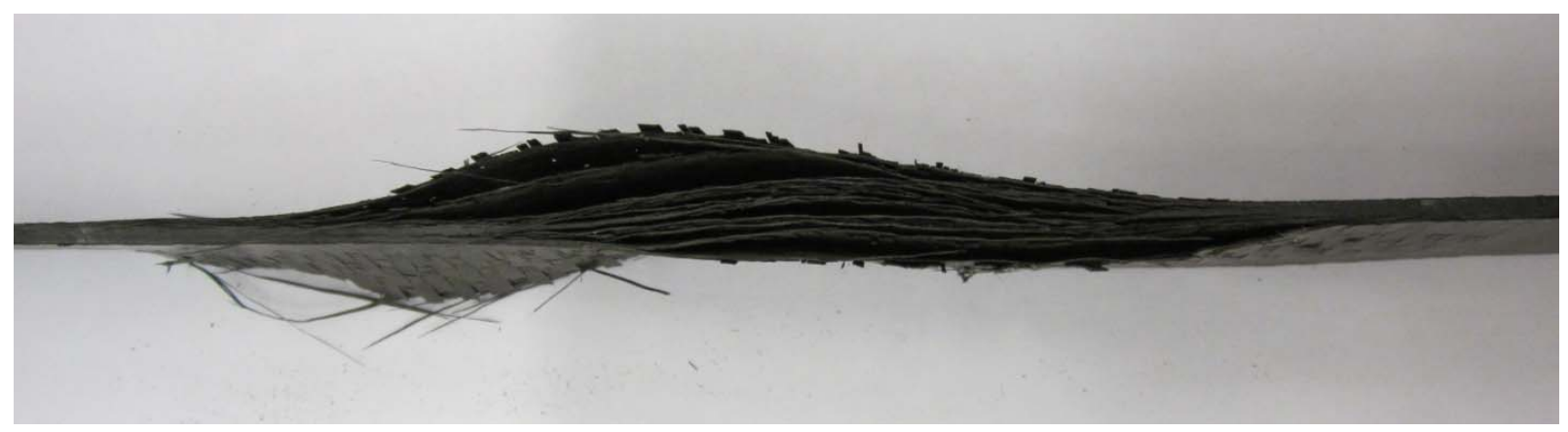

Figure 43: Side view of matrix-failed specimen due to improper curing

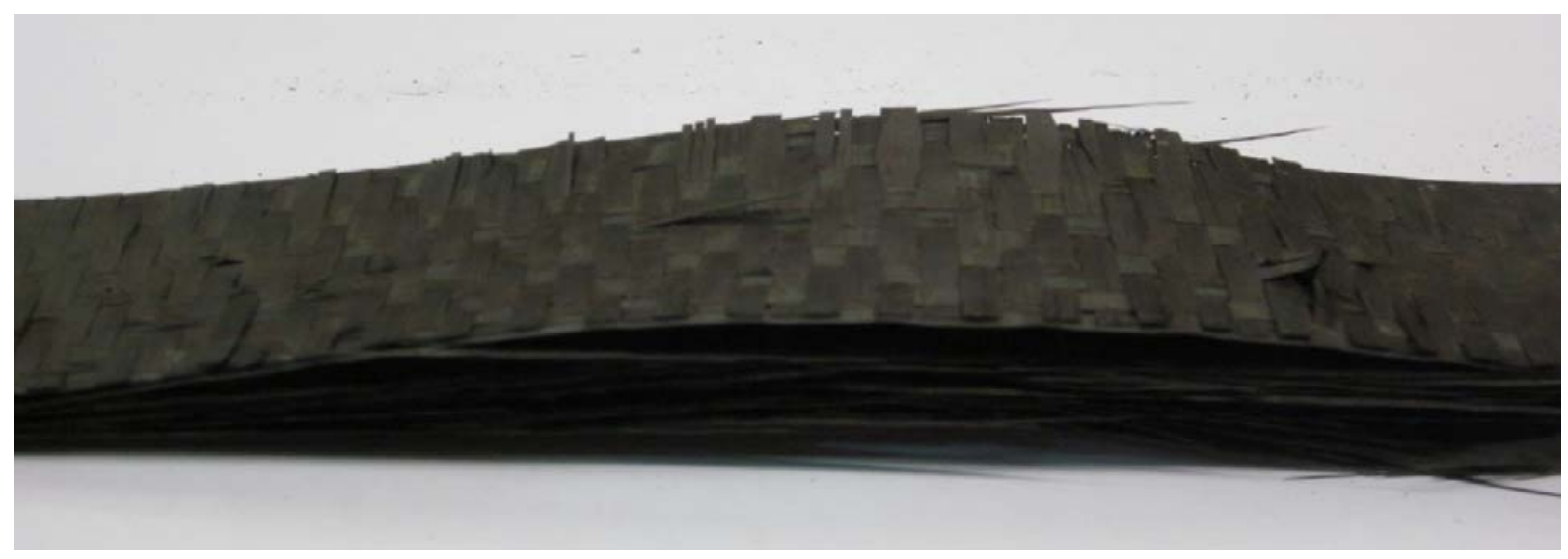

Figure 44: Top view of matrix failure specimen

Transverse fibre fracture was observed in common among the manufactured specimen as fibres are the major load-carrying members. Fibre fracture occurred in the IM7/RP46 specimen as the tensile load of the fibre was exceeded beyond the maximum axial tensile stress. The sample had transverse cut and failing at two or three regions simultaneously or in fractions of time difference. 


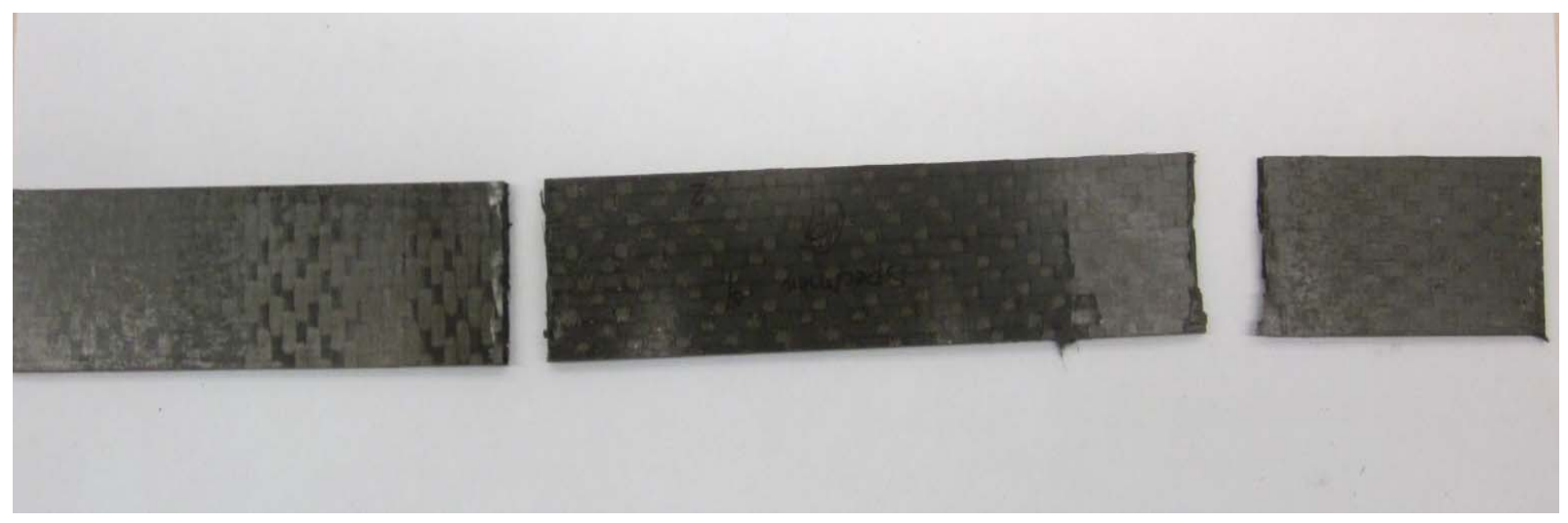

Figure 45: Brittle natured failure of IM7/RP46 specimen

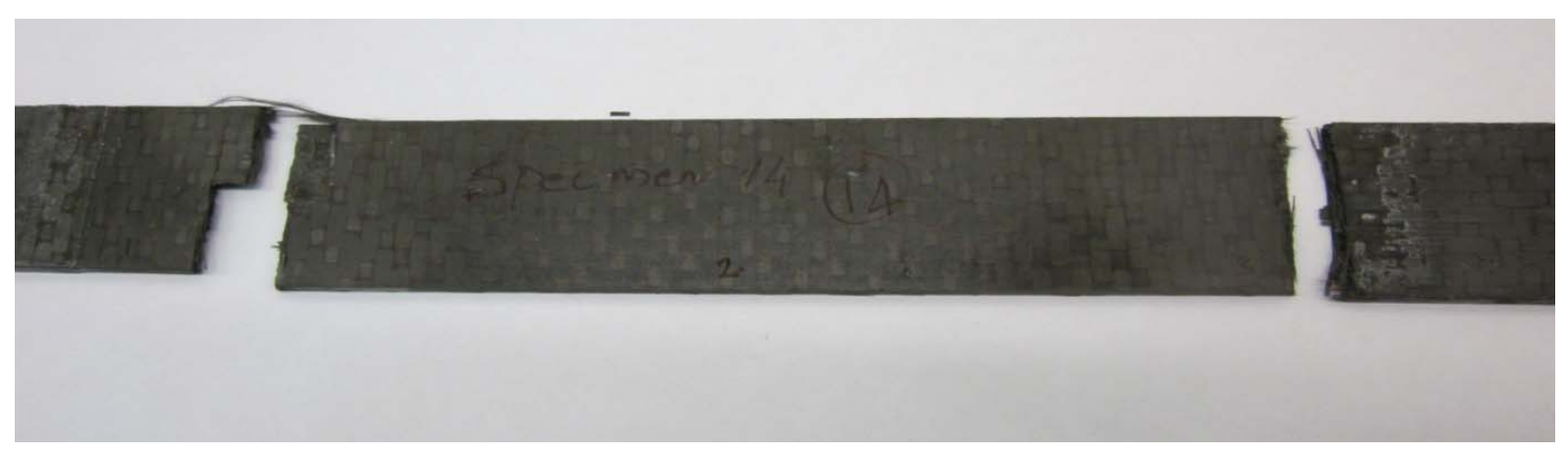

Figure 46: Failure Pattern of IM7/RP46

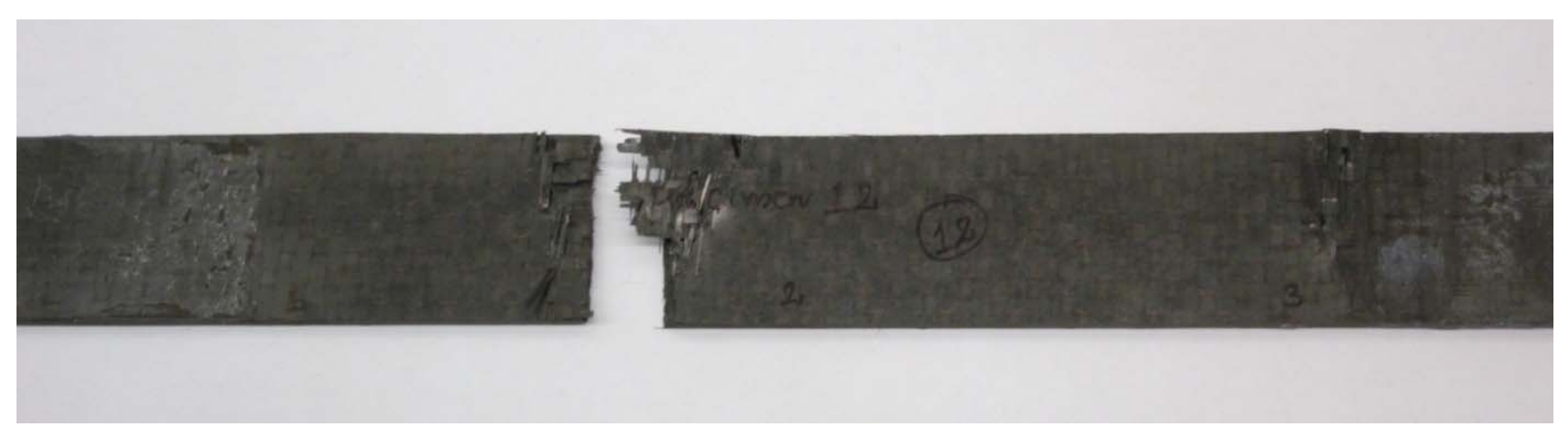

Figure 47: Fabric pull out at the edge of the specimen 


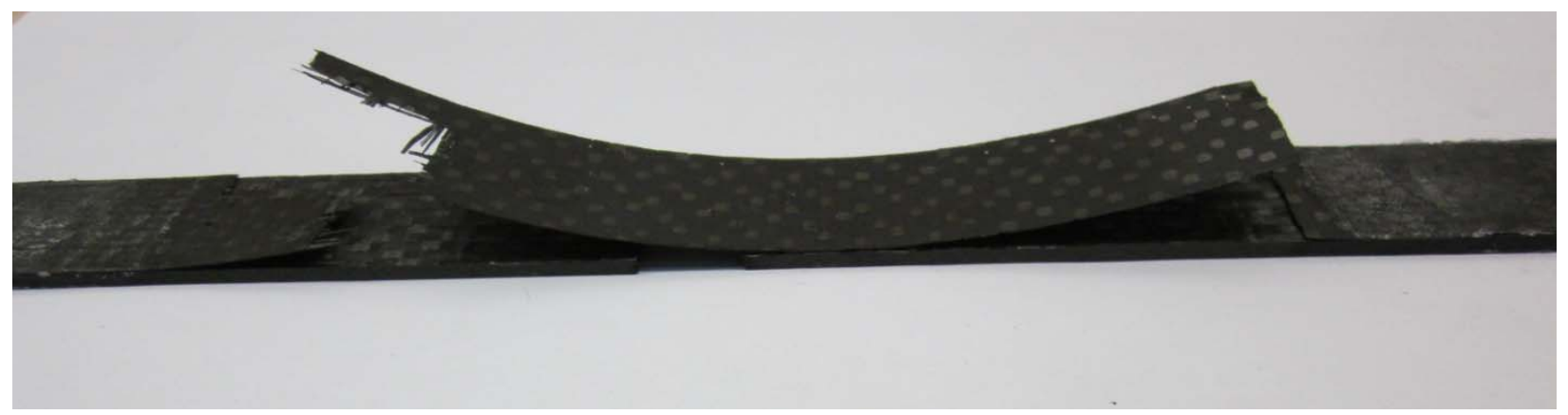

Figure 48: Edge pull out followed by delamination

The failure surface in all the case was perpendicular to the loading direction. Edges pull out and delamination was not dominantly found among the coupons but was noticed in a couple of specimens.

\subsection{HIGH TEMPERATURE TESTING OF IM7/RP46 COUPONS}

The produced IM7/RP46 specimens were tested at elevated temperature in the simulated environmental chamber. Ultimate static testing and fatigue testing was carried out in order to qualify the manufacturing procedure with reference to high temperature application. Initial static testing was performed to generalize the uniformity of the samples produced from in-house manufacturing set up. The real application of the material relies on the result of the high temperature testing as the polyimide resin system was used in verifying practicality of the manufacturing apparatus. The established cost effective method focuses on producing the advanced composites.

\subsubsection{Elevated Temperature Experimental Setup}

The high temperature polymer composite was tested using an in-house designed and manufactured solid steel mechanical grip. The mechanical grips had six bolts on each segment that enabled setting up the gripping pressure of the test material. MTS 647 hydraulic wedge grips were replaced with the abovementioned mechanical grips to overcome the temperature limitation.

A high temperature environmental chamber with a maximum temperature of $800^{\circ} \mathrm{F}$ was mounted on the MTS test frame. The heating chamber has a temperature control system to maintain the 
temperature accuracy within $\pm 1^{\circ} \mathrm{C}$ of the required temperature. A Vortec's cold air gun was used to cool the top and bottom load cell with the compressed air. High temperature extensometer with a gage length of 1 " inch was employed to measure the strain in the specimen under testing. The above mentioned high temperature apparatus setup [12] at FRAMES lab was used to carry out both static and fatigue testing on the IM7/RP46 composite coupons.

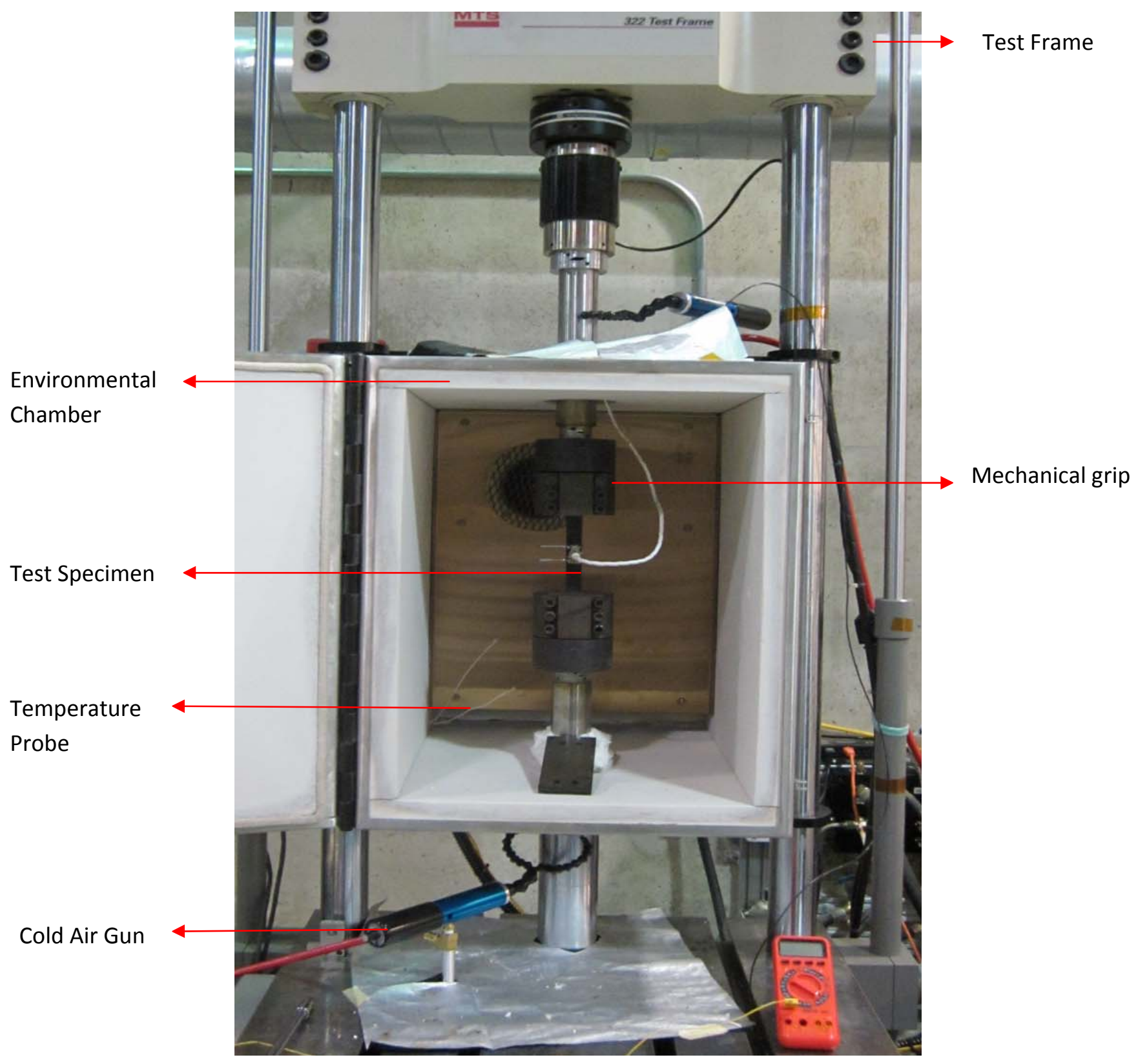

Figure 49: High temperature experiment set-up [Ref. 12] 


\subsubsection{High Temperature Static Testing of IM7/RP46}

The test specimen dimensions were strictly the same as followed for the room temperature ultimate static testing of IM7/RP46 composites. The end tabs were bonded to the specimen with the polyimide tape on the edges [18]. 70 foot-pound Torque force was used to grip the specimen for ultimate static testing. The torque force applied to the mechanical grip was sufficient to hold the specimen in position. The torque wrench was used to apply the required specimen gripping pressure. The test specimen fits in-between the one inch groove of the mechanical grip and the friction force aids to hold the specimen in place while testing.

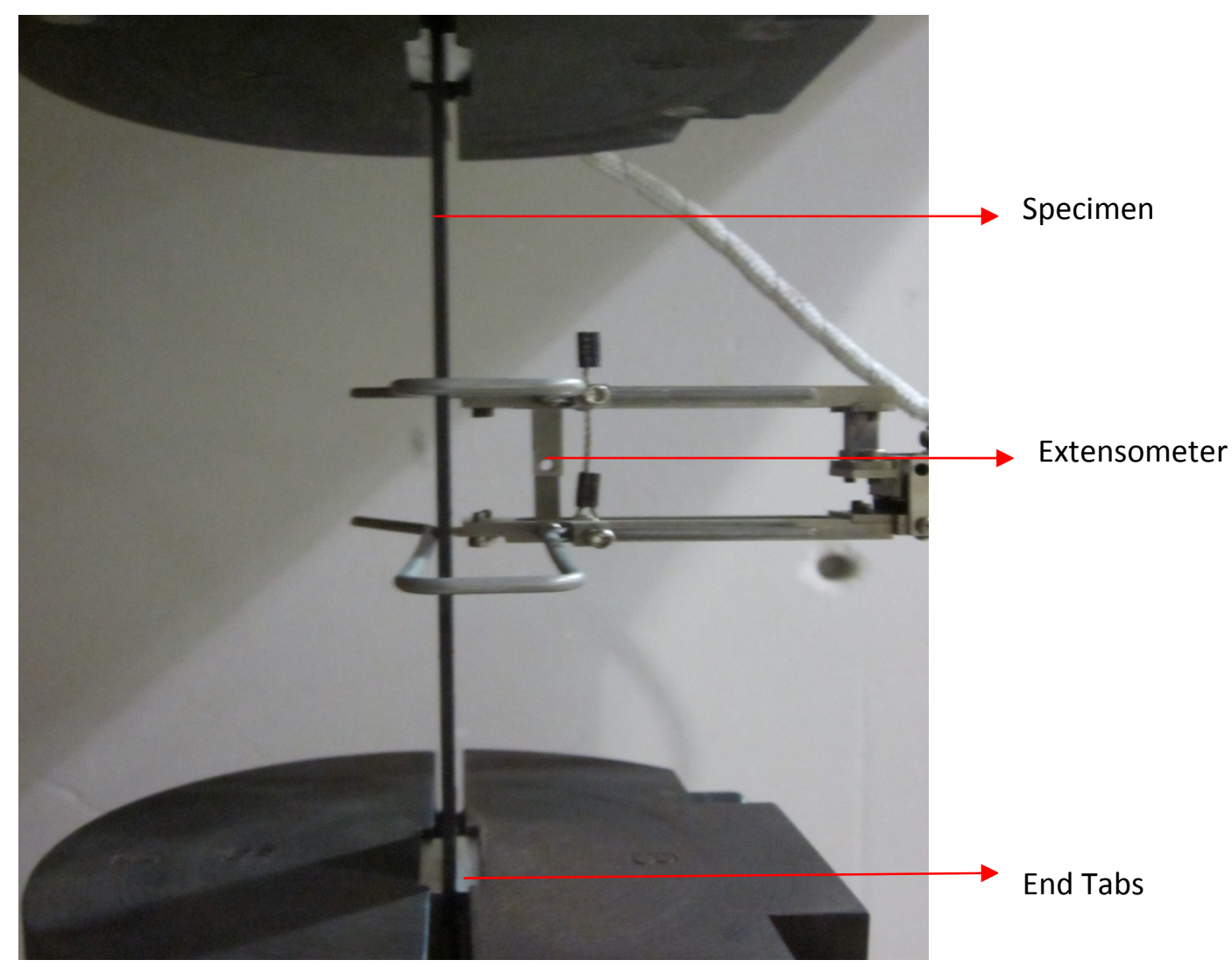

Figure 50: Static testing of IM7/RP46 using mechanical grips

The IM7/RP46 specimens were initially aligned with the grips followed by application of torque force.

The target temperature was set up in the ATS temperature control system with a ramp up rate of $6^{\circ} \mathrm{C}$ 
per minute. Once the target temperature of $225^{\circ} \mathrm{C}$ was reached, the system was held for 40 minutes to attain the uniform temperature throughout the chamber and the test specimen. The specimen was subjected to tension, for example: pulled at a rate of $2.00 \mathrm{~mm} /$ minute until failure occurs. The failed specimen was prepared for microscopic evaluation.

\subsubsection{High Temperature Fatigue Testing}

The high temperature fatigue testing of IM7/RP46 specimen was performed at $225^{\circ} \mathrm{C}$ to predict the design life of manufactured specimen. The fatigue testing could predict in-service life of the manufactured specimen. Coupons with heavy void content, improper bonding between layers and inclusions will eventually lead to failure at lower load cycles. The specimen was loaded up to $60 \%$ of the ultimate failure load. The stress ratio used in the fatigue testing is 0.1 . The specimen was cycled between maximum of $6000 \mathrm{lbs}$ and minimum $600 \mathrm{lbs}$ at a frequency of $5 \mathrm{~Hz}$. The manufactured IM7/RP46 successfully survived up to 250,000 cycles and the fatigue-loaded specimen was subjected to microscopic evaluation.

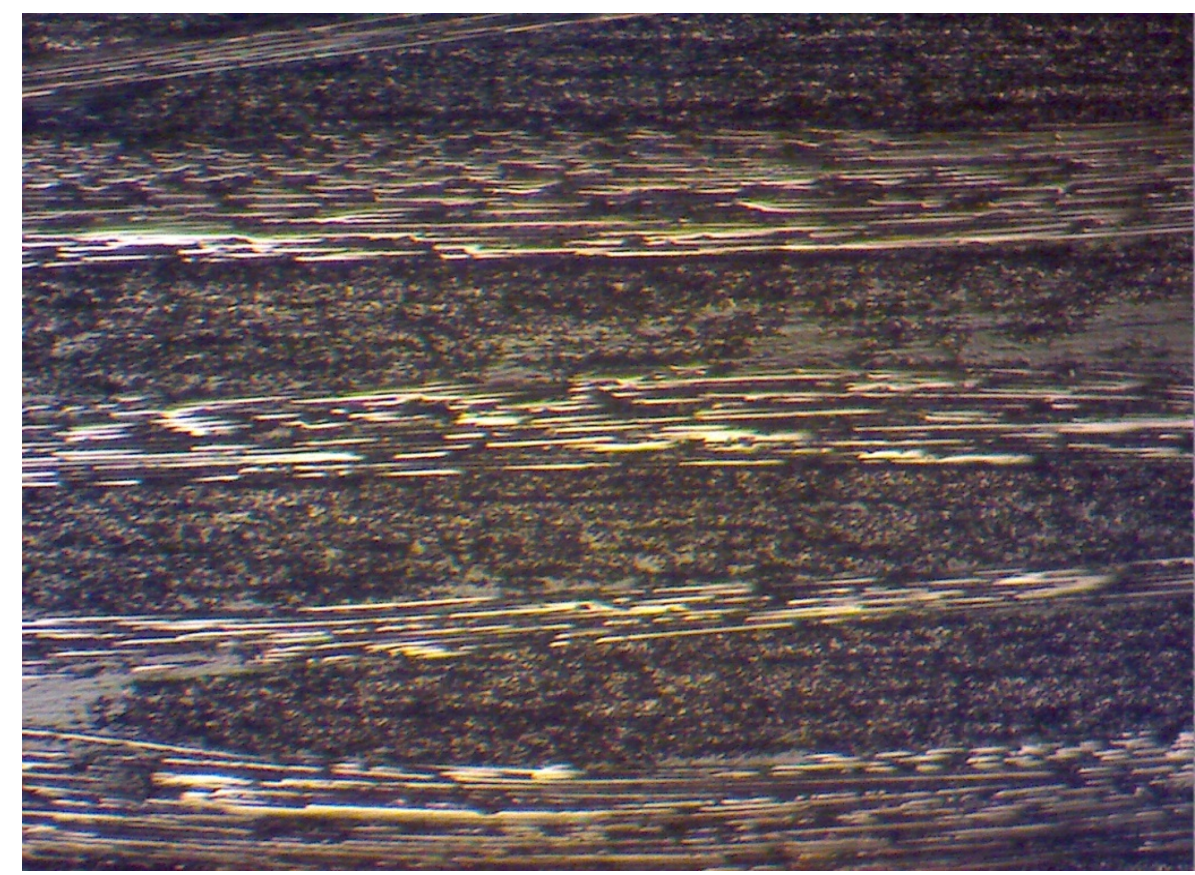

Figure 51: Microscopic image of fatigue tested specimen 
Microscopic evaluation of the fatigue tested specimen showed no significant damage or cracks along the cross section, which can be clearly seen in the above picture.

\subsubsection{Failure Pattern and Stress-Strain Plot of IM7/RP46 at Elevated Temperature}

The stress strain plot and failure pattern of IM7/RP46 at $225^{\circ} \mathrm{C}$ was similar to the results obtained at room temperature. The Young's modulus of the specimen obtained from the slope of the stress-strain curve was found to be $68.9 \mathrm{GPa}$.

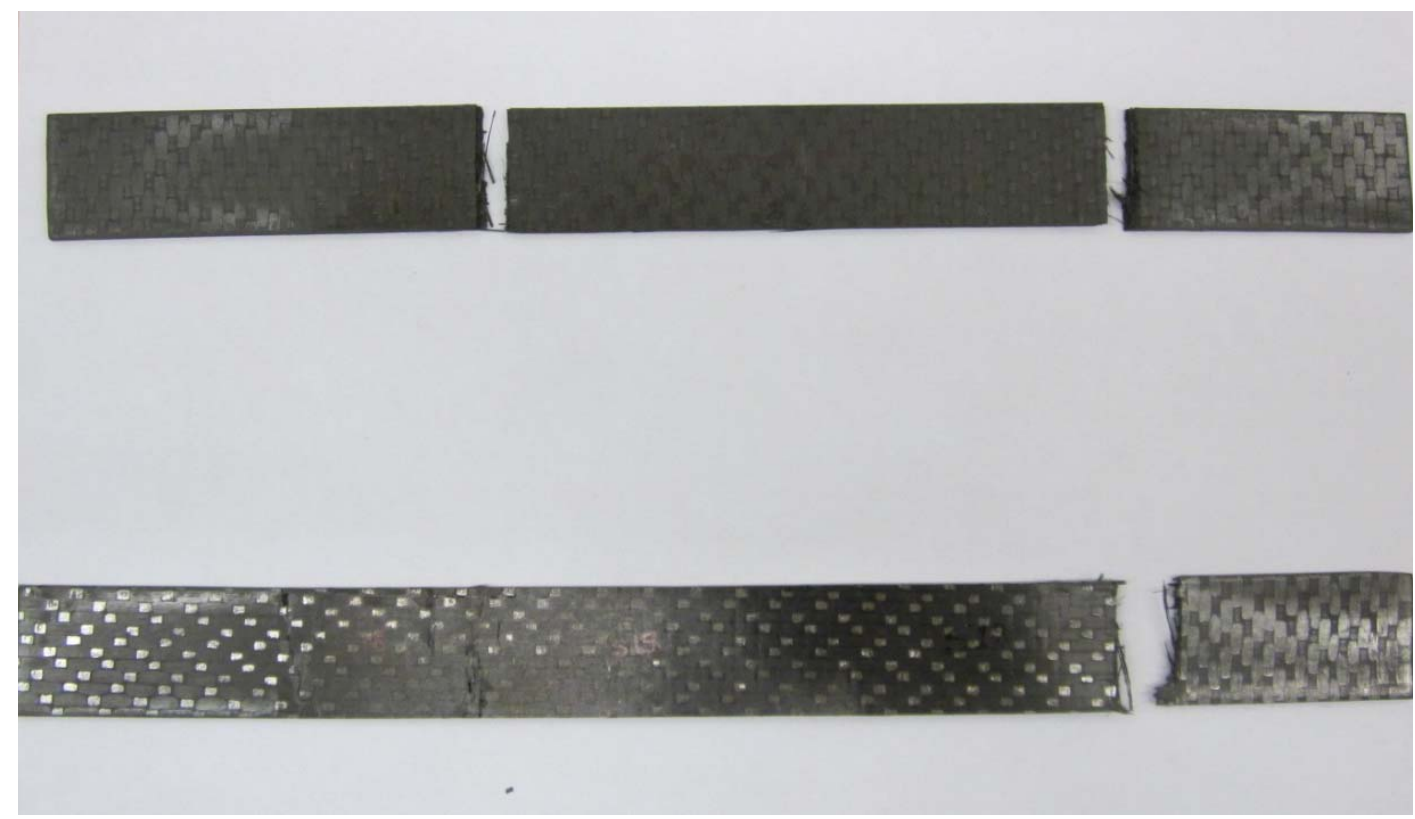

Figure 52: Failure pattern of IM7/RP46 at high temperature 


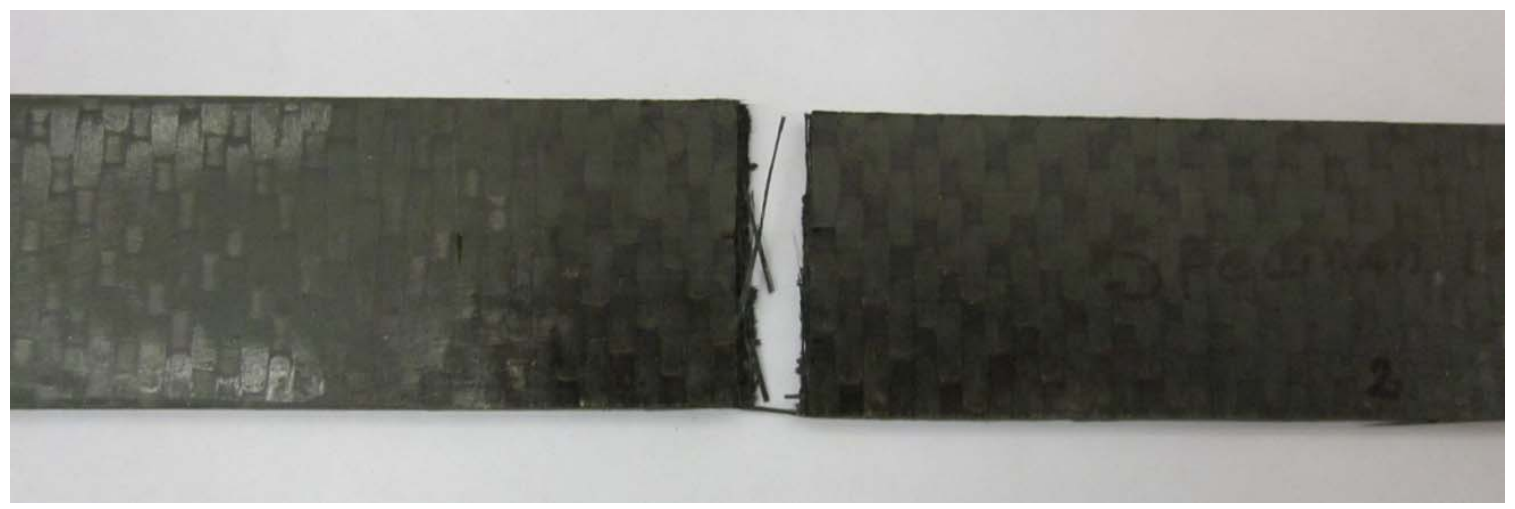

Figure 53: Enlarged view of failed specimen

The failure surface in high temperature testing was perpendicular to the loading direction and transverse fibre fracture was noticed among the failed specimen.

Linear elastic behavior was observed from the stress-strain plot of IM7/RP46 specimen at $225^{\circ} \mathrm{C}$.

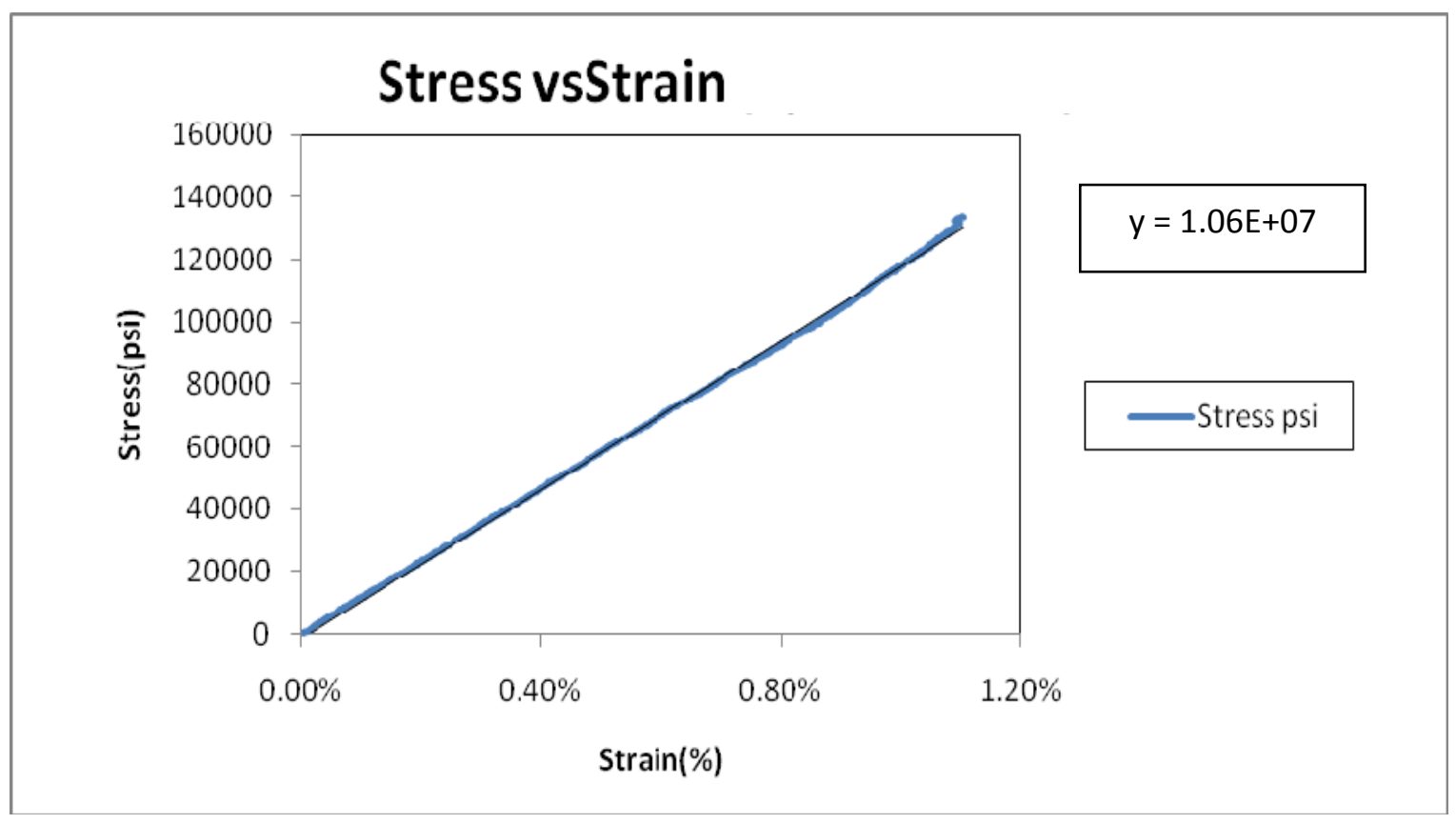

Figure 54: Stress-strain behavior (High temperature tested specimen)

The slope of the stress-strain plot showed the strength of the coupon was $73.6043 \mathrm{GPa}$. 


\subsection{CONCLUDING REMARKS}

In the present chapter quality of produced specimen, ultimate load, maximum stress of specimen, testing procedure and results were discussed followed by microscopic evaluation of the manufactured specimen. 


\section{Chapter 7}

\subsection{MICROSCOPIC ANALYSIS OF IM7/RP46 SPECIMEN}

Image analysis is a branch of metallography, which is the study of material microstructure. Analysis of the material's microstructure aids us to determine whether the material had been processed correctly, reliability of the material, and reason for the material failure.

The first step in the image analysis is sectioning followed by the cutting operation. Sectioning has to be done at the areas of interest or at regions that need to be investigated. Proper sectioning is required to minimize the damage, which might produce changes in microstructure that might lead to erroneous characterization. Correctness in selection of the cutting method is important in order to cut the material without damaging the microstructure. The parameters to be considered for efficient cutting operation include selection of abrasive type, bonding, cutting speed, load and coolant.

The sections close to the failed locations were selected to study the effect of loading on the matrix, matrix-fibre interface, and the fibre. The virgin specimens were also sectioned and cut out to check for manufacturing voids or any impurities that might have been trapped during the layup process.

The sectioned specimens were marked with the permanent marker before cutting. The IM7/RP46 panels were cut with the diamond coated rotary blades that ran at approximately $3000 \mathrm{rpm}$. The blade is cooled by water in order to avoid any damage to the composite and to produce a smooth finish.

\subsection{SPECIMEN PREPARATION}

The cut specimens were grinded through various coarse and fine silicon carbide grit sheets before the final inspection. The initial step requires rough polishing which removes the damage produced during cutting and planar grinding. Proper rough polishing will maintain specimen flatness and retain all inclusions or secondary phases. By eliminating the previous damage and maintaining the microstructural 
integrity of the specimen at this step, a minimal amount of time should be required to remove the cosmetic damage at the final polishing step.

The specimen was grinded with the 220 grit silicon carbide sheet with enough water, to avoid damage to the fibre and matrix in the sample. At this stage it was required to maintain the flatness of the specimen and to rub on the carbide sheet with gentle pressure for 90 seconds. After rubbing, cotton gauze was used to wipe off water from the surface of the specimen. Finally, the surface was cleaned with a jet of compressed air and a drop of alcohol, which was wiped off with the cotton ball. The specimen was allowed to dry and the next polishing was done with the 320 grit silicon carbide sheet which is finer than the 220 grit.

The polishing process started with the coarse 220 grit abrasive paper, followed by 320, 600 and 1200 fine grit abrasive paper. The final step in specimen preparation was rubbing the sample with the microcloth on a mixture of microid diamond compound and diamond extender for about two minutes. The specimen was mounted on the microscope with the mounting clips, focused with the eyepiece and adjusted to have a clear image. The finely adjusted image is captured with a digital microscope imager. 


\subsection{MICROSCOPIC ANALYSIS OF IM7/RP46}

After the polishing was completed the specimen was mounted on the inspection bed for analysis and the distance of the eyepiece was tuned to get a clear picture. The cross section of the tested and virgin specimen was inspected.

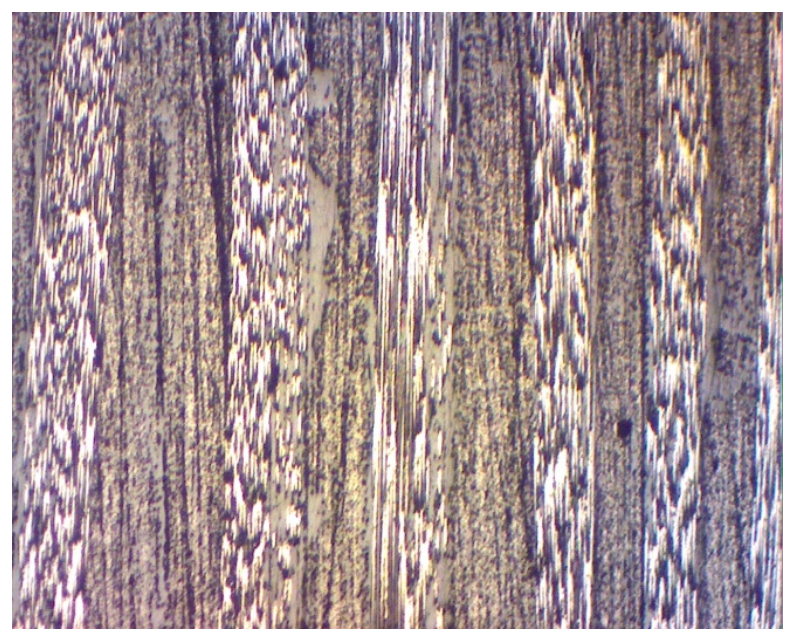

Figure 55: Cross section of tested specimen 13

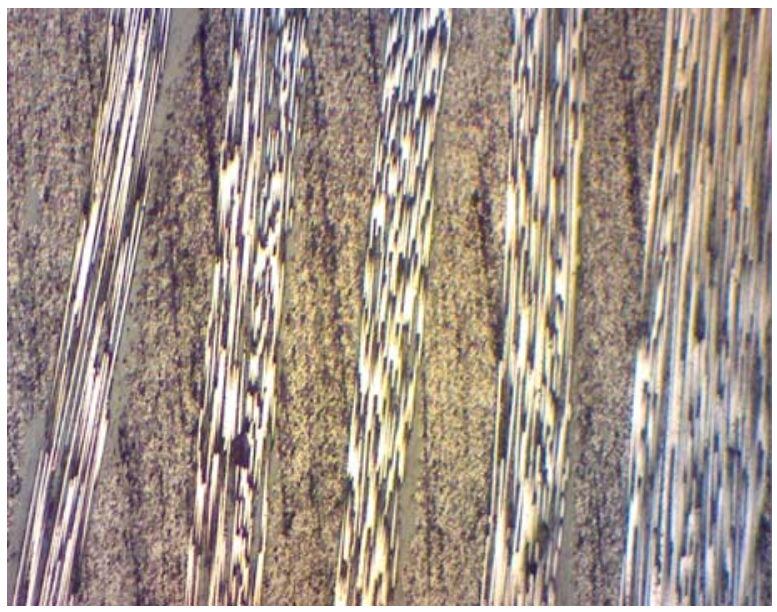

Figure 56: Cross section of tested specimen 10

The microscopic image of the virgin specimen showed that there were not much significant voids in the specimen. The cross section of the virgin specimen was viewed at 60 times magnification. 


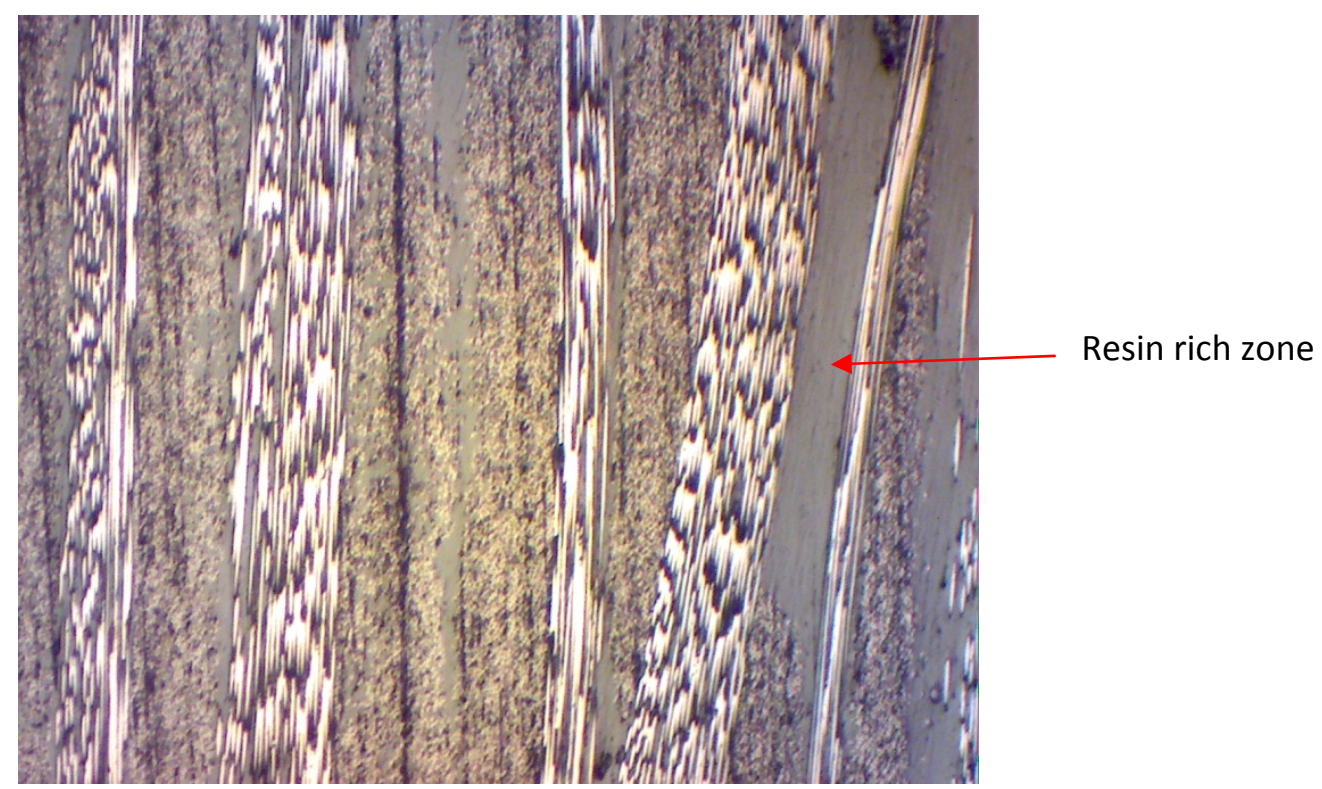

Figure 57: Cross section of tested specimen 10

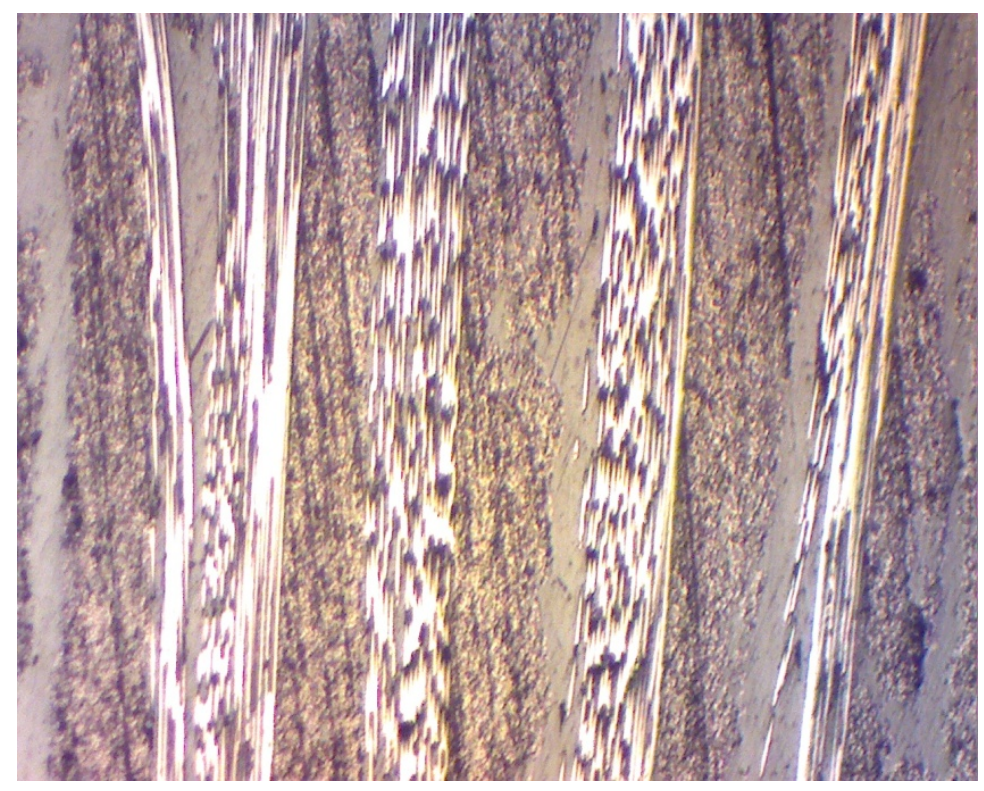

Figure 58: Cross section of Virgin specimen 15 


\subsection{SCANNING ELECTRON MICROSCOPE}

The SEM was performed on IM7/RP46 composites using JEOL JSM-6380, which is a high-performance scanning electron microscope with a resolution of $3.0 \mathrm{~nm}$. An operating voltage of $20 \mathrm{kv}$ was used for imaging. The specimens were mounted on the epoxy puck of 1" diameter and spur coated with the bronze foil along the composite edge. The polishing procedures were same as outlined for microscopic inspection.

SEM imaging of the initially manufactured specimen had more void contents, which were clearly captured at various high magnification levels.

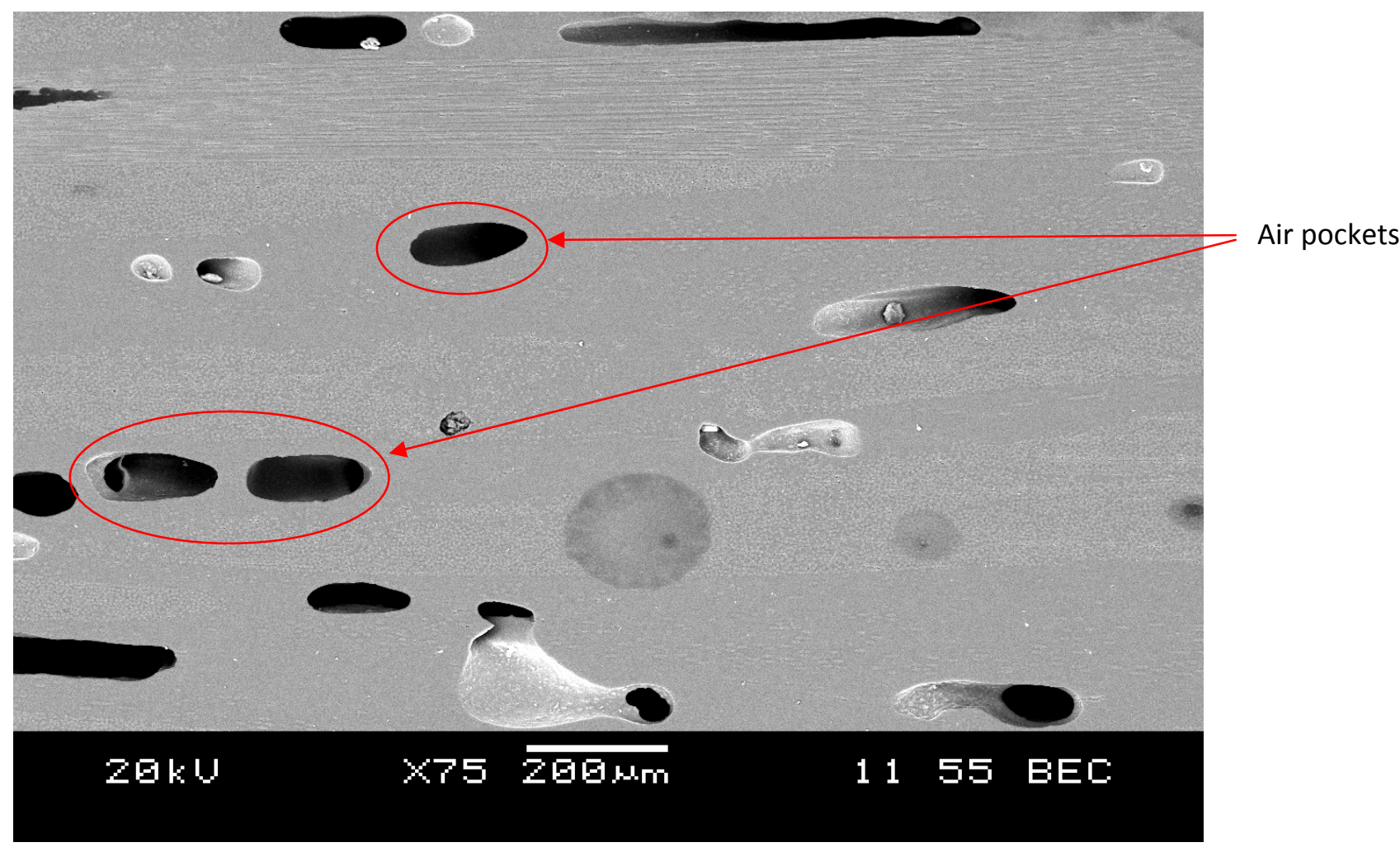

Figure 59: Void content of Novice specimen

Understanding of the cure cycle, established manufacturing setup along with the improved skill level of the fabricator the amount of void content was greatly reduced. Very few isolated voids were observed 
in the lately manufactured specimen. Thus, SEM imaging revealed the true quality of the specimen and room for improving the quality of IM7/RP46 panels.

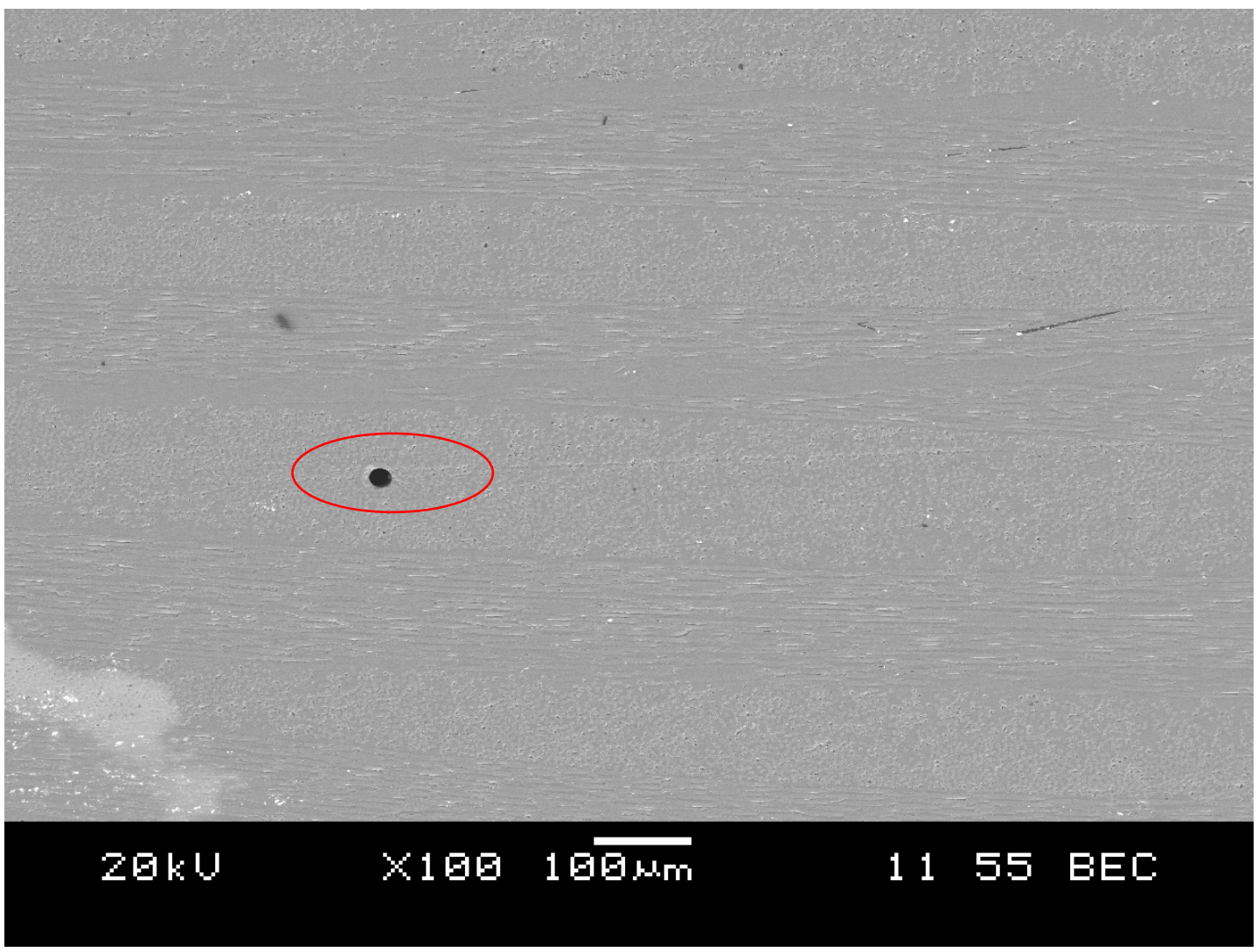

Figure 60: Isolated void observed at $100 \mathrm{x}$ magnifications 


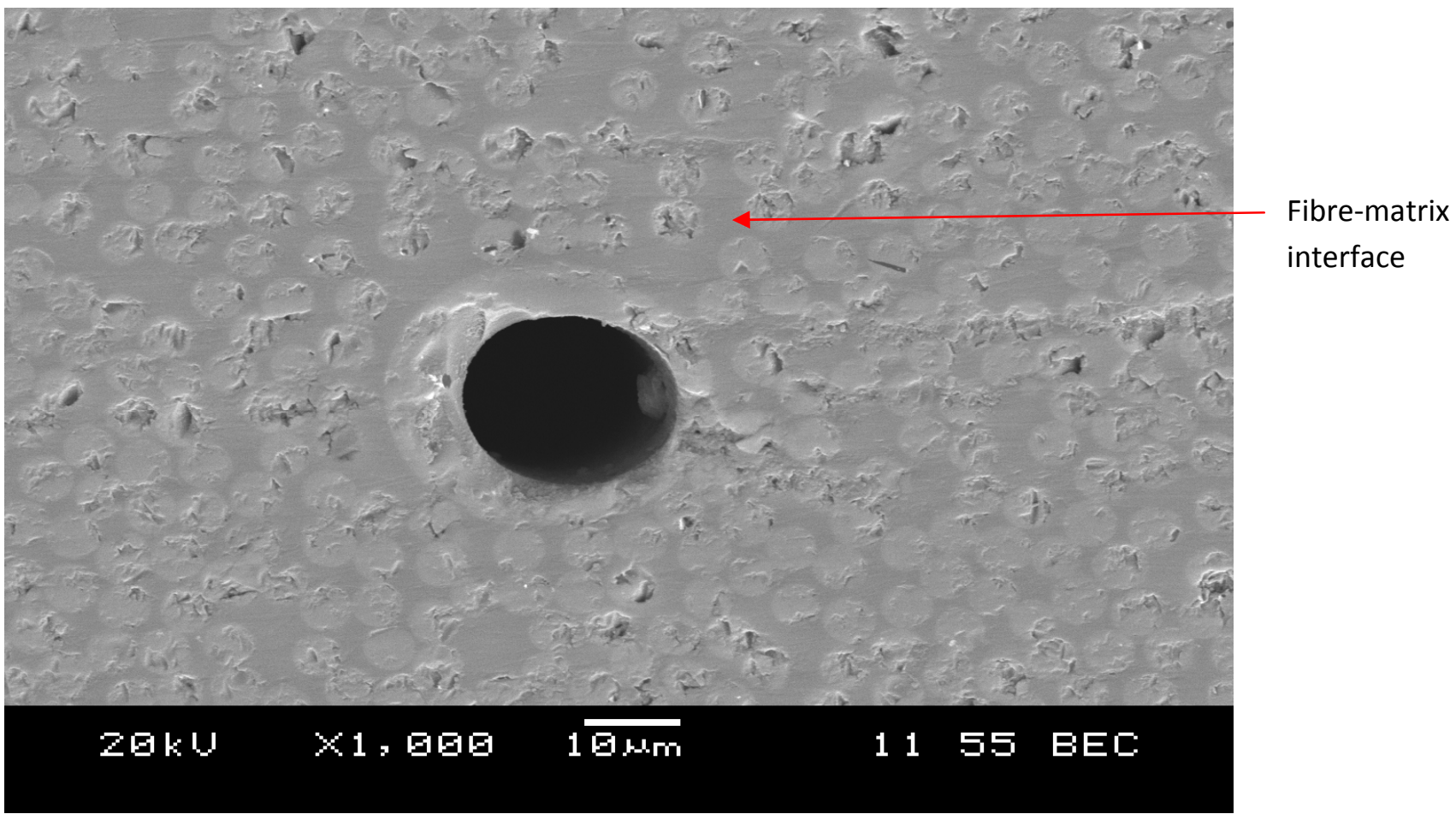

Figure 61: highly magnified image of the void (1000x)

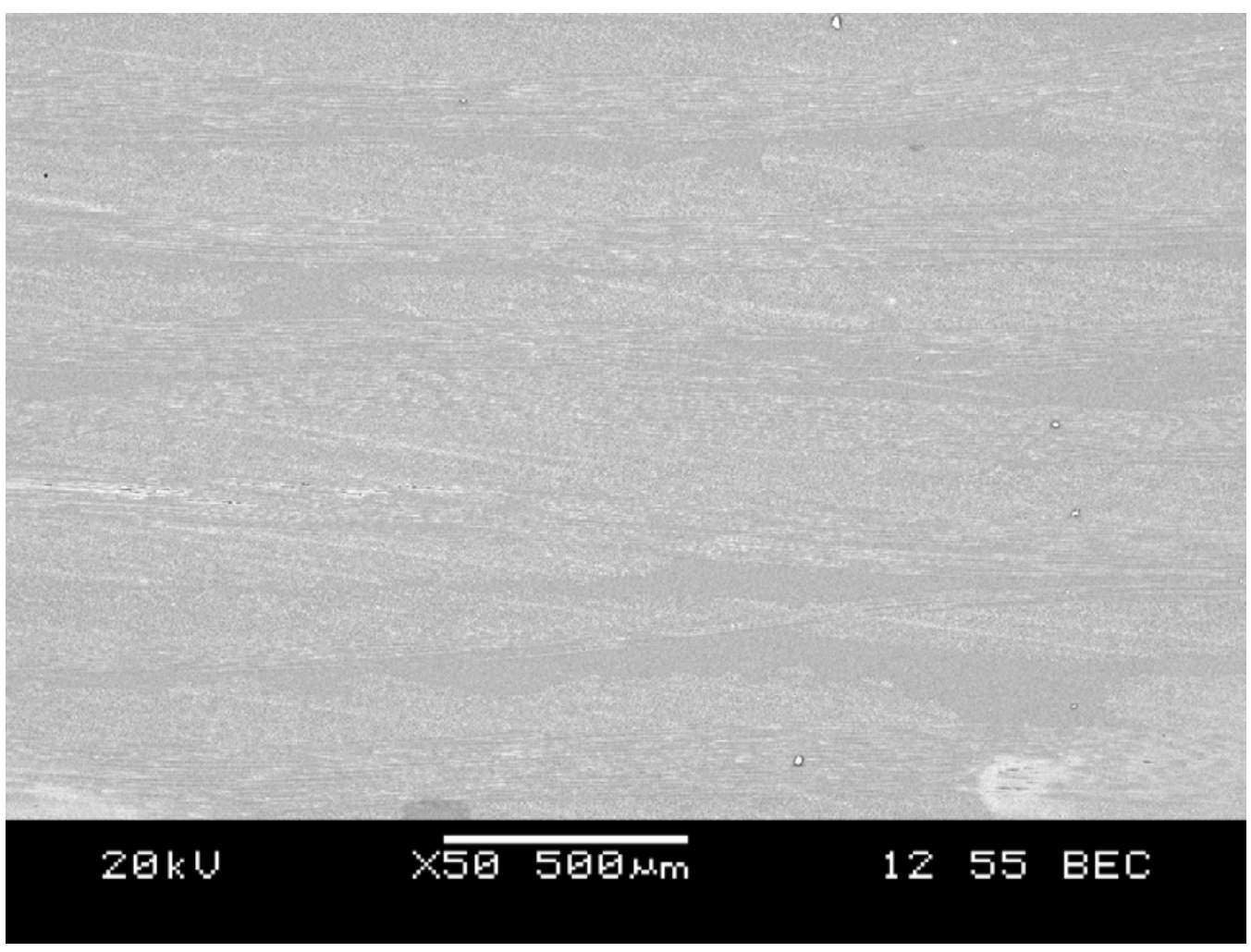

Figure 62: Image of the void free zone of fabricated specimen 


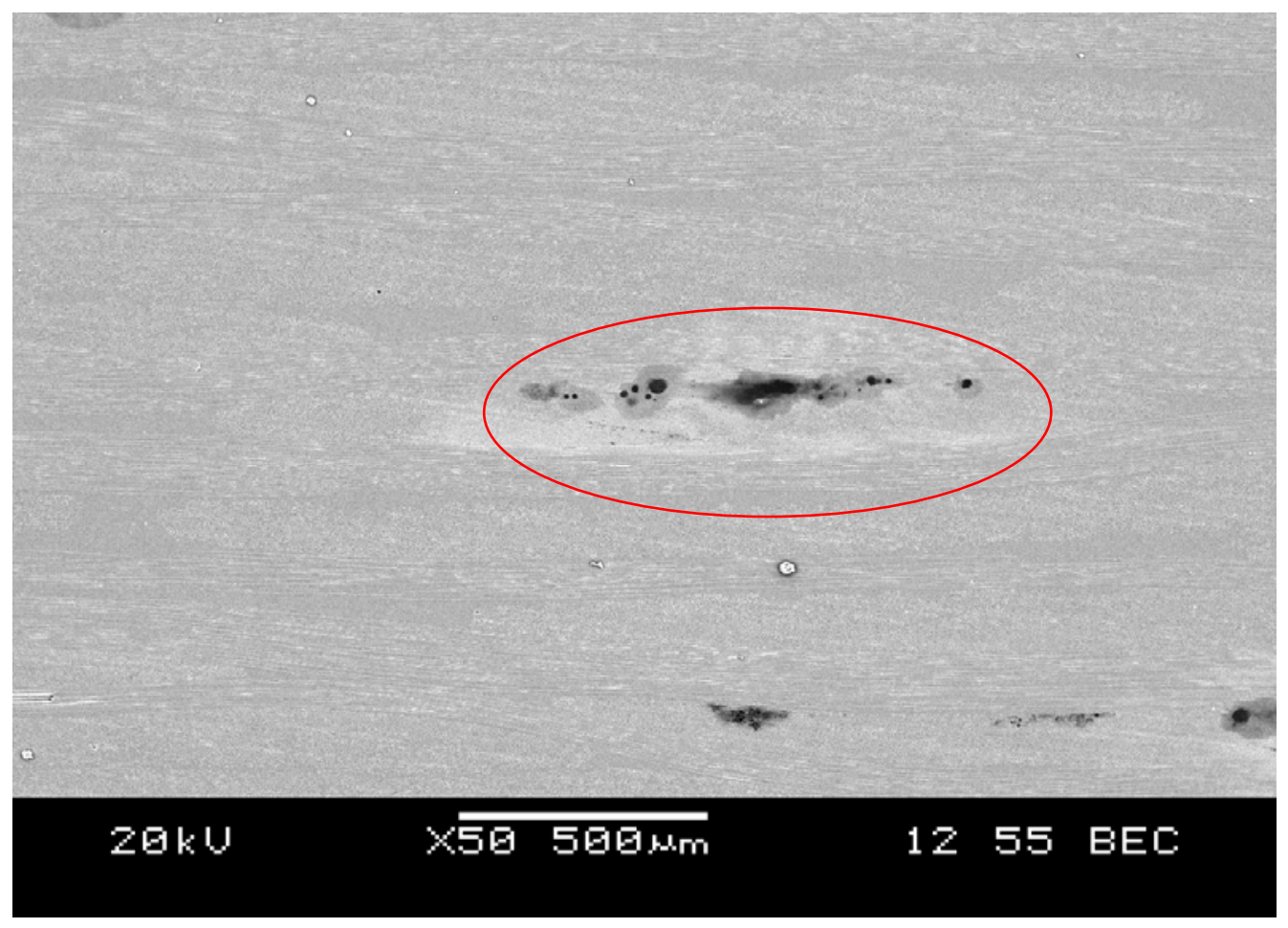

Figure 63: Moisture entrapped zone combined with void content

SEM investigation of the manufactured IM7/RP46 specimen revealed few isolated void contents along the cross section which could have occurred due to air entrapment during the compression cycle because of the air blown inside the convection oven. It may have occurred due to the bubbles that might have formed during the staging process, the staging process removes the moisture trapped in the fibre and brings to the top surface consecutive layup results in entrapment of these bubbles between the fabric layers. These voids could be possible reduced by using vacuum bagging during the initial stage of the compression, which could remove any voids when the resin solidifies to bond the fabric layers.

SEM did not reveal any surface pinholes, blisters, or fibre buckling of foreign particles (inserts) in the composite panel. 


\subsection{SEM EVALUATION OF FAILED IM7/RP46 SPECIMEN}

The tested IM7/RP46 specimen was cut near the failed area to view the local influence of failure in the fibre-matrix interface. The above described specimen preparation procedure was followed to view the sample in the scanning electron microscope.

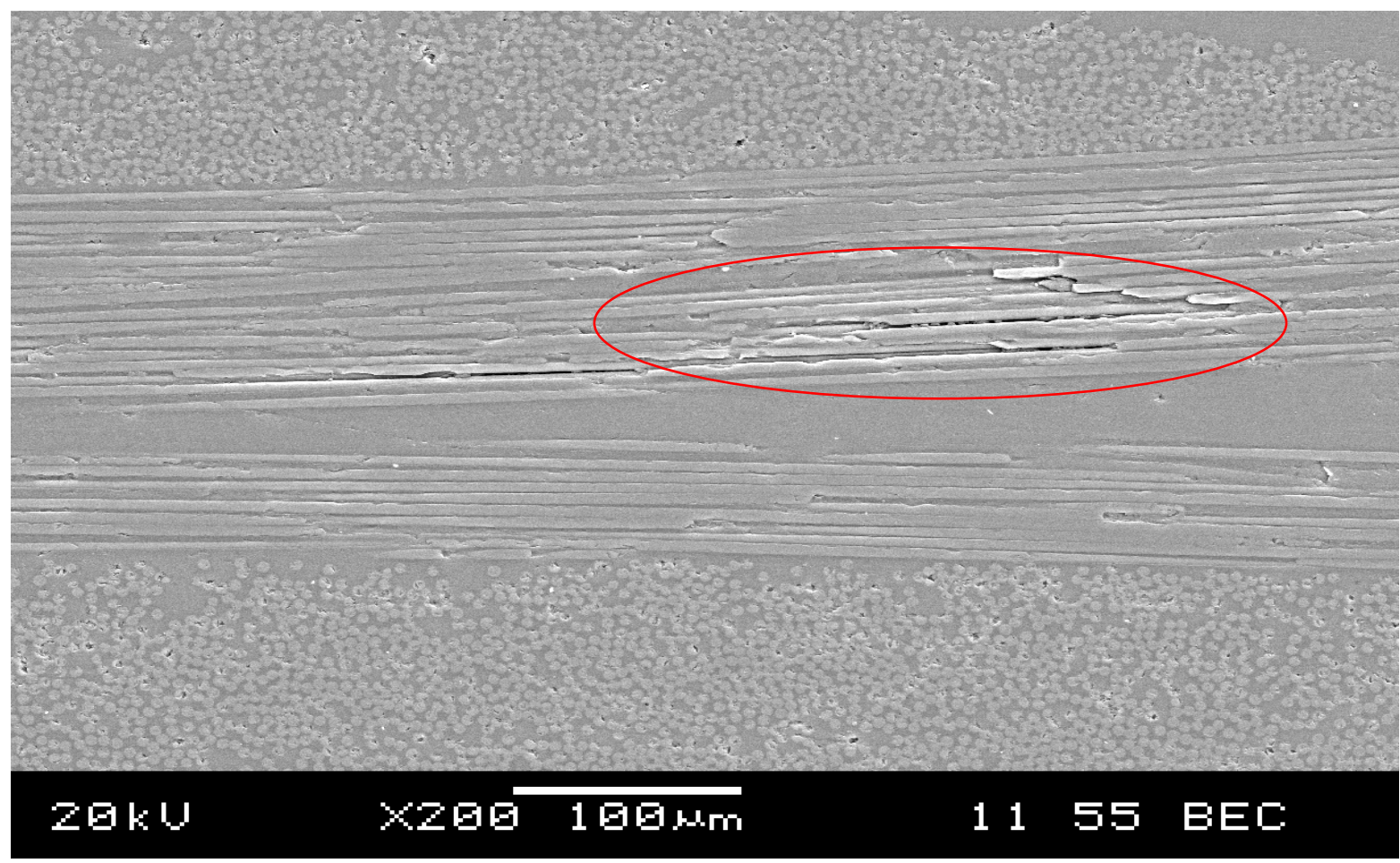

Figure 64: Matrix crack in between the fibre bundle 


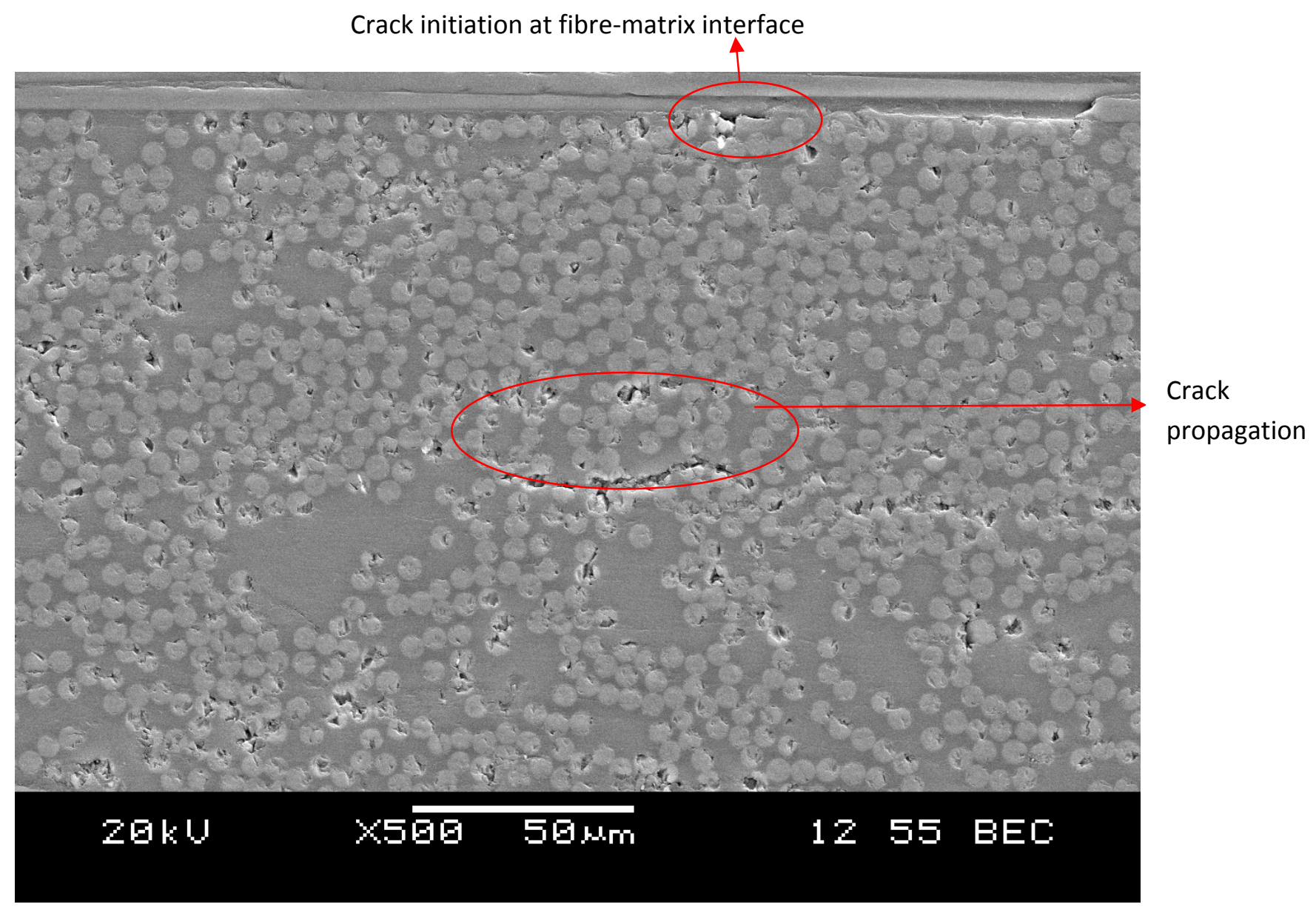

Figure 65: crack initiation and propagation on failed Im7/RP46 sample

\subsection{MICROSCOPIC EVALUATION OF FAILED IM7/RP46 SPECIMEN AT ELEVATED TEMPERATURE}

The microscopic analysis of the specimen tested at elevated temperature revealed the propagation of a longitudinal crack along the fibre direction. 


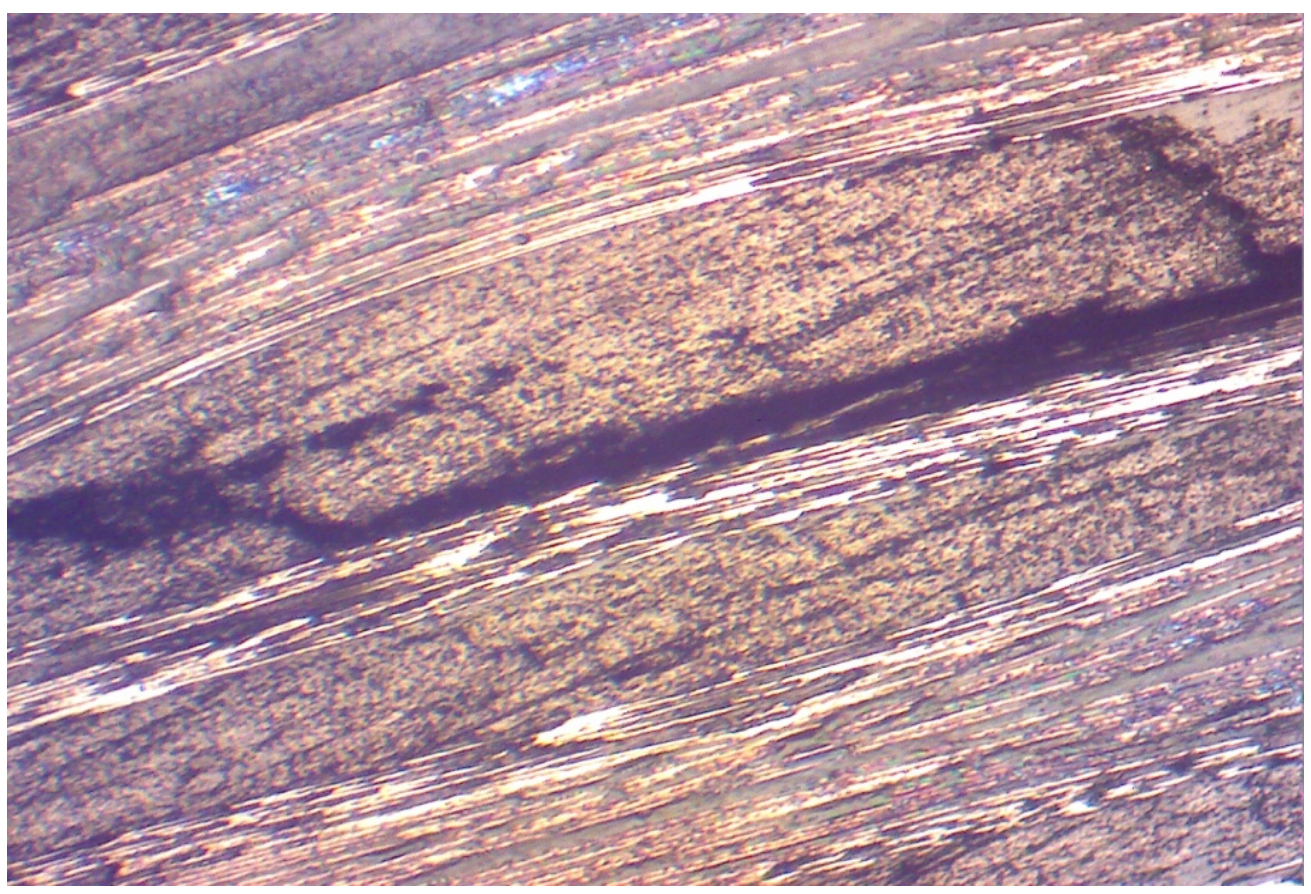

Figure 66: Longitudinal crack along the fibre direction

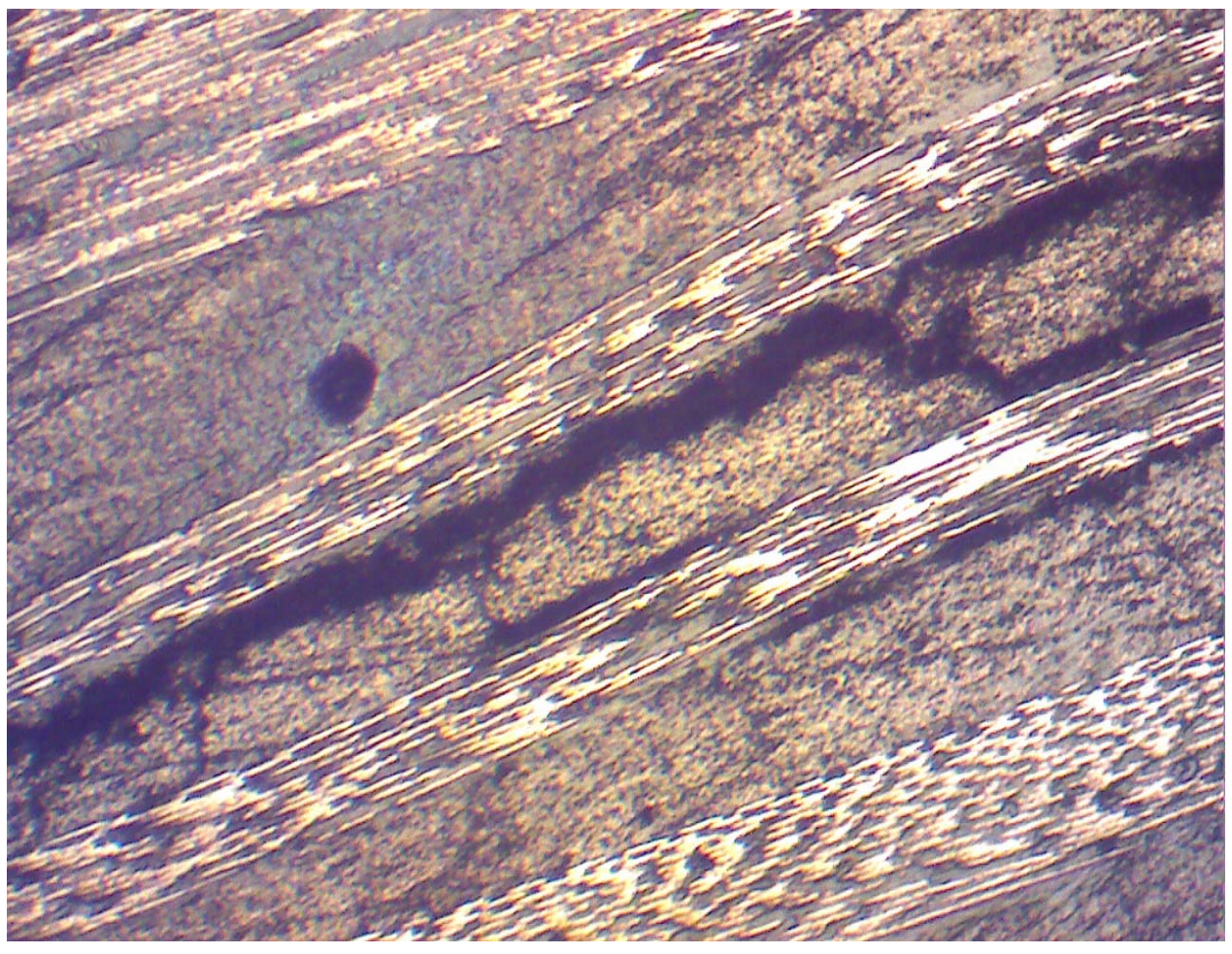

Figure 67: Crack propagation from one fibre bundle to another through matrix 


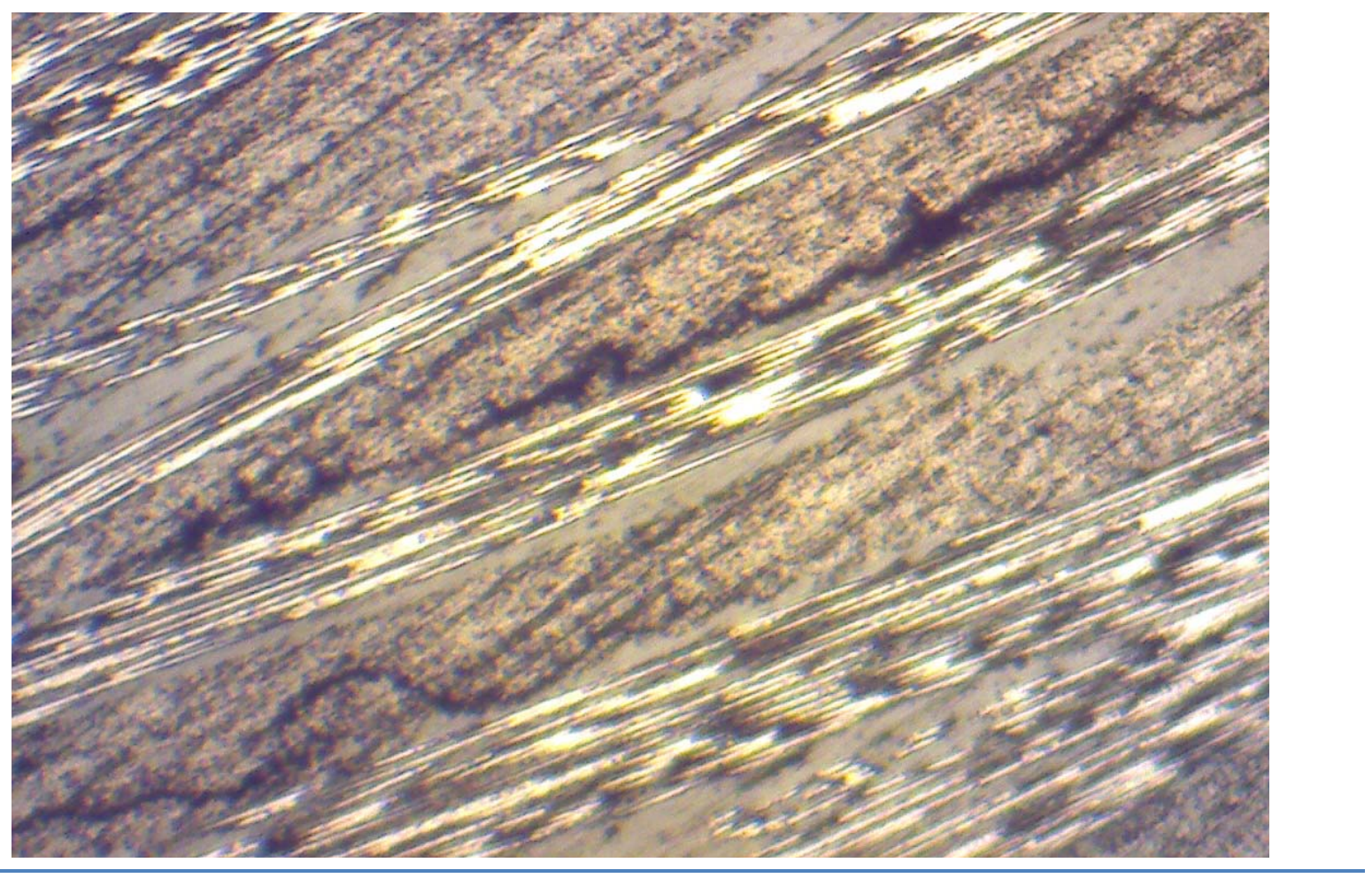

Figure 68: matrix crack in the IM7/RP46 specimen

\subsection{CONCLUDING REMARKS}

Specimen preparation for microscopic evaluation was described in the previous chapter. The images captured through the microscope and scanning electron microscopes were presented. The following chapters discuss obtained test results and scope for improving the in-house manufacturing setup. 


\section{Chapter 8}

\subsection{CONCLUSION}

The set objective was accomplished by implementing the design of the self-reacting frame system for fabricating advanced high $T_{g}$ composite panels. Initial design processes were verified by producing consistent quality flat panels of uniform thickness. As discussed earlier, two IM7/RP46 test coupons were obtained at the end of each manufacturing cycle which was trimmed and end tabbed for further material testing. Uniaxial static tensile testing was conducted on the coupons and ultimate stresses of the samples were calculated. A statistical approach was taken to find the mean value of the test results of the specimen.

Four values out of nine values were found to be under the bell curve area. The statistical approach revealed the need for more static testing in order to build a range of test figures. Considering the economic approach, it was decided to carry out high temperature ultimate static testing to give more valuable results concerned with the behavior of the IM7/RP46 panel as later manufactured specimen yielded consistent stress values. The consistent stress values revealed that the fabricator was able to produce panels of same strength and standard quality panels with the established manufacturing set up.

\subsection{FUTURE SCOPE}

The established manufacturing procedure could be used for compression molding of advanced and room temperature flat composite panels. The manufacture specimen can be cut into coupons for structural testing purposes. High temperature composites manufacturing processes could be semi automated by application of sensors for monitoring temperature and cure cycle. Part temperature could be closely monitored by implementing a thermocouple under the compression molding tool. Provisions can be made in the frame structure to self align the compression molds. Cost effective manufacturing setup can be successfully used for producing high $\mathrm{T}_{\mathrm{g}}$ composite panels on a long run. 


\section{APPENDIX A}

\section{A.1 Specimen Table:}

Initially manufactured IM7/RP46 samples revealed that there is room for improvement of manufacturing procedure in regards to skill level of the manufacturer, as the hand lay-up technique is sensitive to cleanliness of atmosphere and personnel.

Table 8: Specimen Lay-up- Iog

\begin{tabular}{|c|c|c|c|c|c|}
\hline $\begin{array}{c}\text { Specimen } \\
\text { Details }\end{array}$ & $\begin{array}{c}\text { Number of } \\
\text { Layers ( Lay-up) }\end{array}$ & Location 1 & Location 2 & Location 3 & Length \\
\hline Specimen 1 & 8 layers $(0 / 90)_{s}$ & 0.068 & 0.071 & 0.069 & 9.98 \\
\hline Width & & 1.001 & 1.008 & 1.012 & \\
\hline Specimen 2 & 10 layers $(0 / 90)_{s}$ & 0.091 & 0.091 & 0.087 & 9.97 \\
\hline Width & & 1.018 & 1.001 & 0.992 & \\
\hline Specimen 3 & 8 layers $(0 / 90)_{s}$ & 0.066 & 0.070 & 0.068 & 9.97 \\
\hline Width & & 1.043 & 1.070 & 1.085 & \\
\hline Specimen 4 & 10 layers $(0 / 90)_{s}$ & 0.087 & 0.092 & 0.090 & 9.90 \\
\hline Width & & 0.970 & 0.972 & 0.990 & \\
\hline
\end{tabular}




\begin{tabular}{|c|c|c|c|c|c|}
\hline Details & $\begin{array}{c}\text { No. of } \\
\text { Layers(Lay-up) }\end{array}$ & Location 1 & Location 2 & Location 3 & Length \\
\hline Specimen 5 & 10 layers $(0 / 90)_{s}$ & 0.081 & 0.082 & 0.081 & 10.06 \\
\hline Width & & 0.961 & 0.948 & 0.950 & \\
\hline Specimen 6 & 10 layers $(0 / 90)_{s}$ & 0.083 & 0.083 & 0.082 & 10.04 \\
\hline Width & & 1.039 & 1.041 & 1.042 & \\
\hline Specimen 7 & 10 layers $(0 / 90)_{s}$ & 0.092 & 0.092 & 0.091 & 10.00 \\
\hline Width & & 1.000 & 1.004 & 1.004 & \\
\hline Specimen 8 & 10 layers $(0 / 90)_{s}$ & 0.101 & 0.101 & 0.100 & 10.00 \\
\hline Width & & 1.047 & 1.045 & 1.046 & \\
\hline Specimen 9 & 10 layers $(0 / 90)_{s}$ & 0.082 & 0.082 & 0.080 & 9.98 \\
\hline Width & & 1.012 & 1.015 & 1.017 & \\
\hline Specimen 10 & 10 layers $(0 / 90)_{s}$ & 0.080 & 0.082 & 0.082 & 10.00 \\
\hline Width & & 0.990 & 0.995 & 0.987 & \\
\hline Specimen 11 & 10 layers $(0 / 90)_{s}$ & 0.082 & 0.084 & 0.083 & 10.00 \\
\hline Width & & 1.018 & 1.008 & 1.006 & \\
\hline Specimen 12 & 10 layers $(0 / 90)_{\mathrm{s}}$ & 0.080 & 0.082 & 0.082 & 9.97 \\
\hline
\end{tabular}




\begin{tabular}{|lccccc|}
\hline Width & & 1.000 & 0.982 & 0.987 & \\
Specimen 13 & 10 layers $(0 / 90)_{s}$ & 0.083 & 0.084 & 0.083 & 9.96 \\
Width & & 1.020 & 1.017 & 1.031 & \\
Specimen 14 & 10 layers(0/90) & 0.082 & 0.084 & 0.083 & 10.10 \\
Width & & 0.982 & 0.985 & 0.985 & \\
\end{tabular}




\section{APPENDIX B}

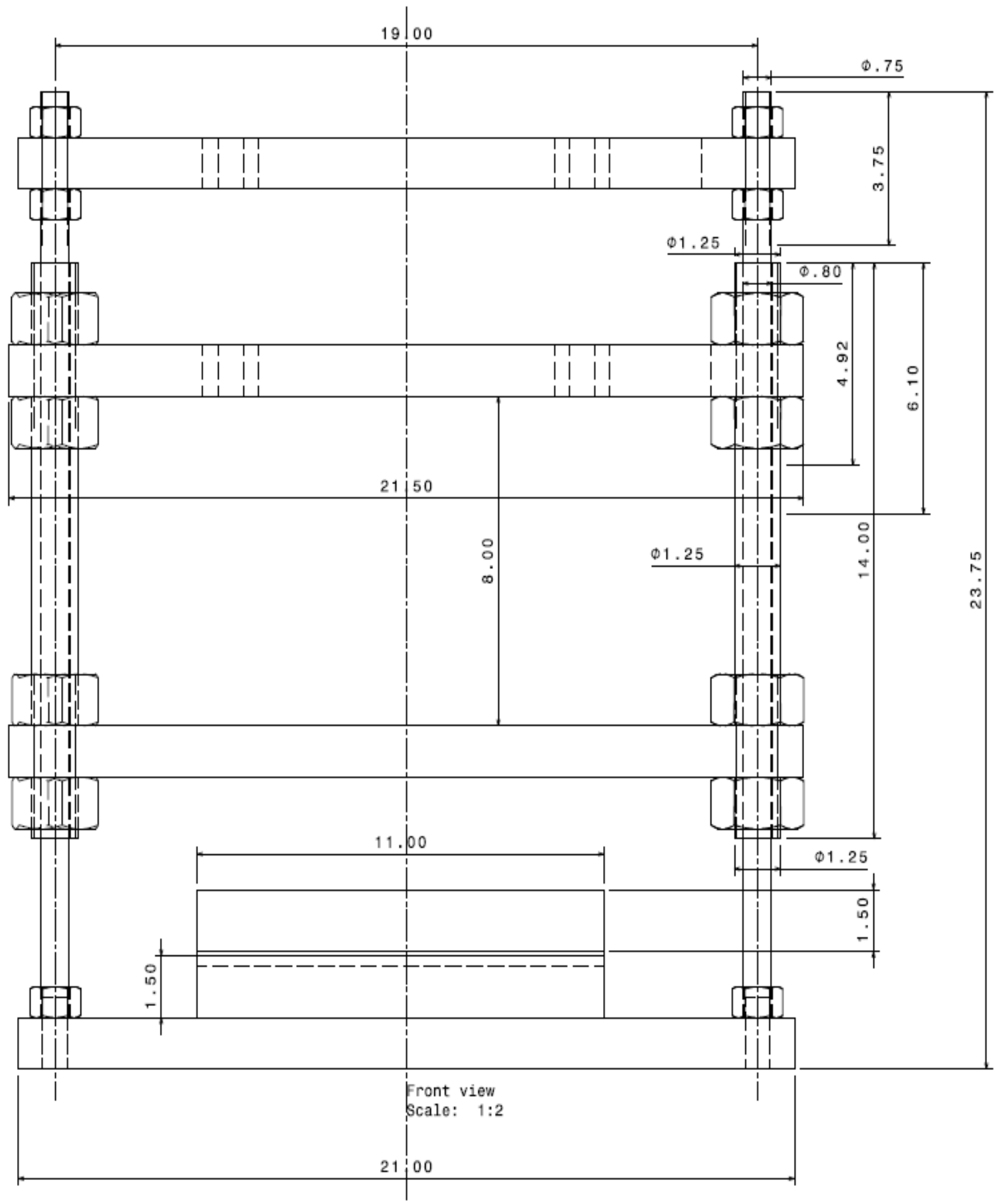

Figure 69: Detailed Drawing of self reacting Frame 
Table 9: Properties of IM7 (6K) Carbon Fabric [Hexcel corporation]

\section{Fibre Properties}

\begin{tabular}{ll}
\hline $\begin{array}{l}\text { Tensile Strength } \\
\begin{array}{l}\text { Tensile Modulus } \\
\text { (Chord 6000-1000) }\end{array}\end{array}$ & $5,310 \mathrm{MPa}$ \\
\hline Ultimate Elongation at Failure & $276 \mathrm{GPa}$ \\
\hline Density & $1.8 \%$ \\
\hline Weight/Length & $1.78 \mathrm{~g} / \mathrm{cm}_{3}$ \\
\hline Approximate Yield & $0.223 \mathrm{~g} / \mathrm{m}$ \\
\hline Tow Cross-Sectional Area & $4.48 \mathrm{~m} / \mathrm{g}$ \\
\hline Filament Diameter & $0.13 \mathrm{~mm} 2$ \\
\hline Carbon Content & $5.2 \mathrm{microns}$ \\
\hline Twist & $95.0 \%$ \\
\hline
\end{tabular}

Table 10: Properties of the RP46 Resin [Unitech LLC]

\begin{tabular}{ll}
\hline \multicolumn{1}{c}{ Resin Properties } & \multicolumn{1}{c}{ Units } \\
\hline Operating Temperature $-150^{\circ} \mathrm{F}-675^{\circ} \mathrm{F}$ & $-150^{\circ} \mathrm{F}-675^{\circ} \mathrm{F}$ \\
\hline Glass transition Temperature & $310^{\circ} \mathrm{C}$ \\
\hline Density & $1.32 \mathrm{~g} / \mathrm{cc}$ (cured) \\
\hline Fracture Toughness $\left(\mathrm{G}_{1 \mathrm{c}}\right)$ & $235 \mathrm{~J} / \mathrm{m}^{2}$ \\
\hline Young's modulus & $6.09 \times 10^{5}$ \\
\hline Coefficient of Thermal Expansion & $22.4 \pm 0.001 \times 10^{-6} /{ }^{\circ} \mathrm{F}$ \\
\hline
\end{tabular}




\section{REFERENCES:}

1. Akovali, G. Handbook of Composite Fabrication. Smithers Rapra Technology, 2001.

2. Committee on Evaluation of Long-Term Aging of Materials and Structures Using Accelerated Test Methods, Commission on Engineering and Technical Systems, National Research Council. Accelerated Aging of Materials and Structures: The Effects of Long-Term Elevated-Temperature Exposure. The National Academic Press, 1996.

3. Corporation, Maverick. "List of High Temperature Matrix." www.Maverickcorp.com. June 2001. http://www.maverickcorp.com/research.htm (accessed may 15, 2010).

4. Council, National Research. Accelerated Aging of Materials and Structures: The Effects of LongTerm Elevated-Temperature Exposures. National Academy Press , 1996.

5. H Hou, S P Wilkinson, N J Johnston, R H Pater and T L Schneiderk. "Processing and Properties of IM7/LARC TM -RP46 Polyimide Composites." High Performance Polymers, December 1996: vol. 8 no. 4 491-505.

6. Hasiotis T., Badogiannis E. and Tsouvalis N.G. "Application of Ultrasonic C-Scan Techniques for Tracing Defects in Laminated Composite Materials." 4th International conference on NDT. Chania,crete-Greece: Hellenic Society for NDT, 2001.

7. Hexcel. "HexForce Reinforcements." http://www.hexcel.com. December 2010. http://www.hexcel.com/Resources/DataSheets/Brochure-Data-

Sheets/HexForce_Technical_Fabrics_Handbook.pdf (accessed March 26, 2011).

8. Jr, Flake C Campbell. Manufacturing Technology for Aerospace Structural Materials. Elsevier Science, 2006.

9. Mallick, P.K. Fibre-Reinforced Composites: Materials, Manufacturing, and Design. . CRC Press, 1993.

10. McCleary, Sherri F. "Pultrusion of PMR-15." International SAMPE Technical Conference, 1991: 969-981.

11. Montesano, John Giovanni. High Temperature fatigue in Polymer matrix composites;. PH.D Thesis, Toronto: Ryerson university, 2012.

12. P., Hutapea, and Yuan F.G. "The effect of thermal aging on the Mode-I interlaminar fracture behavior of a high-temperature IM7/LaRC-RP46 composite." Composites Science and Technology, June 1999: Volume 59, Number 8, pp. 1271-1286(16).

13. Prasad, Thammiah. Investigation of vartm processing of high temperature RP-46 resin system. M.S (Thesis), Florida State University , 2004. 
14. Robitaille, Susan. "Cyanate Ester Resins." In ASM Handbook Volume 21, by ASM International, 126-131. ASM International, 2001.

15. Ruth H. Pater, Paul A. Curtob,. "Advanced materials for space applications." Acta Astronautica, 2007: 1121-1129.

16. Steven L. Donaldson, Daniel B. Miracle. ASM Handbook Composites Volume 21. ASM International, 2001.

17. strong, A.Brent. Fundamentals of Composite Manufacturing Materials, Methods and Application. Society of Manufacturing Engineers, 2008, 2nd edition.

18. systems, SP. "SP systems guide to composites." www.bolton.ca.uk. http://www.bolton.ac.uk/CODATE/SPGuidetoComposites.pdf (accessed march 20, 2011).

19. Quickstep. (2010, September). Retrieved January 18, 2011, from http://www.quickstep.com.au/:http://www.quickstep.com.au/files/document/328_Quickstep_ Website_Presentation_September_2010.pdf

20. Teagle, P.R. The quality control and non-destructive evaluation of composite aerospace components. Elsevier Ltd, 1983.

21. W.X.Wang and Y.Takao, F.G.Yuan, B.D.Potter, R.H.Pater. "The Interlaminar Mode Fracture of IM7/LaRC-RP 46 Composites at High Temperatures." Journal of Composite Materials, 1998: vol. 32 no. 16 1508-1526.

22. Wilson, Doug. "Recent advances in polyimide composites." High Performance Polymers, 1993: vol. 5, 77-95.

23. Yuan, P. Hutapea and F.G. "The effect of thermal aging on the Mode-I interlaminar fracture behavior of a high-temperature IM7/LaRC-RP46 composite." Composites science and technology, 1999: 1271-1286. 